Supporting Information

\title{
Crystal Fluidity Reflected by Fast Rotational Motion at the Core, Branches and Peripheral Aromatic Groups of a Dendrimeric Molecular Rotor
}

\author{
Xing Jiang, Zachary J. O’Brien, Song Yang, Lan Huong Lai, Jeffrey Buenaflor, Colleen \\ Tan, Saeed Khan, K. N. Houk, ${ }^{*}$ and Miguel A. Garcia-Garibay* \\ Department of Chemistry and Biochemistry, University of California, Los Angeles, California \\ 90095-1569, United States
}

Email: mgg@chem.ucla.edu; houk@chem.ucla.edu 


\section{Contents}

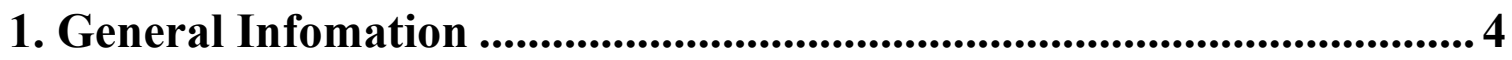

2. Synthesis and Characterization of compounds......................................5

2.1. Synthesis of 4-(3,3,3-triphenylpropynyl)phenyl bromide 4 ................................ 5

2.2. Synthesis of tris[4-(3,3,3-triphenylpropynyl)phenyl]methanol 5 …...................... 9

2.3. Synthesis of 3,3,3-tris[4-(3,3,3-triphenylpropynyl)phenyl]propyne 6.................. 13

2.4. Synthesis of 1,4-bis $\{3,3,3$-tris[4-(3,3,3-triphenylpropynyl)phenyl]-

propynyl $\}$ benzene 2

2.5. Synthesis of 1,4-bis $\{3,3,3$-tris[4-(3,3,3-triphenylpropynyl)phenyl]-

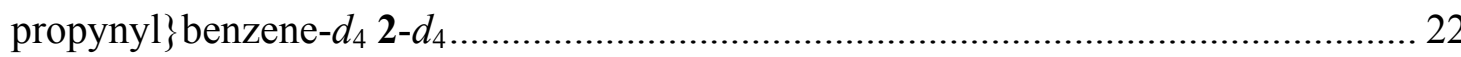

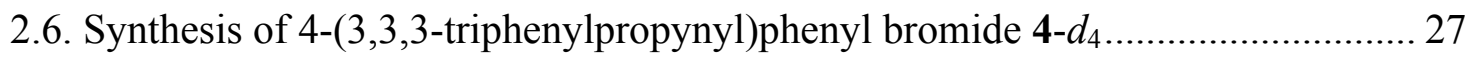

2.7. Synthesis of tris[4-(3,3,3-triphenylpropynyl)phenyl]methanol 5- $d_{12} \ldots \ldots \ldots \ldots \ldots \ldots . . . . . . .31$

2.7. Synthesis of tris[4-(3,3,3-triphenylpropynyl)phenyl]propyne 6- $d_{12} \ldots \ldots \ldots \ldots \ldots \ldots \ldots . . . . . . . .35$

2.8. Synthesis of 1,4-bis $\{3,3,3$-tris[4-(3,3,3-triphenylpropynyl)phenyl]-

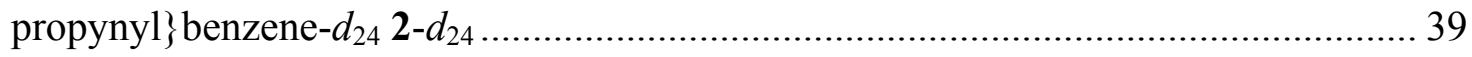

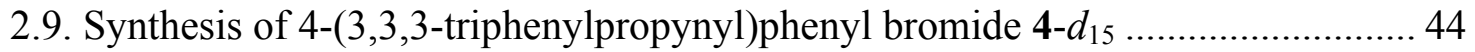

2.10. Synthesis of tris[4-(3,3,3-triphenylpropynyl)phenyl]methanol 5- $d_{45} \ldots \ldots \ldots \ldots \ldots \ldots . . . .48$

2.11. Synthesis of tris[4-(3,3,3-triphenylpropynyl)phenyl]propyne 6- $d_{45} \ldots \ldots \ldots \ldots \ldots \ldots \ldots . . . . .52$

2.12. Synthesis of 1,4-bis $\{3,3,3$-tris[4-(3,3,3-triphenylpropynyl)phenyl]-

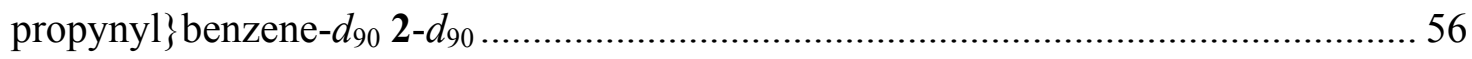

3. Crystallization, X-Ray Diffraction of Single Crystals, and PXRD .... 60

3.1. Crystallization Conditions and X-Ray Diffraction of Single Crystals.................... 60

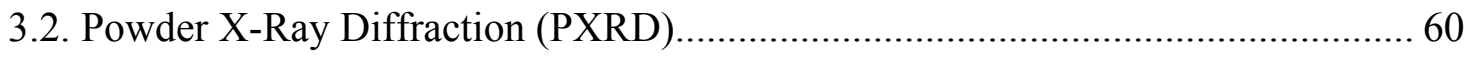

\section{Solid-state ${ }^{2}$ H NMR Quadrupolar Echo Experiment and Simulation}

4.1. Solid-state ${ }^{2} \mathrm{H}$ NMR Quadrupolar Echo Experiment ......................................... 61

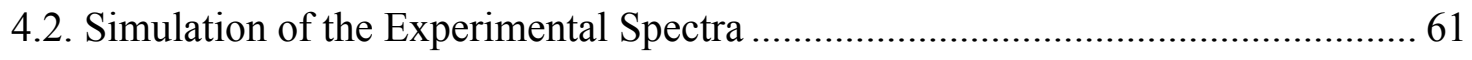

5. Molecular Dynamics Simulation .................................................................... 63

5.1. Molecular Dynamics Simulation and Modes of Rotation in Vacuum................... 64 
5.2. Estimated Free Energy Change of Rotation...

6. Temperature Dependence of Activation Energies ................................... 66

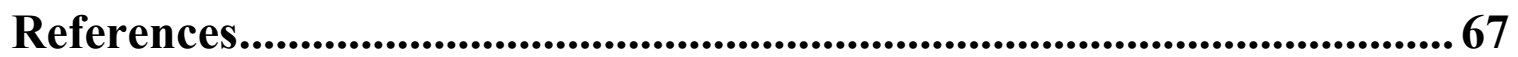




\section{General Infomation}

Unless otherwise notified all commercially available compounds were purchased and used as received without further purification. 3,3,3-Triphenylpropyne $\mathbf{3}^{1}$ and 3,3,3-triphenylpropyne-3$d_{15}{ }^{2}$ were prepared as previously reported in the literature. Thin-layer chromatography (TLC) plates pre-coated with silica gel $60 \mathrm{~F}_{254}$ were purchased and they were visualized using a UV lamp. Flash column chromatography was performed using silica gel (230-400 mesh) as the stationary phase. Anhydrous tetrahydrofuran (THF) and benzene ( $\mathrm{PhH}$ ) were distilled from sodium-benzophenone in a continuous still under an atmosphere of argon. Anhydrous toluene (Tol) was distilled from calcium hydride under argon. Triethylamine $\left(\mathrm{NEt}_{3}\right)$ was dried over potassium hydroxide $(\mathrm{KOH})$ overnight before used. Melting points of solids were measured without calibration of the apparatus. ${ }^{1} \mathrm{H}$ NMR and ${ }^{13} \mathrm{C}$ NMR spectra in solution were recorded at $500 \mathrm{MHz}$ and $125 \mathrm{MHz}$, respectively. Chemical shifts are reported in ppm and the (residual) solvent signals of $\mathrm{CDCl}_{3}$ ( ${ }^{1} \mathrm{H}$ NMR: $\delta 7.26 \mathrm{ppm} ;{ }^{13} \mathrm{C}$ NMR: $\delta 77.0 \mathrm{ppm}$ ) were used as reference. Multiplicities of the peaks are reported as singlet (s), doublet (d), triplet ( $\mathrm{t})$, or multiplet $(\mathrm{m})$. The coupling constants $J$ are reported in Hz. Infrared spectra (IR) were obtained with a HATR-FTIR instrument. Mass spectra were acquired on MALDI-TOF (low-res), LIFDI-TOF (high-res), and ESI/APCI-TOF (high-res) instruments. 


\section{Synthesis and Characterization of compounds}

\subsection{Synthesis of 4-(3,3,3-triphenylpropynyl)phenyl bromide 4}

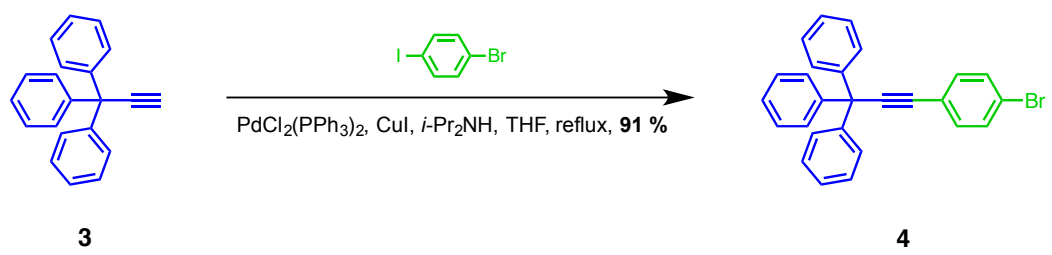

To a $250 \mathrm{~mL}$ 3-neck flask with stir bar and condenser were added 3,3,3-triphenylpropyne 3 (2.007 g, $7.48 \mathrm{mmol})$, 4-bromo-1-iodobenzene (2.116 g, $7.48 \mathrm{mmol})$, anhydrous THF (80 mL), and di-iso-propylamine $(40 \mathrm{~mL})$ under argon. The resulting mixture was degased for $60 \mathrm{~min}$ before palladium bis(triphenylphosphine) dichloride (524 $\mathrm{mg}, 0.748 \mathrm{mmol}$ ) and copper iodide $(0.142 \mathrm{~g}, 0.748 \mathrm{mmol})$ were added into the flask. The reaction mixture was refluxed for 6 hours and then cooled down to room temperature. Saturated $\mathrm{NH}_{4} \mathrm{Cl}$ solution $(100 \mathrm{~mL})$ was added in to quench the reaction, and the compound was extracted with DCM $(100 \mathrm{~mL})$ twice. The combined organic layers were washed with brine, dried over anhydrous $\mathrm{MgSO}_{4}$, and concentrated to give a crude. Flash column chromatography of the crude product using hexanes as the eluent provided the desired compound 4 (2.890 g, $91 \%)$.

4: White solid, m.p. $139-140{ }^{\circ} \mathrm{C} ;{ }^{1} \mathrm{H}$ NMR (500 MHz, $\mathrm{CDCl}_{3}$, ppm): $\delta 7.27-7.32$ (m, 15H), 7.367.37 (m, 2H), 7.44-7.46 (m, 2H); ${ }^{13} \mathrm{C}$ NMR (125 MHz, $\left.\mathrm{CDCl}_{3}, \mathrm{ppm}\right): \delta$ 56.1, 84.0, 96.9, 122.2, 122.5, 126.9, 128.1, 129.1, 131.5, 133.1, 145.1; IR (powder, $\left.\mathrm{cm}^{-1}\right): v$ 695(s), 743(s), 757(s), 827(s), 890(w), 1009(m), 1032(m), $1069(\mathrm{~m}), 1178(\mathrm{w}), 1261(\mathrm{w}), 1394(\mathrm{w}), 1445(\mathrm{~m}), 1487(\mathrm{~s})$, 1597(m), 1728(w), 3031(w), 3056(w); HRMS (ESI/APCI, TOF): m/z calculated for $\mathrm{C}_{27} \mathrm{H}_{20} \mathrm{Br}$ $\left(\mathrm{MH}^{+}\right): 420.0743$, found: 420.0738 . 

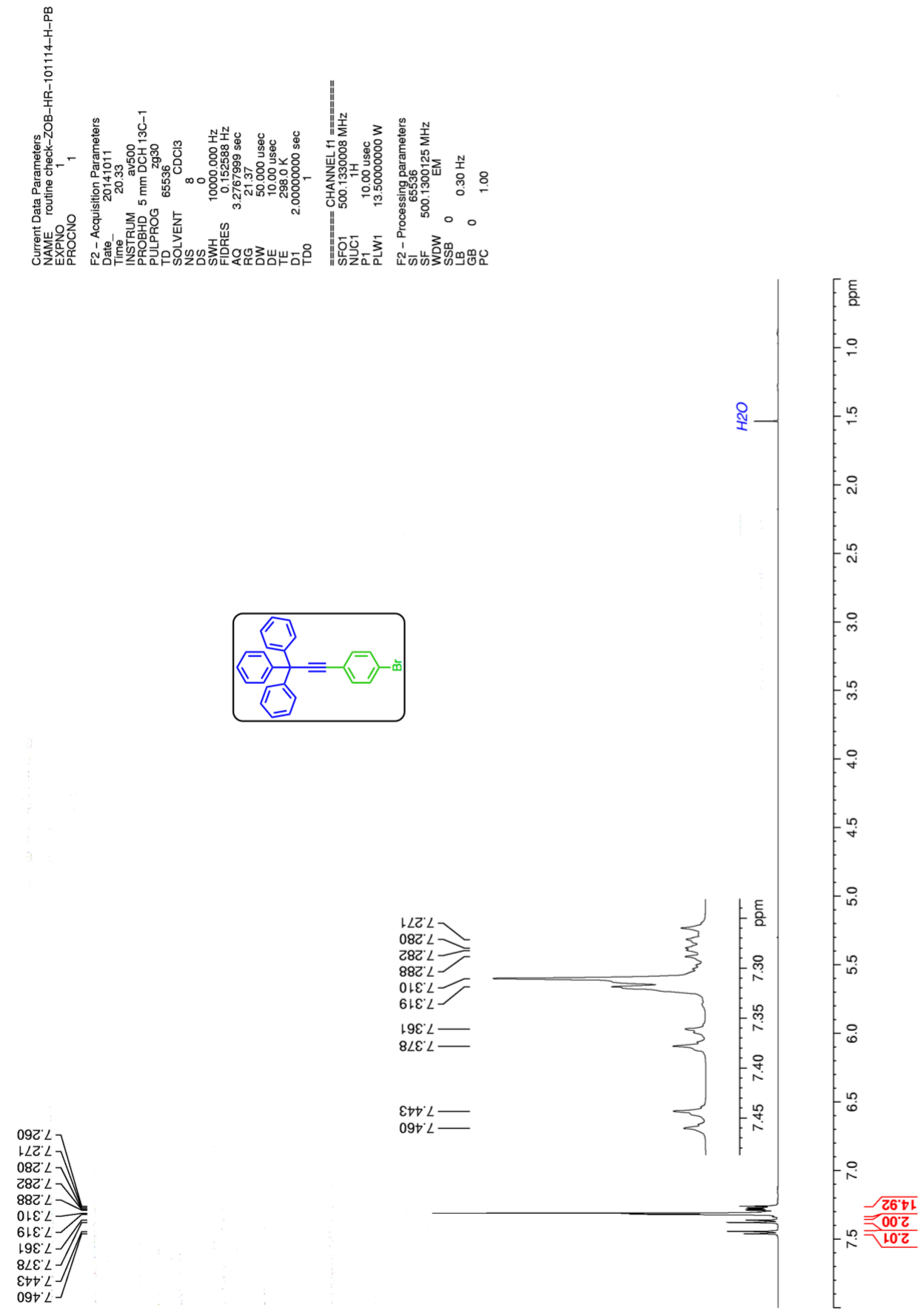

Figure S1. ${ }^{1} \mathrm{H}$ NMR of compound 4 at $500 \mathrm{MHz}$ in $\mathrm{CDCl}_{3}$. 

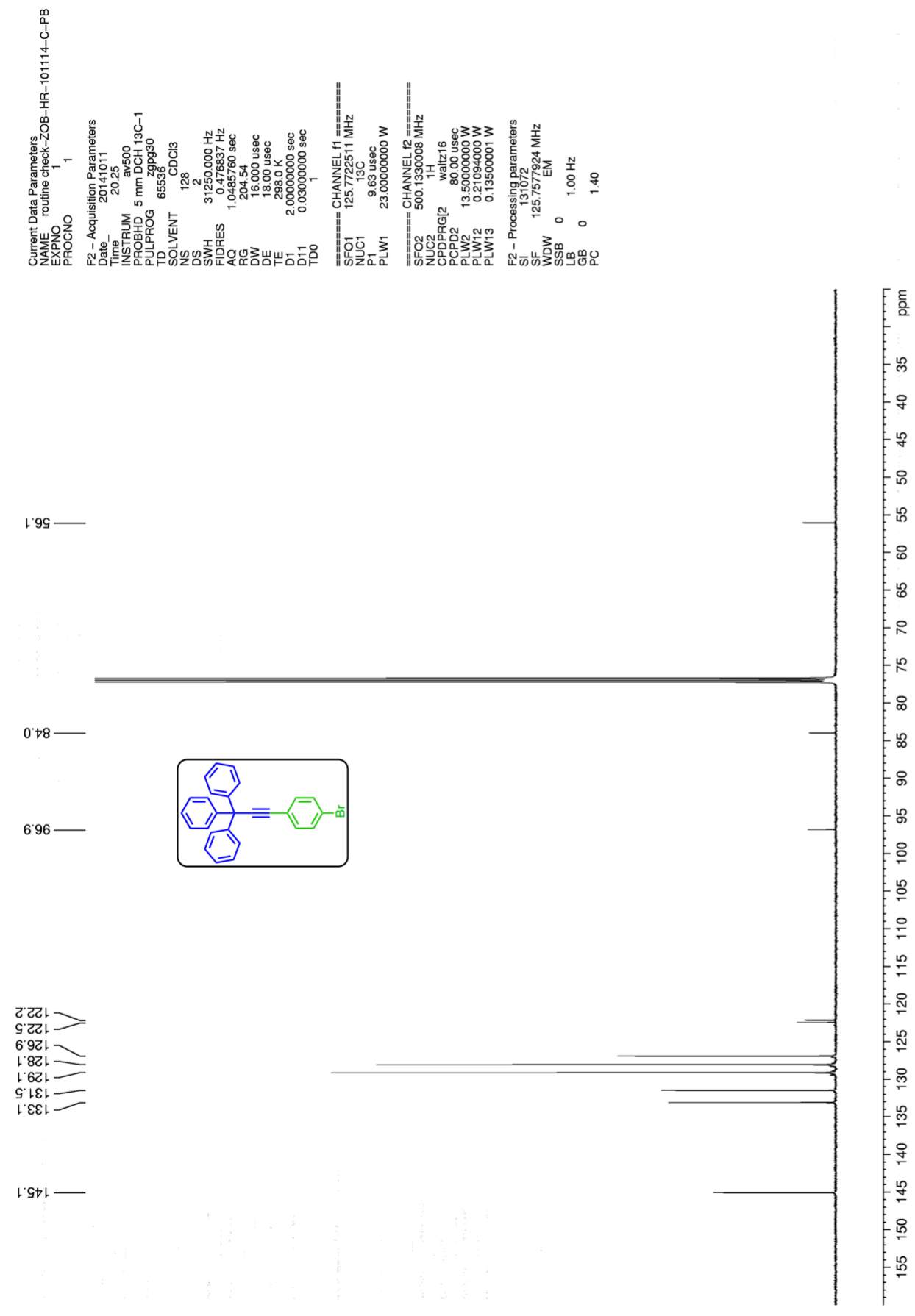

Figure S2. ${ }^{13} \mathrm{C}$ NMR of compound 4 at $125 \mathrm{MHz}$ in $\mathrm{CDCl}_{3}$. 


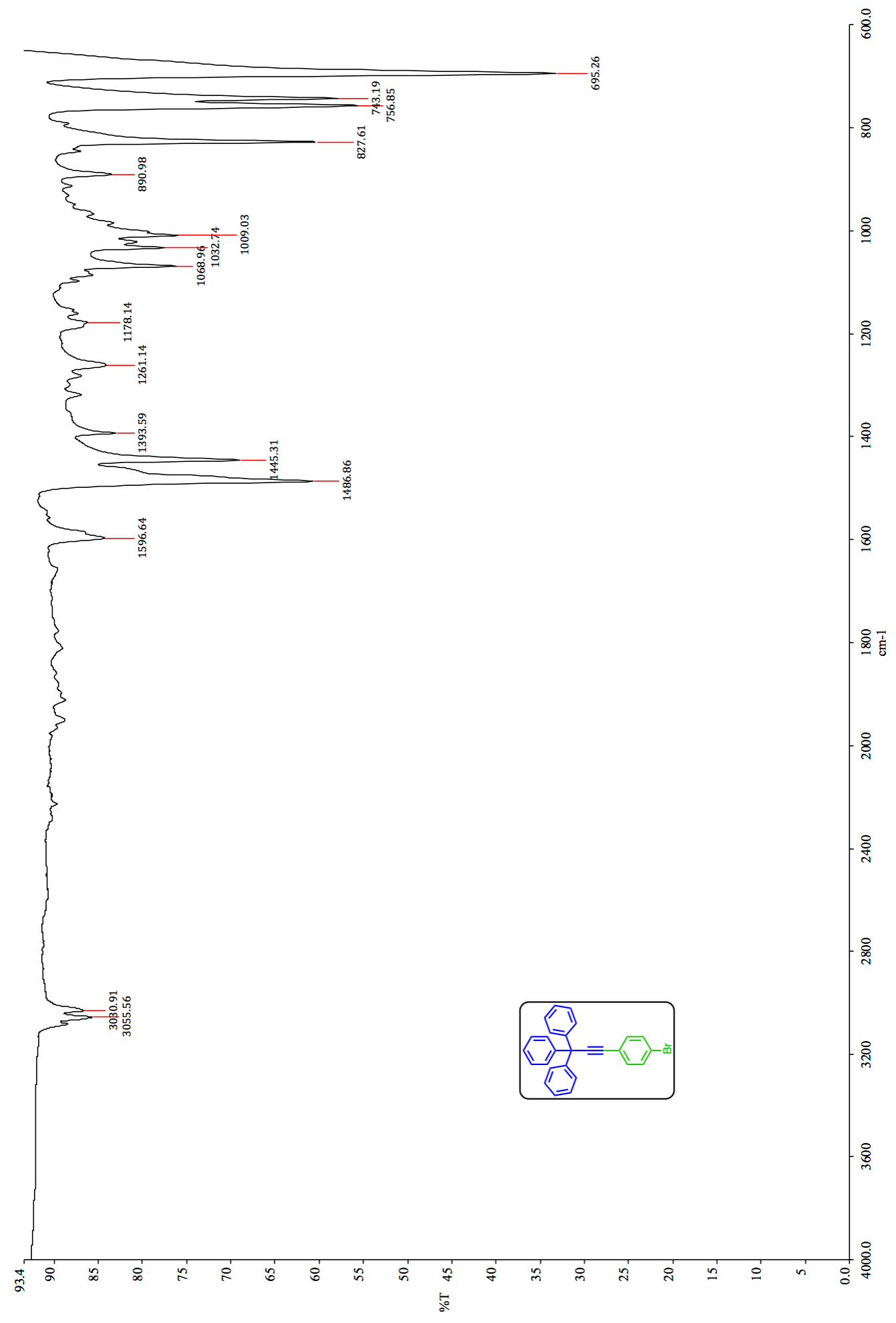

Figure S3. IR of compound 4. 


\subsection{Synthesis of tris[4-(3,3,3-triphenylpropynyl)phenyl]methanol 5}

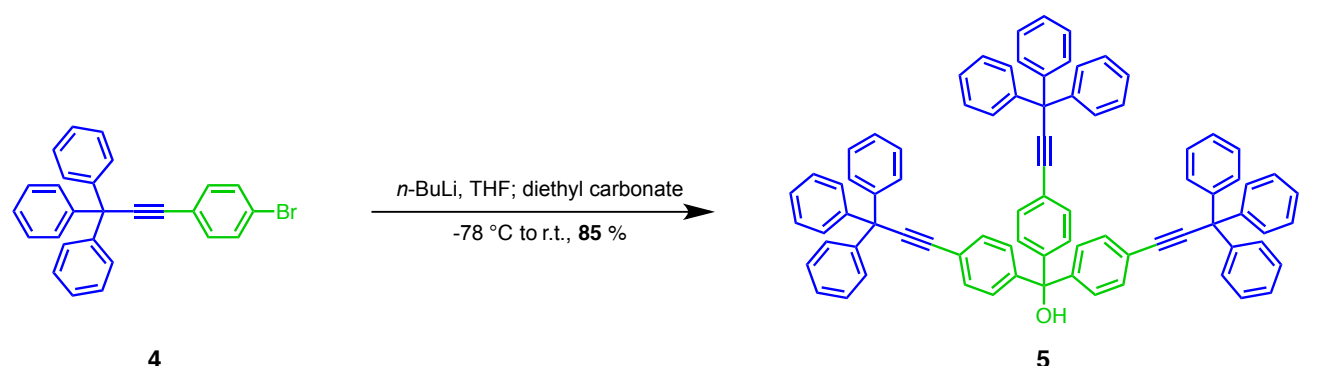

To a solution of arylbromide $4(1.009 \mathrm{~g}, 2.38 \mathrm{mmol})$ in anhydrous THF $(10 \mathrm{~mL})$ in a round bottom flask was add $n$-BuLi (1.09 M solution in hexane, $2.83 \mathrm{~mL}, 3.08 \mathrm{mmol})$ dropwise under argon at $-78{ }^{\circ} \mathrm{C}$. The reaction mixture was stirred in the cooling bath for 1 hour before an excess of diethyl carbonate $(0.58 \mathrm{~mL}, 4.79 \mathrm{mmol})$ was added into the flask and it was stirred for another hour before it was allowed to warm up to room temperature. Saturated $\mathrm{NH}_{4} \mathrm{Cl}$ solution $(50 \mathrm{~mL})$ was added in to quench the reaction, and the product was extracted with diethyl ether $(50 \mathrm{~mL})$ twice. The combined organic layers were washed consecutively with water and brine, dried over anhydrous $\mathrm{MgSO}_{4}$, and concentrated to give a brownish crude. Flash column chromatography of the crude product (dry loading) using a hexanes-ether mixture $(4: 1, \mathrm{v} / \mathrm{v})$ as the eluent provided the desired compound 5 (715 mg, $85 \%)$.

5: White solid, m.p. $286-287{ }^{\circ} \mathrm{C} ;{ }^{1} \mathrm{H}$ NMR (500 MHz, $\left.\mathrm{CDCl}_{3}, \mathrm{ppm}\right): \delta 2.75$ (s, 1H), 7.24 (app. d, $J=9.0 \mathrm{~Hz}, 6 \mathrm{H}$ ), 7.27-7.36 (m, 45H), 7.48 (app. d, $J=9.0 \mathrm{~Hz}, 6 \mathrm{H}) ;{ }^{13} \mathrm{C} \mathrm{NMR}\left(125 \mathrm{MHz}, \mathrm{CDCl}_{3}\right.$, ppm): $\delta 56.1,81.6,84.7,96.2,122.8,126.8,127.7,128.0,129.1,131.3,145.2,145.9$; IR (powder, $\left.\mathrm{cm}^{-1}\right): v 695(\mathrm{~s}), 744(\mathrm{~s}), 830(\mathrm{~s}), 890(\mathrm{w}), 907(\mathrm{w}), 1024(\mathrm{~m}), 1184(\mathrm{~m}), 1319(\mathrm{w}), 1403(\mathrm{w}), 1446(\mathrm{~m})$, 1490(s), 1596(m), 3026(w), 3058(w), 3569(w); HRMS (LIFDI, TOF): m/z calculated for $\mathrm{C}_{82} \mathrm{H}_{58} \mathrm{O}$ $\left(\mathrm{M}^{+}\right)$: 1058.4482 , found: 1058.4448 . 

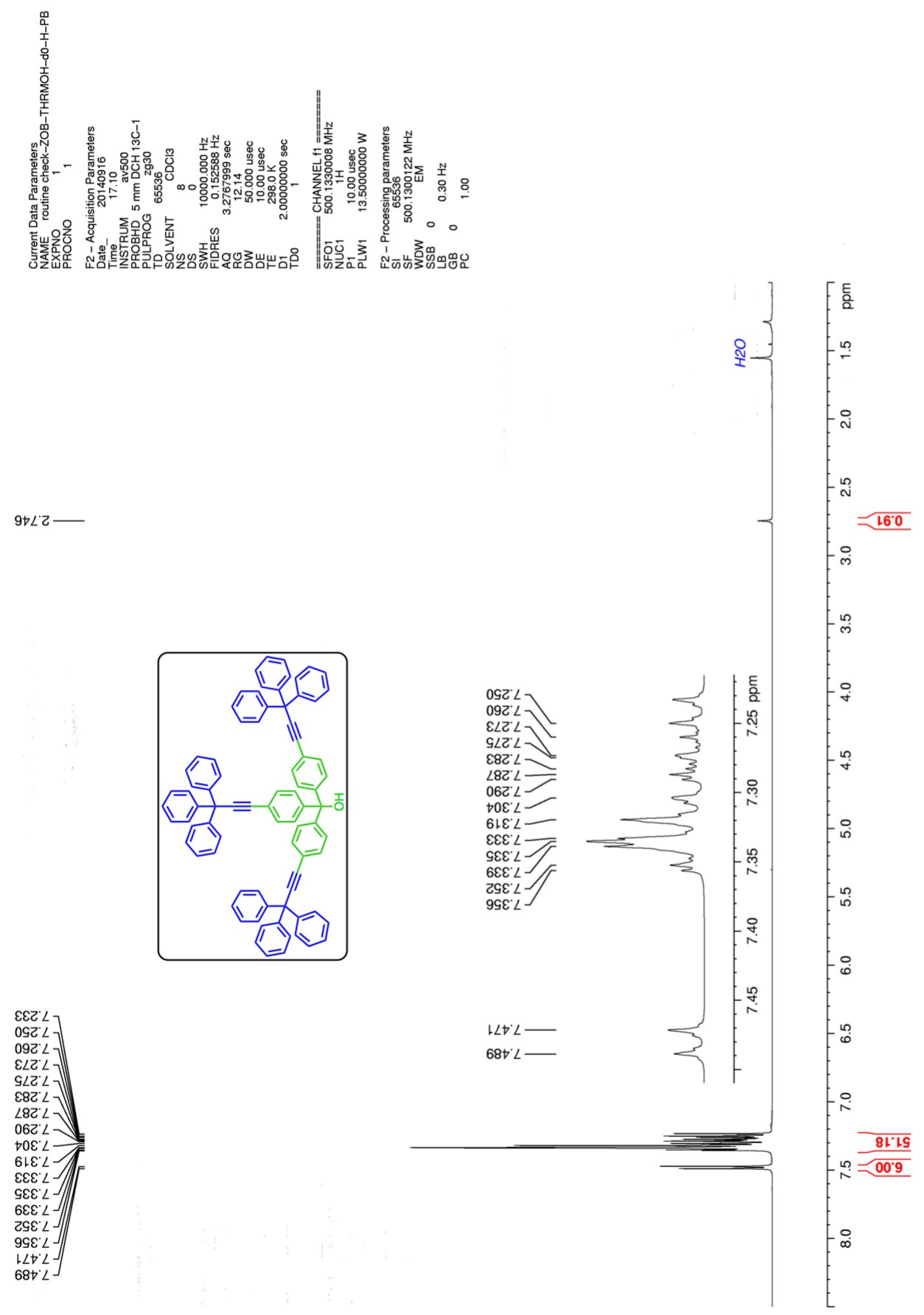

Figure S4. ${ }^{1} \mathrm{H}$ NMR of compound 5 at $500 \mathrm{MHz}$ in $\mathrm{CDCl}_{3}$. 

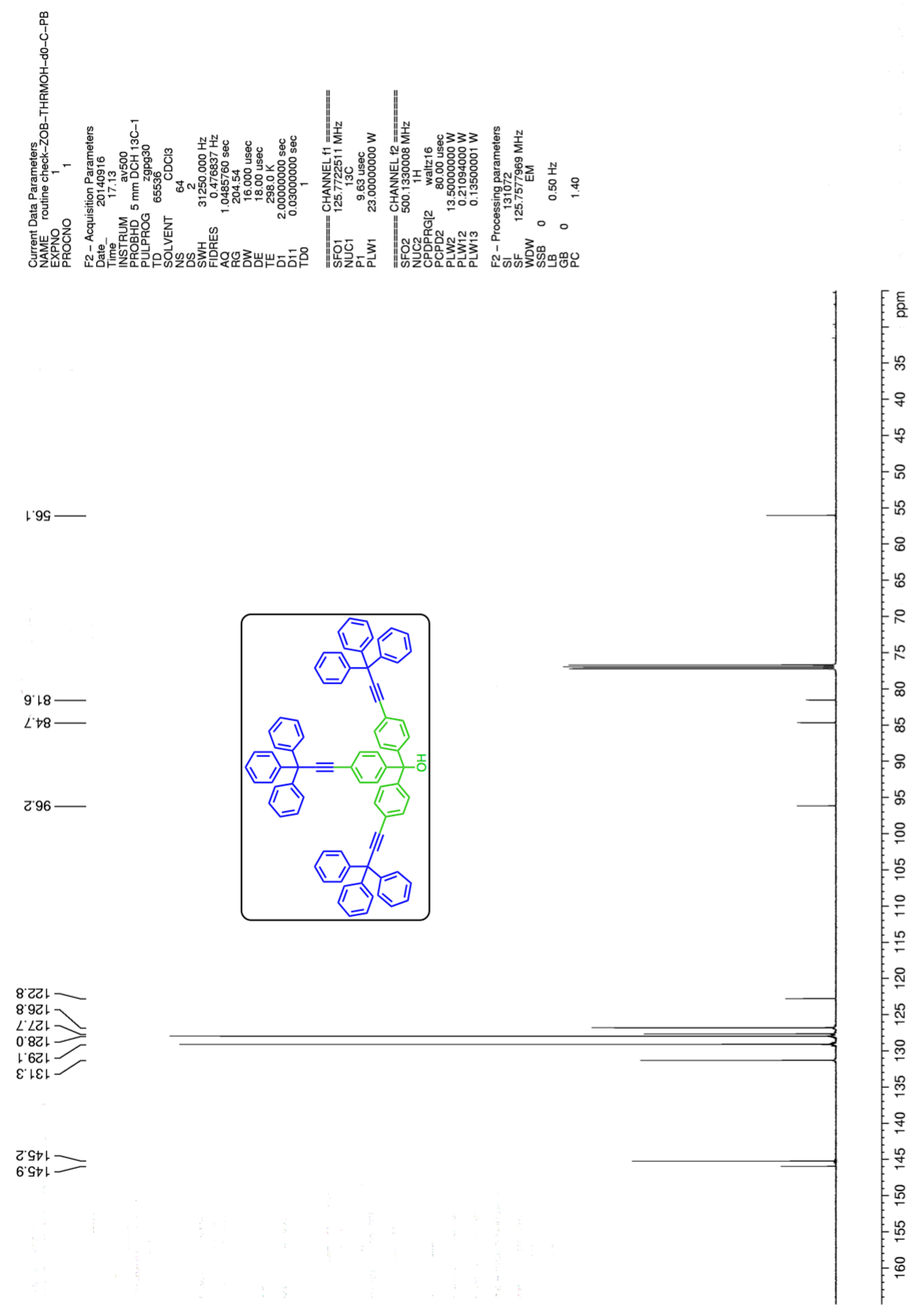

Figure S5. ${ }^{13} \mathrm{C}$ NMR of compound 5 at $125 \mathrm{MHz}$ in $\mathrm{CDCl}_{3}$. 


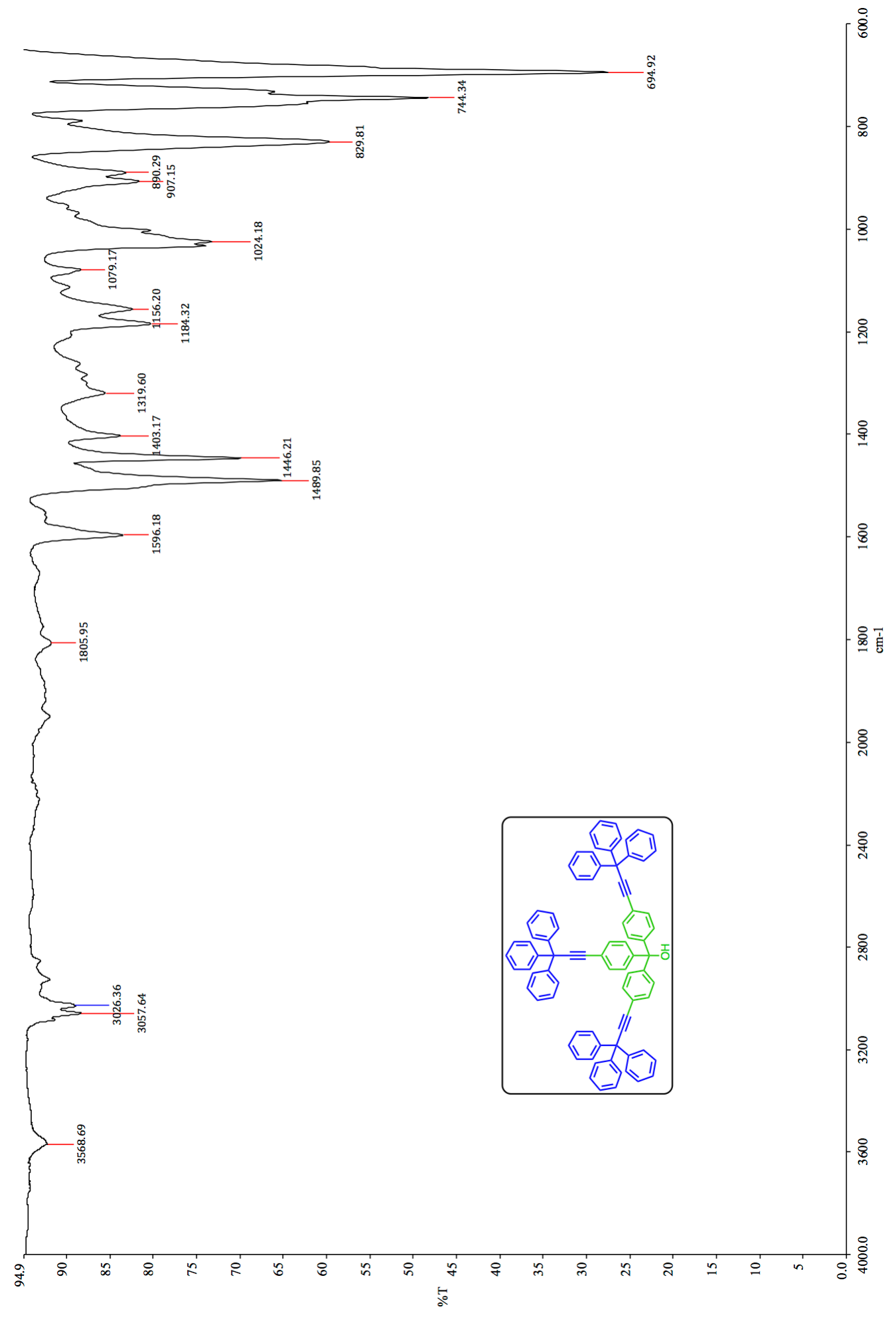

Figure S6. IR of compound 5. 


\subsection{Synthesis of 3,3,3-tris[4-(3,3,3-triphenylpropynyl)phenyl]propyne 6}
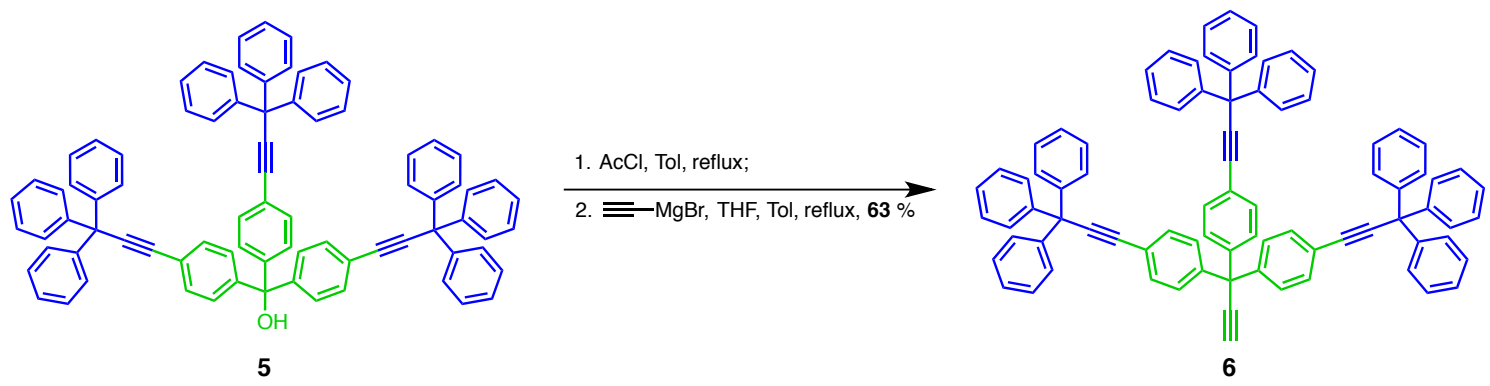

Triarylmethanol 5 (1126 mg, $1.063 \mathrm{mmol})$, anhydrous toluene $(5 \mathrm{~mL})$, and acetyl chloride $(5 \mathrm{~mL})$ were added to a round bottom flask equipped with a condenser, and the resulting mixture was heated up to reflux for 5 hours. The solvents were removed by evaporation under reduced pressure. Anhydrous toluene $(10 \mathrm{~mL})$ was added into the flask and the solvent was removed again. The residue was taken up in $100 \mathrm{~mL}$ anhydrous toluene. The toluene solution was heated to reflux under Ar before ethynylmagnesium bromide (0.5 M solution in THF, $10 \mathrm{~mL}, 5.0 \mathrm{mmol})$ was added to the flask, and the reaction mixture was heated to reflux overnight before it was allowed to cool down to room temperature. Saturated $\mathrm{NH}_{4} \mathrm{Cl}$ solution $(50 \mathrm{~mL})$ was added in to quench the reaction, and the compound was extracted with DCM $(200 \mathrm{~mL})$. The organic layer was washed with brine, dried over anhydrous $\mathrm{Na}_{2} \mathrm{SO}_{4}$, and concentrated to give a dark brown crude. Flash column chromatography (dry loading) of the crude product using a mixture of hexanes and DCM $(4: 1, \mathrm{v} / \mathrm{v})$ as the eluent yielded the desired compound $6(720 \mathrm{mg}, 63 \%)$.

6: White solid, m.p. $254-255{ }^{\circ} \mathrm{C} ;{ }^{1} \mathrm{H}$ NMR (500 MHz, $\left.\mathrm{CDCl}_{3}, \mathrm{ppm}\right): \delta 2.77$ (s, 1H), 7.27 (app. d, $J=8.5 \mathrm{~Hz}, 6 \mathrm{H}$ ), $7.29-7.40$ (m, 45H), 7.50 (app. d, $J=8.5 \mathrm{~Hz}, 6 \mathrm{H}) ;{ }^{13} \mathrm{C} \mathrm{NMR}\left(125 \mathrm{MHz}, \mathrm{CDCl}_{3}\right.$, ppm): $\delta 55.1,56.1,74.3,84.7,88.4,96.2,122.5,126.8,128.0,128.9,129.1,131.4,144.0,145.2$; IR (powder, $\left.\mathrm{cm}^{-1}\right): v$ 696(s), 743(s), 827(s), 890(w), 1025(m), 1026(m), 1079(w), 1183(m), 1283(w), 1406(w), 1446(m), 1490(s), 1596(m), 3026(w), 3058(w), 3298(w); HRMS (ESI/APCI, TOF): $\mathrm{m} / \mathrm{z}$ calculated for $\mathrm{C}_{84} \mathrm{H}_{59}\left(\mathrm{MH}^{+}\right)$: 1067.4611, found: 1067.4620 . 


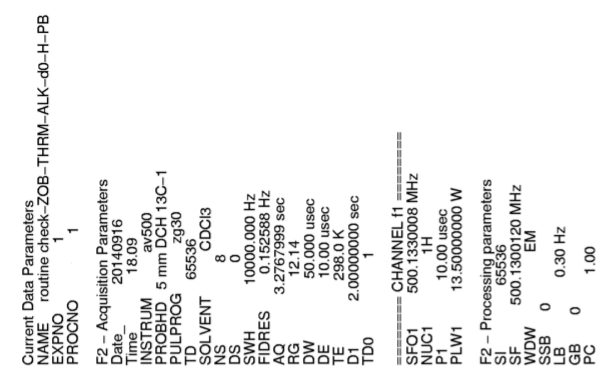

ต9Lว

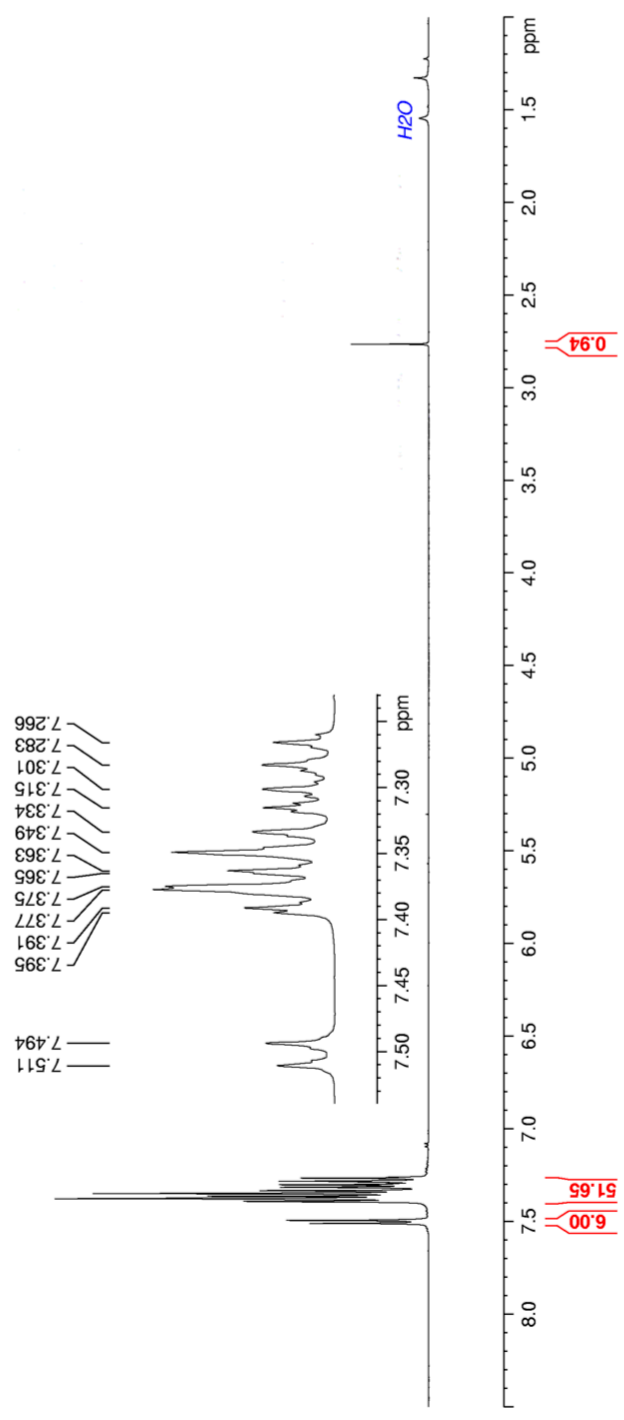

Figure S7. ${ }^{1} \mathrm{H}$ NMR of compound 6 at $500 \mathrm{MHz}$ in $\mathrm{CDCl}_{3}$. 


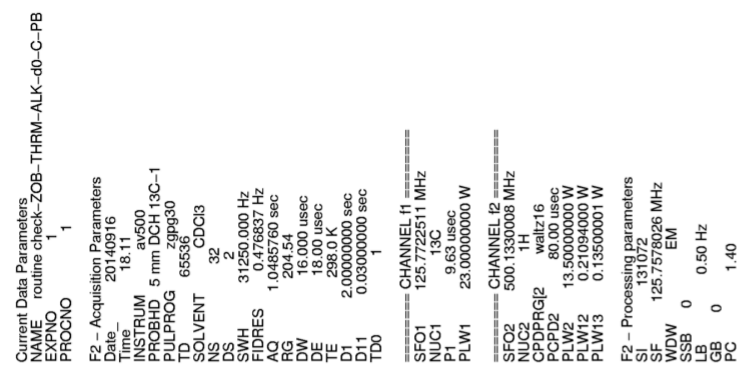

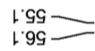

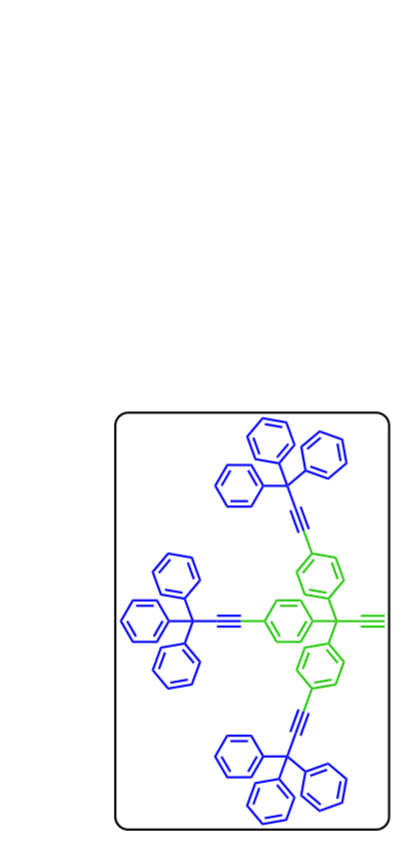

$\varepsilon^{\prime} \triangleright L$

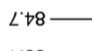

788

$\tau 96$

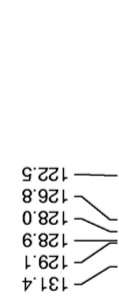

$0 \cdot \cot =$

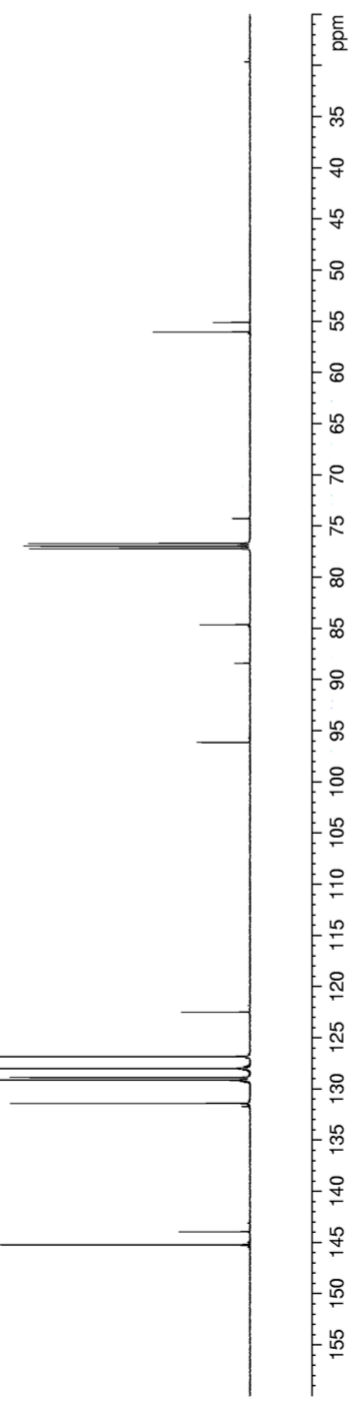

Figure S8. ${ }^{13} \mathrm{C}$ NMR of compound 6 at $125 \mathrm{MHz}$ in $\mathrm{CDCl}_{3}$. 


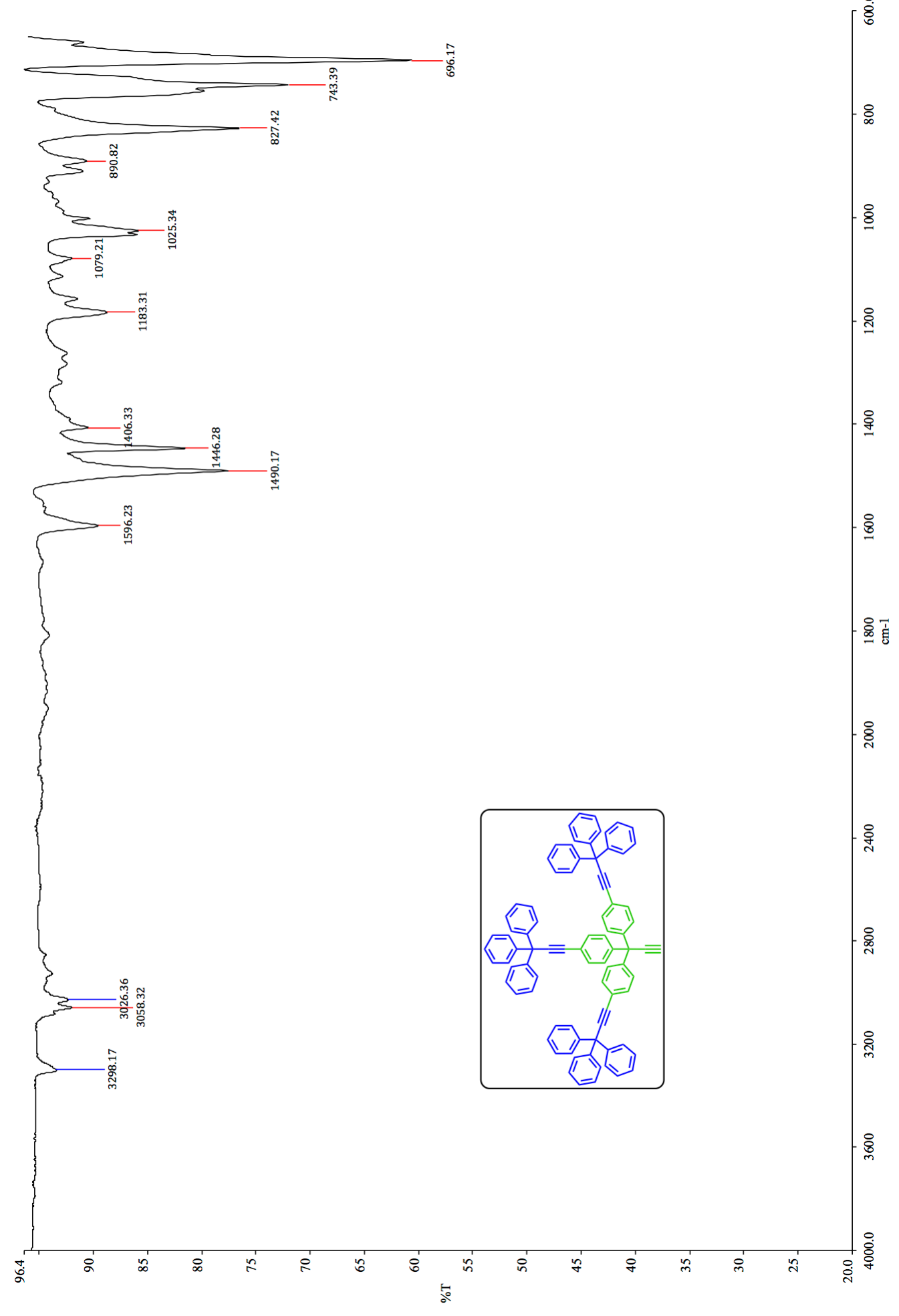

Figure S9. IR of compound 6. 


\subsection{Synthesis of 1,4-bis $\{3,3,3$-tris [4-(3,3,3-triphenylpropynyl)phenyl]- propynyl\}benzene 2}

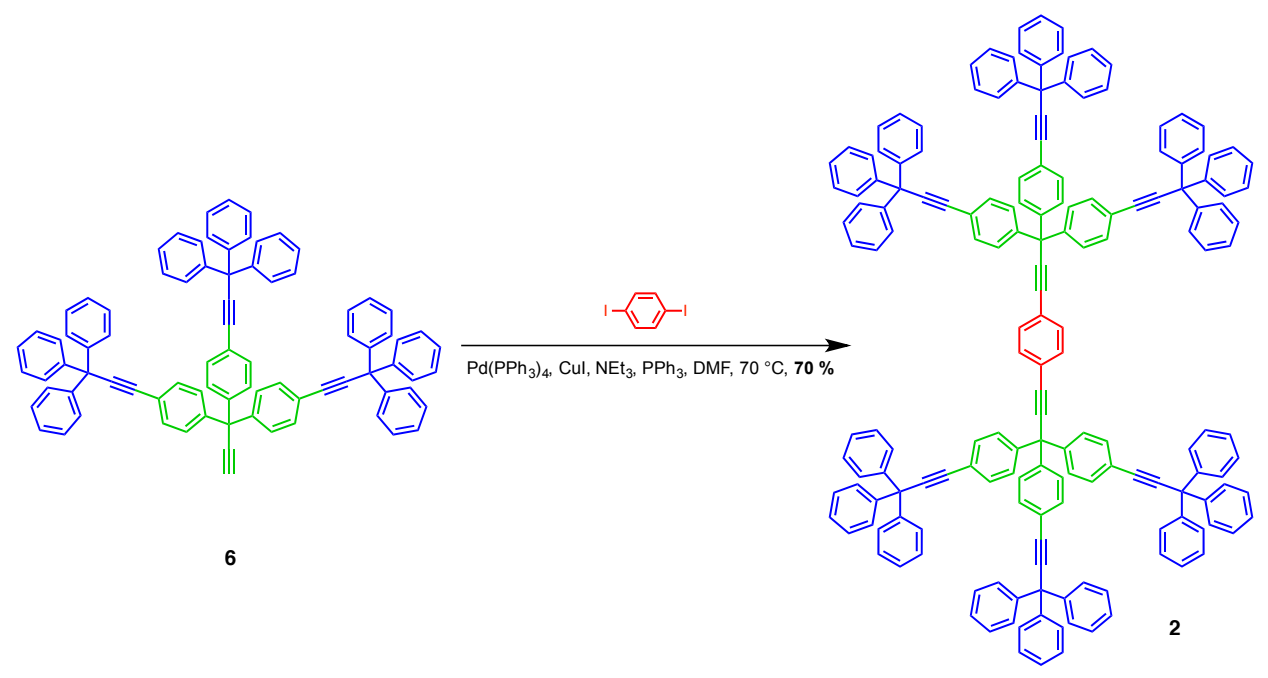

To a $10 \mathrm{~mL}$ round bottom flask was added 6 (73 mg, $0.068 \mathrm{mmol})$, 1,4-diiodobenzene (12.3 $\mathrm{mg}$, $0.037 \mathrm{mmol})$, triphenylphosphine $(5.2 \mathrm{mg}, 0.020 \mathrm{mmol})$, and triethylamine $(0.3 \mathrm{~mL})$ in anhydrous DMF $(2.5 \mathrm{~mL})$, and the resulting mixture was cooled down to $-78{ }^{\circ} \mathrm{C}$ before it was connected to vacuum for $30 \mathrm{~min}$ to remove residual oxygen dissolved in the solvent. Then palladium tetrakis(triphenylphosphine) (11.6 mg, $0.010 \mathrm{mmol})$ and copper iodide $(1.9 \mathrm{mg}, 0.010 \mathrm{mmol})$ were added to the flask under argon. The reaction mixture was stirred at $70{ }^{\circ} \mathrm{C}$ overnight and it was then poured into saturated $\mathrm{NH}_{4} \mathrm{Cl}$ solution $(20 \mathrm{~mL})$. The mixture was extracted with $\mathrm{DCM}$ $(20 \mathrm{~mL})$ twice and the combined organic layers were washed with $\mathrm{H}_{2} \mathrm{O}$ and brine consecutively, and dried over $\mathrm{Na}_{2} \mathrm{SO}_{4}$. The solvent was removed in vacuo and a light brown crude was obtained. Flash column chromatography (dry loading) using a mixture of hexanes and DCM (3:1, v/v) removed most of the impurities in the crude. Further purification by crystallizations from a hexanes-benzene mixture $(2: 1, \mathrm{v} / \mathrm{v})$ yielded the pure product $2(52 \mathrm{mg}, 70 \%)$.

2: White solid, m.p. $401-403{ }^{\circ} \mathrm{C} ;{ }^{1} \mathrm{H}$ NMR (500 MHz, $\left.\mathrm{CDCl}_{3}, \mathrm{ppm}\right): \delta 7.26-7.36$ (m, 102H), 7.43 (s, 4H), 7.48 (app. d, $\left.J=9.0 \mathrm{~Hz}, 12 \mathrm{H}) ;{ }^{13} \mathrm{C} \mathrm{NMR} \mathrm{(125} \mathrm{MHz,} \mathrm{CDCl}_{3}, \mathrm{ppm}\right): \delta 55.8,56.1,84.7$, $85.5,96.0,96.2,122.5,122.9,126.8,128.0,128.9,129.1,131.5,131.5,144.4,145.2$; IR (powder, $\left.\mathrm{cm}^{-1}\right): v 696(\mathrm{~s}), 743(\mathrm{~s}), 830(\mathrm{~m}), 890(\mathrm{w}), 1025(\mathrm{~m}), 1184(\mathrm{~m}), 1261(\mathrm{w}), 1405(\mathrm{w}), 1447(\mathrm{~m}), 1490(\mathrm{~s})$, 1596(m), 3028(w), 3058(w); MS (MALDI, TOF): $\mathrm{m} / \mathrm{z}$ calculated for $\mathrm{C}_{174} \mathrm{H}_{118} \mathrm{Na}\left(\mathrm{MNa}^{+}\right): 2231$ (100\%), 2232 (94\%), 2233 (58 \%), 2230 (53\%), 2234 (18\%), found: 2231(100\%), 2232 (89 \%), 2233 (60\%), 2230 (58\%), 2234 (28\%). 

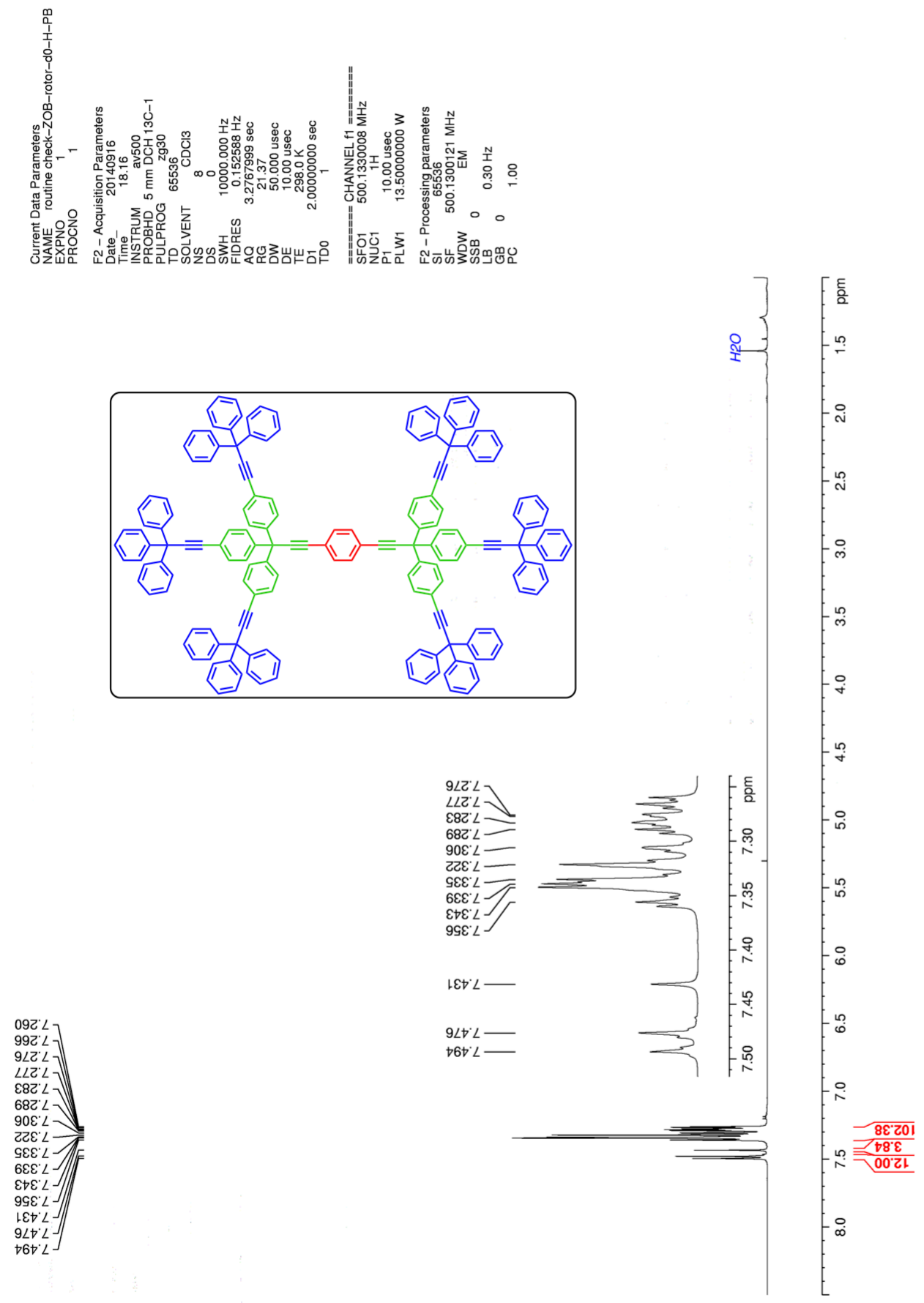

Figure S10. ${ }^{1} \mathrm{H}$ NMR of compound 2 at $500 \mathrm{MHz}$ in $\mathrm{CDCl}_{3}$. 

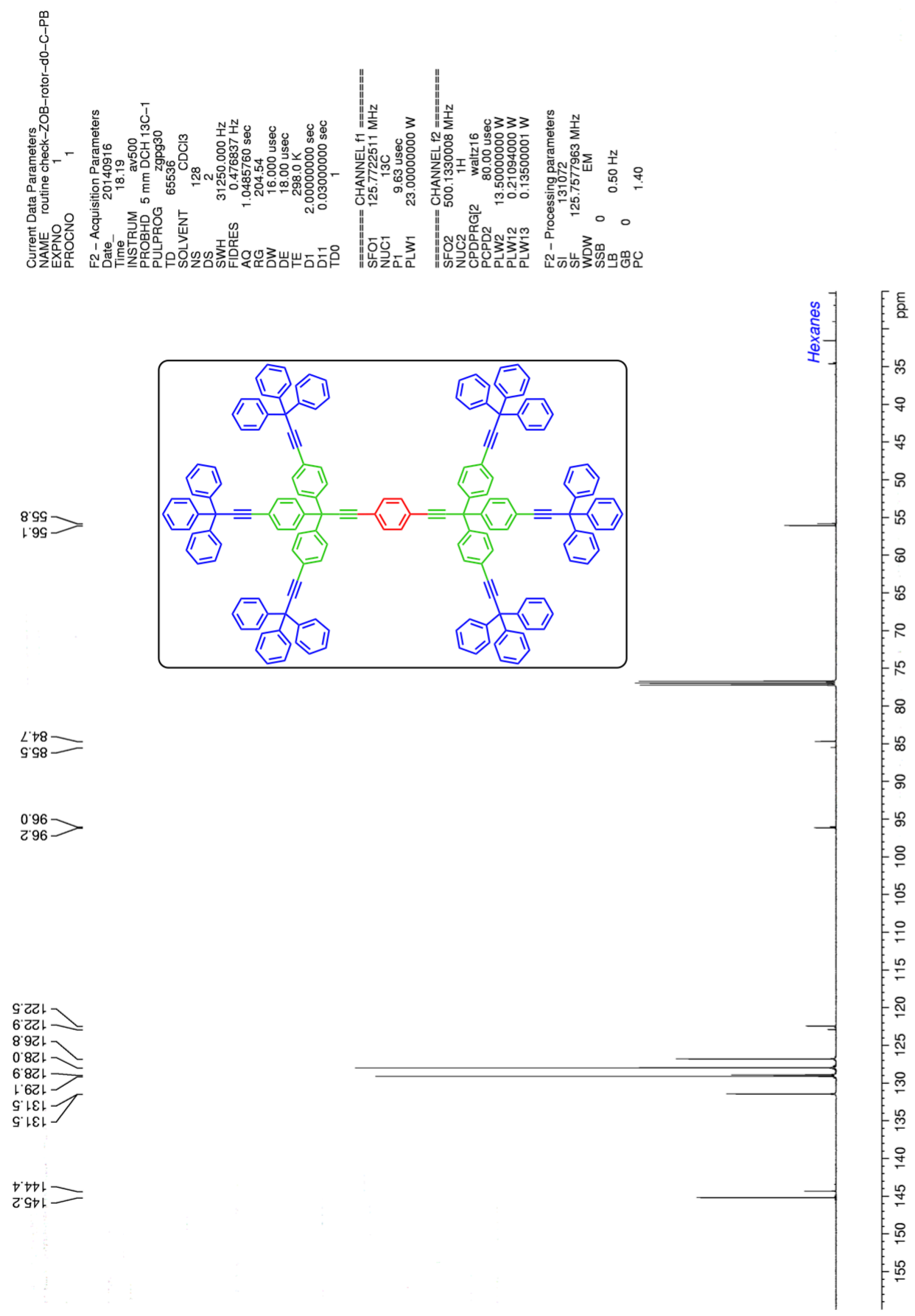

Figure 11. ${ }^{13} \mathrm{C}$ NMR of compound 2 at $125 \mathrm{MHz}$ in $\mathrm{CDCl}_{3}$. 


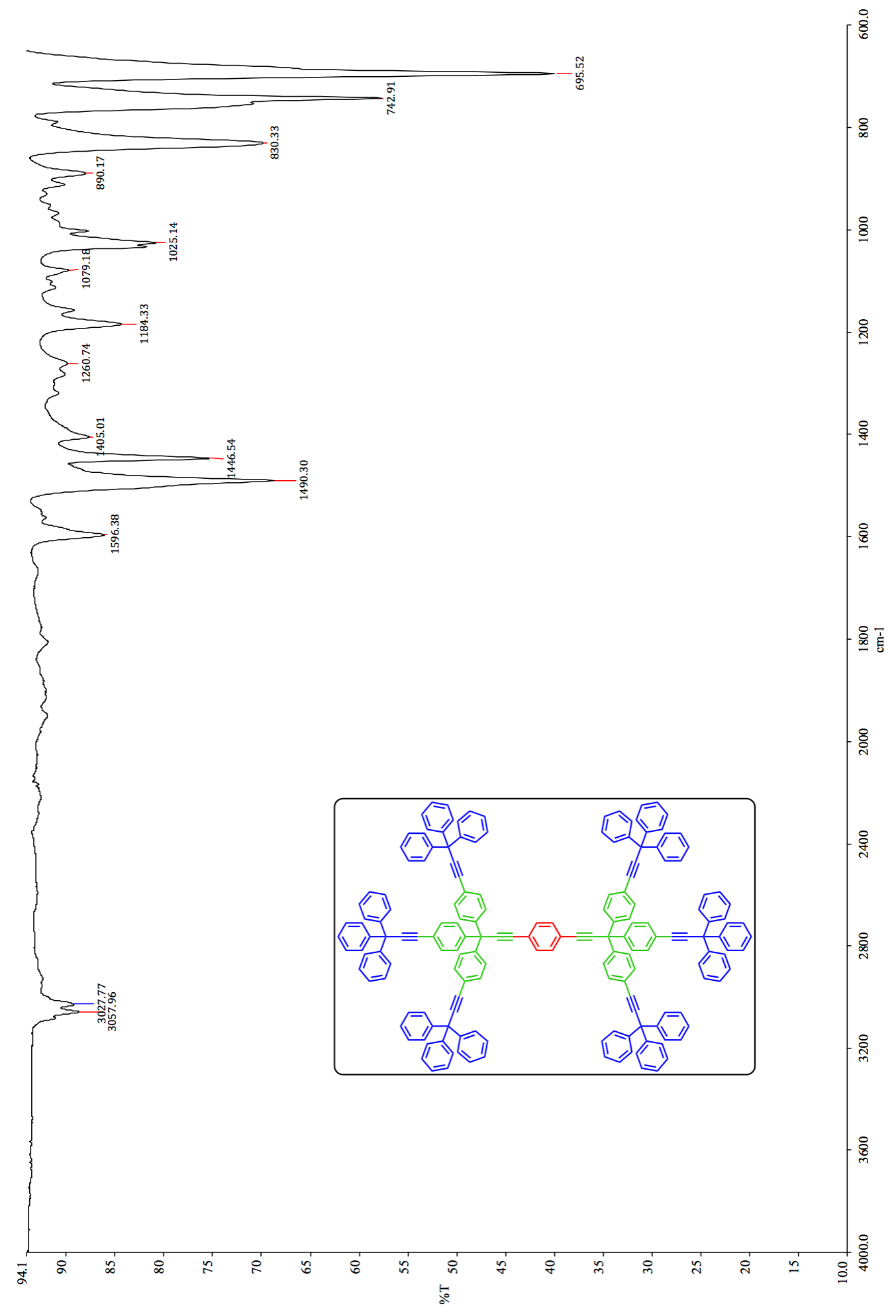

Figure S12. IR of compound 2. 


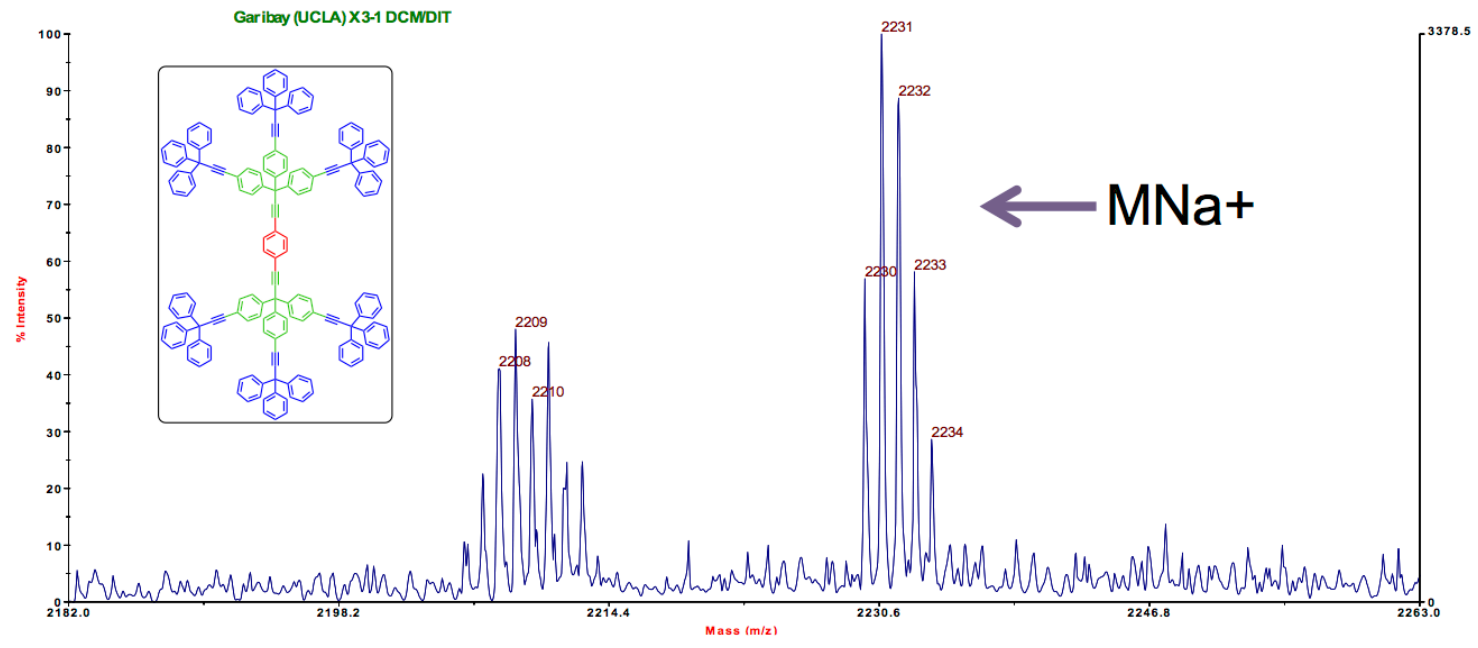

Figure S13. MS (MALDI, TOF) of compound 2 showing the cluster corresponding to $\mathrm{MNa}^{+}$. 


\subsection{Synthesis of 1,4-bis $\{3,3,3-$ tris [4-(3,3,3-triphenylpropynyl)phenyl]- propynyl $\}$ benzene- $d_{4} 2-d_{4}$}

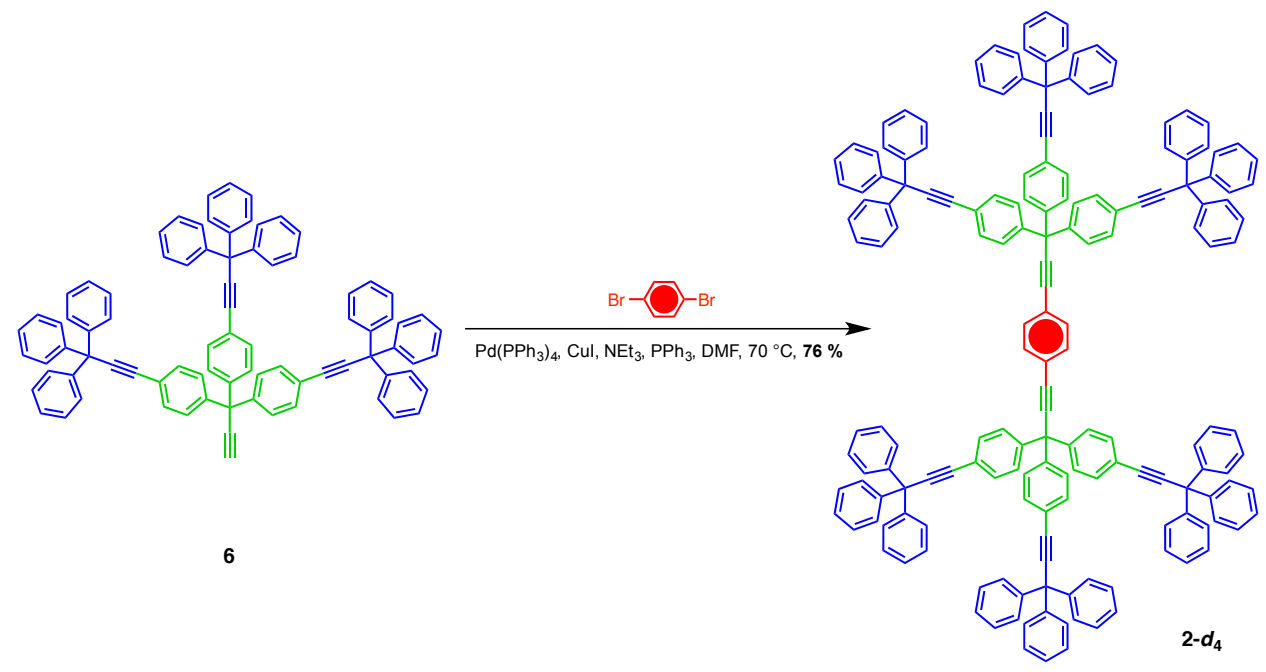

To a $25 \mathrm{~mL}$ round bottom flask was added $6(300 \mathrm{mg}, 0.281 \mathrm{mmol})$, 1,4-dibromobenzene- $d_{4}$ $(33.7 \mathrm{mg}, 0.140 \mathrm{mmol})$, triphenylphosphine $(14.7 \mathrm{mg}, 0.056 \mathrm{mmol})$, and triethylamine $(0.5 \mathrm{~mL})$ in anhydrous DMF $(3 \mathrm{~mL})$, and the resulting mixture was cooled down to $-78{ }^{\circ} \mathrm{C}$ before it was connected to vacuum for $30 \mathrm{~min}$ to remove oxygen dissolved in the solvent. Then palladium tetrakis(triphenylphosphine) (32 mg, $0.028 \mathrm{mmol})$ and copper iodide $(5.3 \mathrm{mg}, 0.028 \mathrm{mmol})$ were added into the flask under argon atmosphere. The reaction mixture was stirred at $70{ }^{\circ} \mathrm{C}$ overnight before it was poured into saturated $\mathrm{NH}_{4} \mathrm{Cl}$ solution $(50 \mathrm{~mL})$. The compound was extracted with DCM $(30 \mathrm{~mL})$ twice and the combined organic layers were washed with $\mathrm{H}_{2} \mathrm{O}$ and brine consecutively, and dried over anhydrous $\mathrm{Na}_{2} \mathrm{SO}_{4}$. The solvent was removed in vacuo and a light brown crude was obtained. Flash column chromatography (dry loading) using a mixture of hexanes and DCM $(3: 1, v / v)$ removed most of the impurities in the crude. Further purification by crystallizations from a hexanes-benzene mixture $(1: 1, \mathrm{v} / \mathrm{v})$ yielded the pure product $2-d_{4}(237$ $\mathrm{mg}, 76 \%)$.

2- $d_{4}$ : White solid, m.p. $400-401{ }^{\circ} \mathrm{C} ;{ }^{1} \mathrm{H}$ NMR (500 MHz, $\left.\mathrm{CDCl}_{3}, \mathrm{ppm}\right): \delta 7.24-7.33(\mathrm{~m}, 102 \mathrm{H})$, 7.46 (app. d, $J=8.5 \mathrm{~Hz}, 12 \mathrm{H}) ;{ }^{13} \mathrm{C}$ NMR $\left(125 \mathrm{MHz}, \mathrm{CDCl}_{3}, \mathrm{ppm}\right): \delta 55.8,56.1,84.7,85.5,96.1$, 96.2, 122.5, 122.7, 126.8, 128.0, 128.9, 129.1, 131.1 (t, $J=25.0 \mathrm{~Hz}), 131.5,144.4$, 145.2; IR $\left(\right.$ powder, $\left.\mathrm{cm}^{-1}\right): \quad v$ 695(s), 744(s), 829(m), 891(w), 1026(m), 1079(w), 1184(w), 1446(m), 1490(m), 1596(w), 3026(w), 3058(w); MS (MALDI, TOF): $\mathrm{m} / \mathrm{z}$ calculated for $\mathrm{C}_{174} \mathrm{H}_{114} \mathrm{D}_{4} \mathrm{Na}$ $\left(\mathrm{MNa}^{+}\right): 2235$ (100\%), 2236 (95\%), 2237 (59\%), 2234 (53\%), 2238 (27\%), found: 2235 (100 \%), 2236 (85\%), 2237 (61\%), 2234 (52\%), 2238 (32\%). 

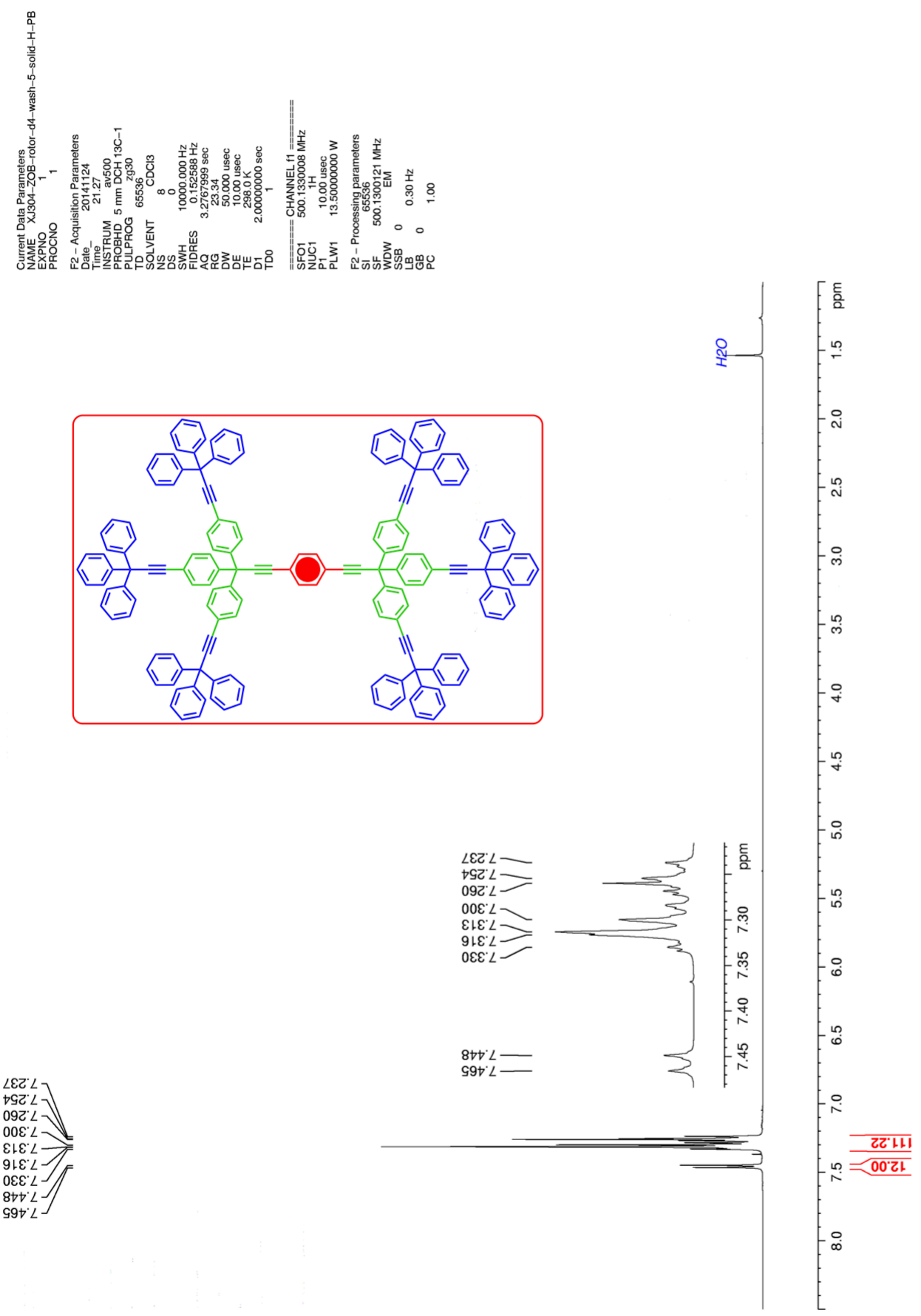

Figure S14. ${ }^{1} \mathrm{H}$ NMR of compound $2-d_{4}$ at $500 \mathrm{MHz}$ in $\mathrm{CDCl}_{3}$. 

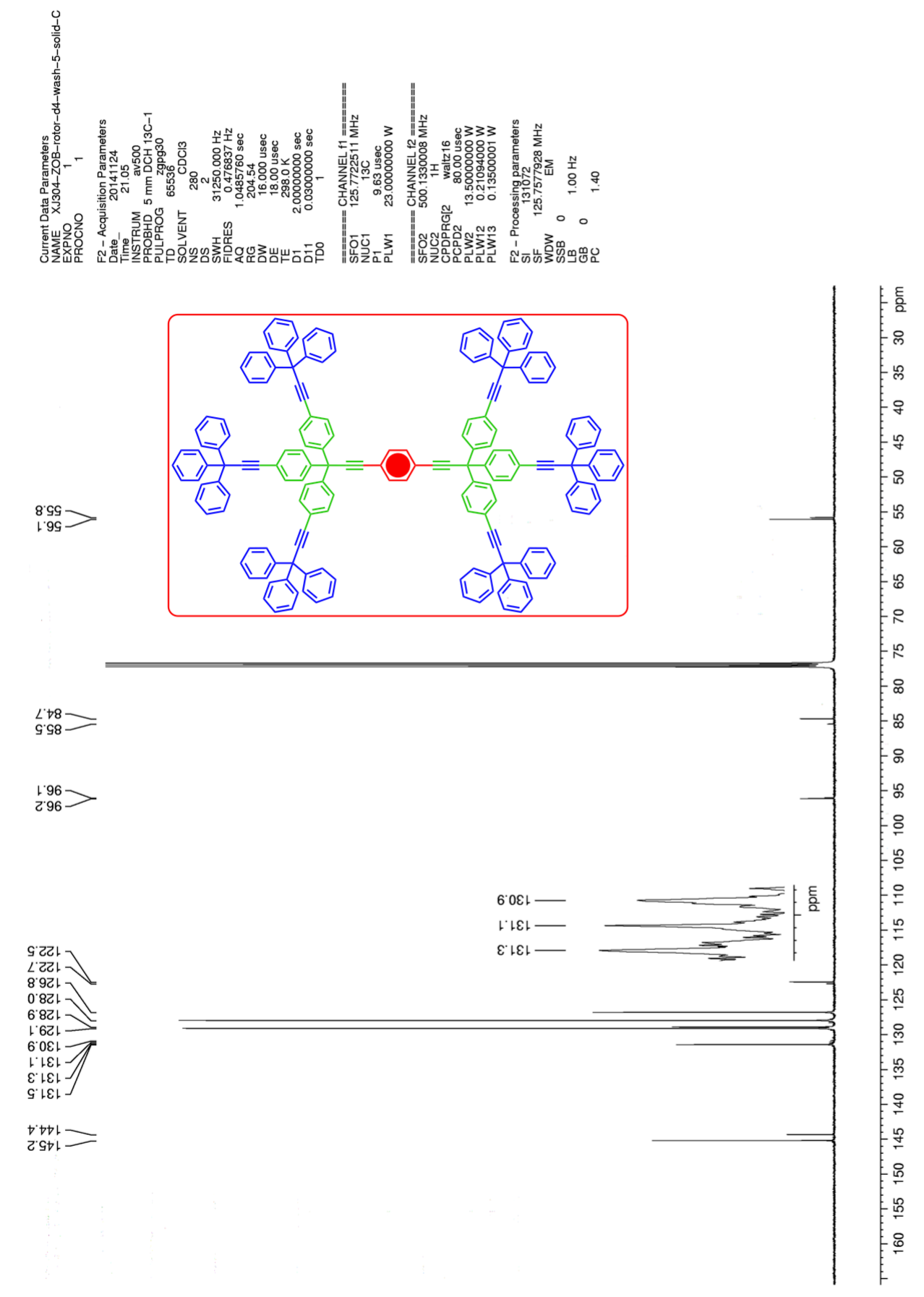

Figure S15. ${ }^{13} \mathrm{C}$ NMR of compound 2- $d_{4}$ at $125 \mathrm{MHz}$ in $\mathrm{CDCl}_{3}$. 


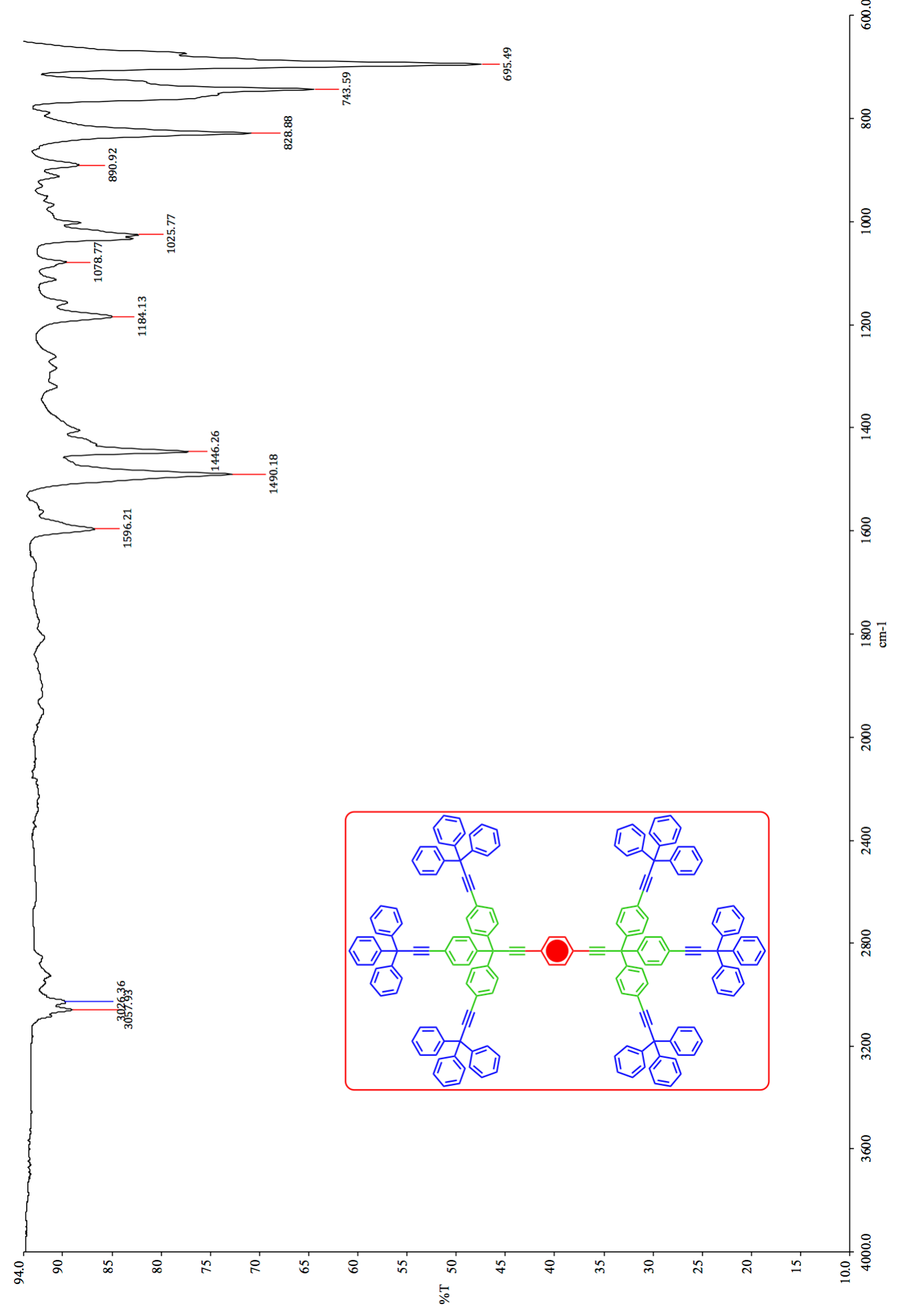

Figure 16. IR of compound 2- $d_{4}$. 


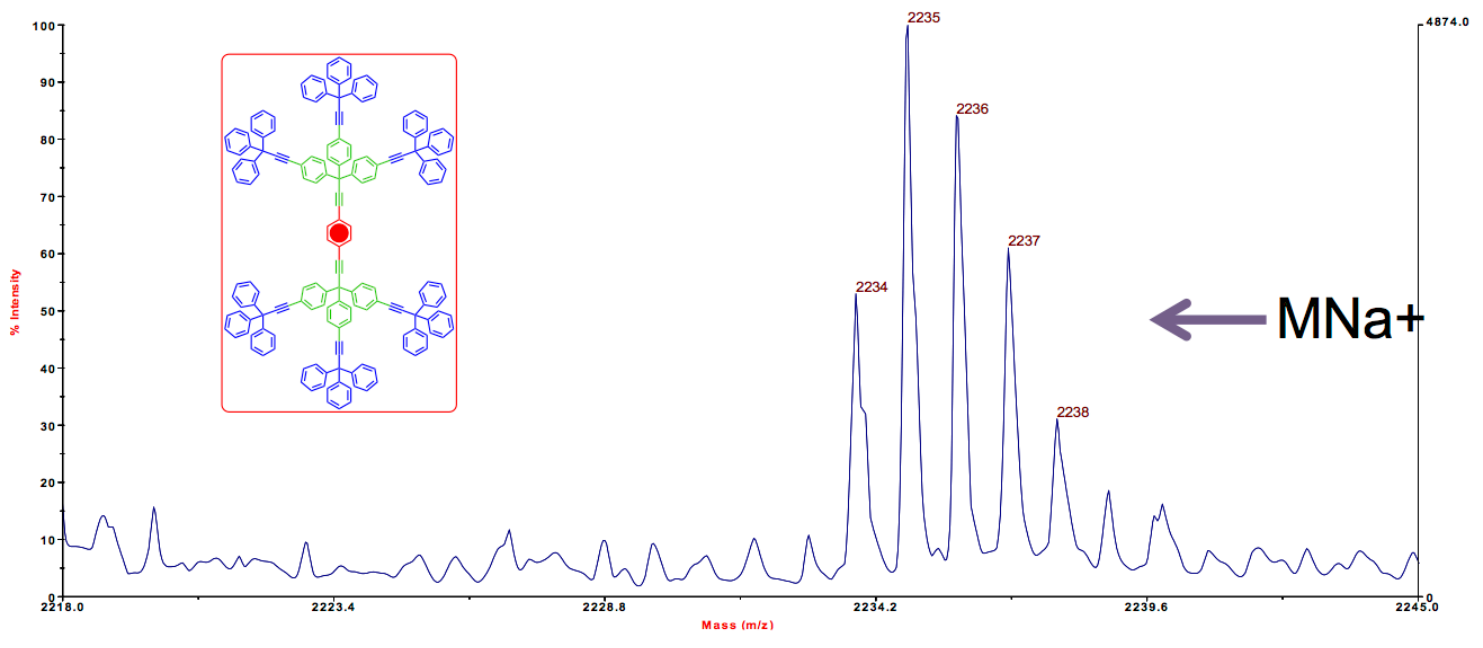

Figure S17. MS (MALDI, TOF) of compound 2- $d_{4}$ showing the cluster corresponding to $\mathrm{MNa}^{+}$. 


\subsection{Synthesis of 4-(3,3,3-triphenylpropynyl)phenyl bromide 4- $d_{4}$}

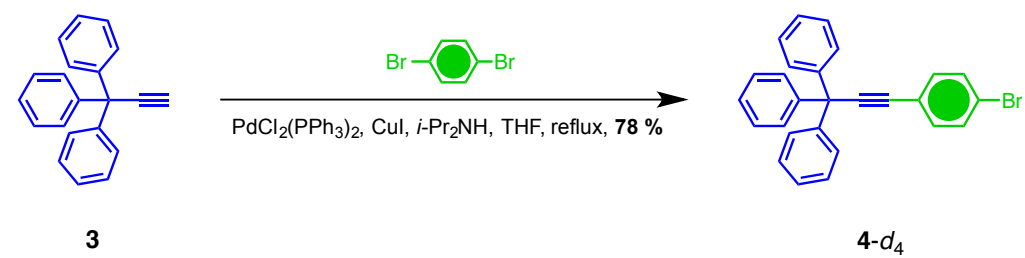

To a 3-neck flask with stir bar, additional funnel, and condenser were added 1,4-dibromobenzene$d_{4}(5.001 \mathrm{~g}, 20.8 \mathrm{mmol})$, anhydrous THF $(20 \mathrm{~mL})$, and di-iso-propylamine $(20 \mathrm{~mL})$ under argon. 3,3,3-Triphenylpropyne 3 (1.000 g, $3.73 \mathrm{mmol})$ was dissolved in anhydrous THF (20 $\mathrm{mL})$ in the additional funnel. Both the solutions were degased for $30 \mathrm{~min}$ before palladium bis(triphenylphosphine) dichloride $(78 \mathrm{mg}, 0.11 \mathrm{mmol})$ and copper iodide $(21 \mathrm{mg}, 0.11 \mathrm{mmol})$ were added into the flask. The reaction mixture in the 3-neck flask was heated to reflux and then the solution of 3 in the additional funnel was added into the flask slowly over $30 \mathrm{~min}$. The reaction mixture was reflux for 2 hours before it was allowed to cool down to room temperature. Saturated $\mathrm{NH}_{4} \mathrm{Cl}$ solution $(100 \mathrm{~mL})$ was added in to quench the reaction, and the compound was extracted with ether $(100 \mathrm{~mL})$ twice. The combined organic layers were washed with water and brine, dried over $\mathrm{Na}_{2} \mathrm{SO}_{4}$. The solvent was evaporated in vacuo and flash column chromatography of the residue using hexanes as the eluent provided the desired compound $4-d_{4}(1.241 \mathrm{~g}, 78 \%)$.

4- $d_{4}$ : White solid, m.p. $139-140{ }^{\circ} \mathrm{C} ;{ }^{1} \mathrm{H}$ NMR (500 MHz, $\left.\mathrm{CDCl}_{3}, \mathrm{ppm}\right): \delta 7.30-7.41$ (m, 15H); ${ }^{13} \mathrm{C}$ NMR (125 MHz, $\left.\mathrm{CDCl}_{3}, \mathrm{ppm}\right): \delta$ 56.1, 84.0, 96.9, 121.9, 122.2, 126.9, 128.0, 129.1, 131.0 (t, $J=25.5 \mathrm{~Hz}), 132.6(\mathrm{t}, J=25.2 \mathrm{~Hz}), 145.0$; IR (powder, $\left.\mathrm{cm}^{-1}\right): v 696(\mathrm{~s}), 735(\mathrm{~s}), 754(\mathrm{~s}), 818(\mathrm{w})$, 890(w), 1017(m), 1032(m), 1079(w), 1180 (w), 1307(w), 1386(m), 1445(m), 1490(m), 1596(w), 1954(w), 3023(w), 3057(w); HRMS (ESI/APCI, TOF): $\mathrm{m} / \mathrm{z}$ calculated for $\mathrm{C}_{27} \mathrm{H}_{16} \mathrm{D}_{4} \mathrm{Br}\left(\mathrm{MH}^{+}\right)$: 427.0994, found: 427.0996 . 

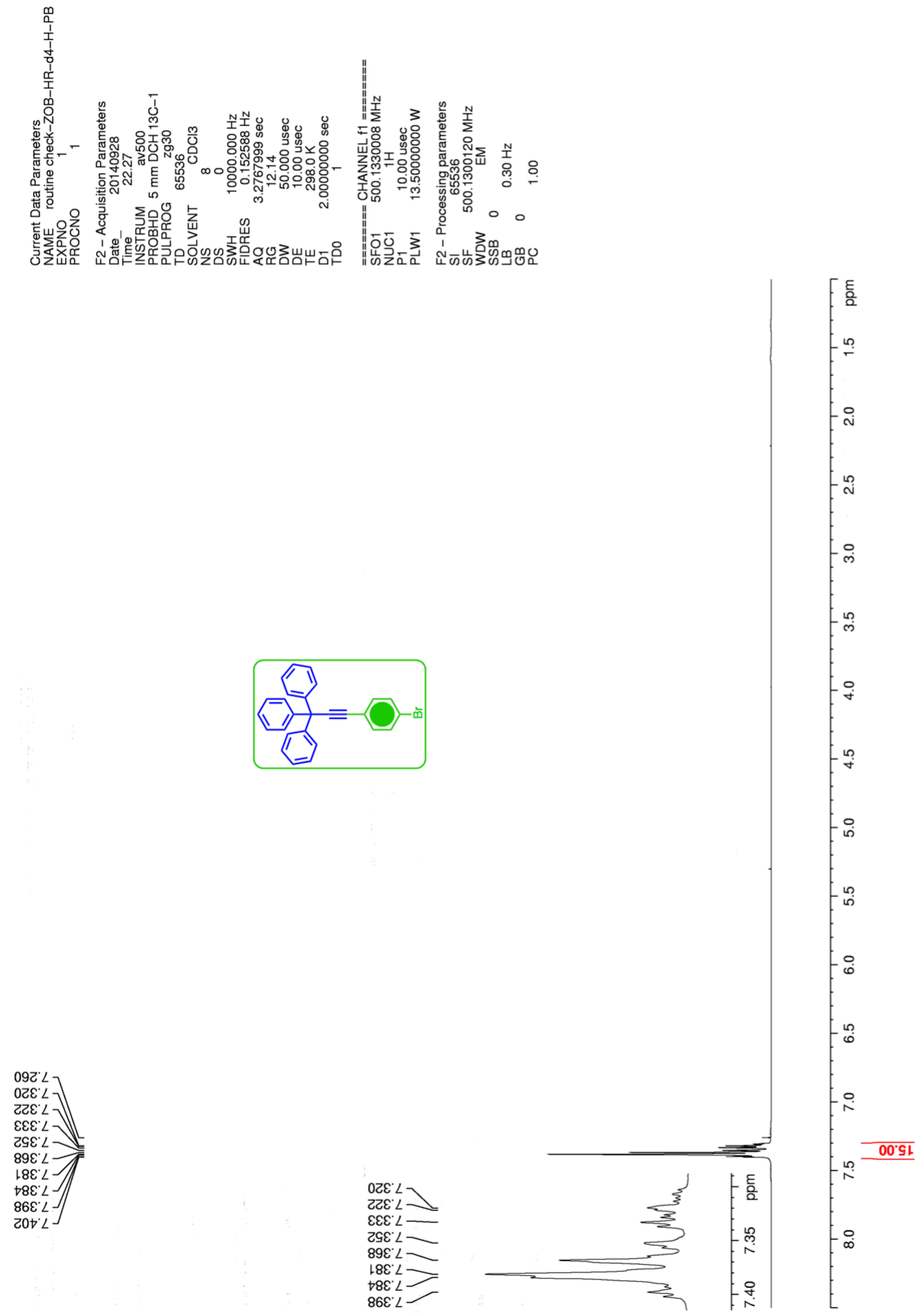

Figure S18. . ${ }^{1} \mathrm{H}$ NMR of compound $4-d_{4}$ at $500 \mathrm{MHz}$ in $\mathrm{CDCl}_{3}$. 

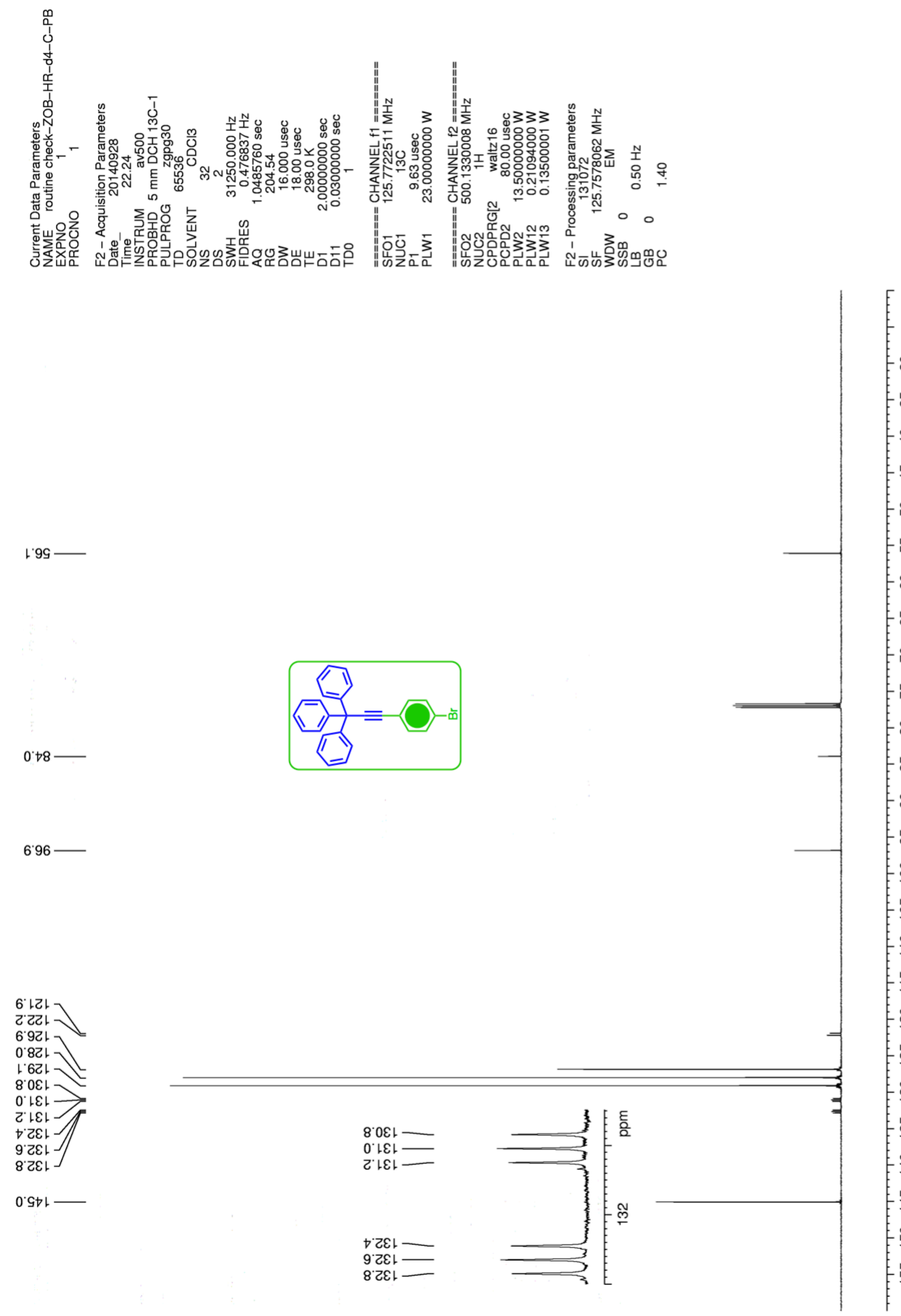

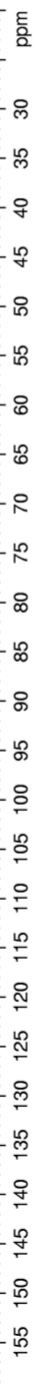

Figure S19. ${ }^{13} \mathrm{C}$ NMR of compound $4-d_{4}$ at $125 \mathrm{MHz}$ in $\mathrm{CDCl}_{3}$. 


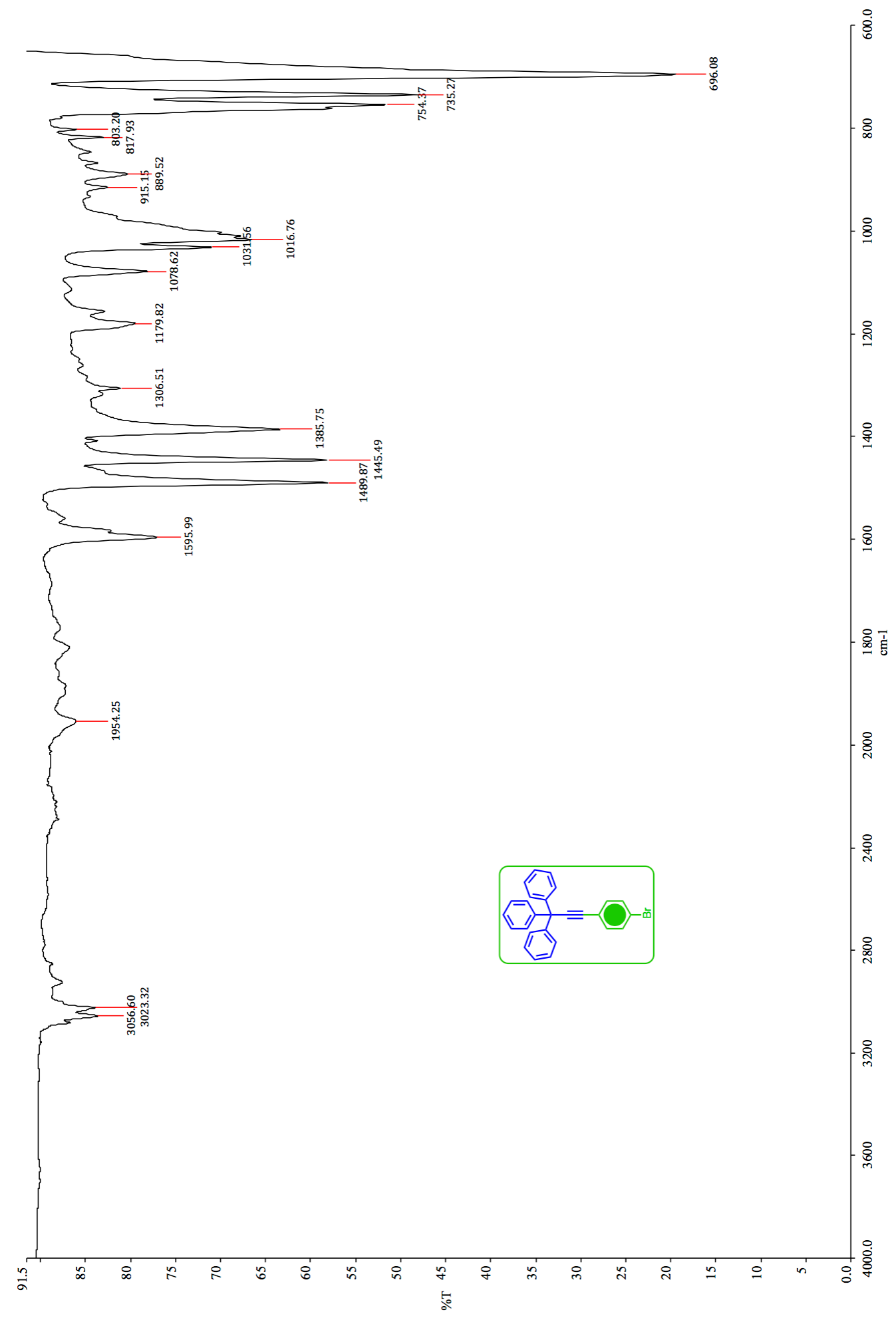

Figure S20. IR of compound 4- $d_{4}$. 


\subsection{Synthesis of tris [4-(3,3,3-triphenylpropynyl)phenyl]methanol 5- $d_{12}$}

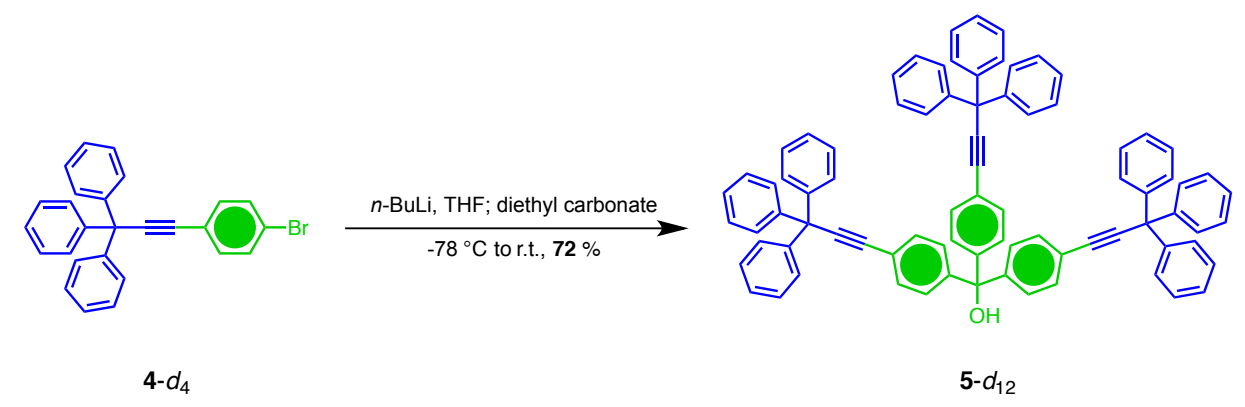

To a solution of arylbromide $4-d_{4}(1628 \mathrm{mg}, 3.81 \mathrm{mmol})$ in THF $(20 \mathrm{~mL})$ in a $100 \mathrm{~mL}$ round bottom flask in an acetone-dry ice bath was added $n$-BuLi $(1.6 \mathrm{M}$ solution in hexane, $2.40 \mathrm{~mL}$, $3.84 \mathrm{mmol}$ ) under argon atmosphere. The reaction mixture was stirred in the chilling bath for 1 hour before an excess of diethyl carbonate $(1.0 \mathrm{~mL}, 8.3 \mathrm{mmol})$ was added into the flask. The reaction mixture was stirred at $-78{ }^{\circ} \mathrm{C}$ for another hour and it was allowed to gradually warm up to room temperature. Saturated $\mathrm{NH}_{4} \mathrm{Cl}$ solution $(50 \mathrm{~mL})$ was added in to quench the reaction, and the compound was extracted with DCM $(50 \mathrm{~mL})$ twice. The combined organic layers were washed consecutively with water and brine, dried over $\mathrm{Na}_{2} \mathrm{SO}_{4}$, and concentrated to give a yellow crude. Flash column chromatography of the crude product (dry loading) using a hexanes-ether mixture $(4: 1, \mathrm{v} / \mathrm{v})$ as the eluent provided the desired compound 5- $d_{12}(976 \mathrm{mg}, 72 \%)$.

5- $d_{12}$ : Yellow Solid, m.p. $285-286{ }^{\circ} \mathrm{C} ;{ }^{1} \mathrm{H}$ NMR (500 MHz, $\left.\mathrm{CDCl}_{3}, \mathrm{ppm}\right): \delta 2.78$ (s, 1H), 7.30 7.33 (m, 9H), 7.35-7.38 (m, 18H), 7.40-7.41 (m, 18H); $\left.{ }^{13} \mathrm{C} \mathrm{NMR} \mathrm{(125} \mathrm{MHz,} \mathrm{CDCl}_{3}, \mathrm{ppm}\right): \delta$ 56.1, 81.5, 84.6, 96.2, 122.6, 126.8, 127.3 (t, $J=24.1 \mathrm{~Hz}$ ), 128.0, 129.1, 130.9 (t, $J=24.3 \mathrm{~Hz}$ ), 145.2, 145.8; IR (powder, $\left.\mathrm{cm}^{-1}\right): v 680(\mathrm{~m}), 696(\mathrm{~s}), 740(\mathrm{~m}), 756(\mathrm{~m}), 828(\mathrm{w}), 900(\mathrm{~m}), 1000(\mathrm{w})$, 1032(m), 1102(w), 1185(w), 1322(w), 1417(w), 1447(m), 1490(m), 1596(w), 3026(w), 3058(w), 3563(w); HRMS (LIFDI, TOF): $\mathrm{m} / \mathrm{z}$ calculated for $\mathrm{C}_{82} \mathrm{H}_{46} \mathrm{D}_{12} \mathrm{O}\left(\mathrm{M}^{+}\right)$: 1070.5235, found: 1070.5280 . 


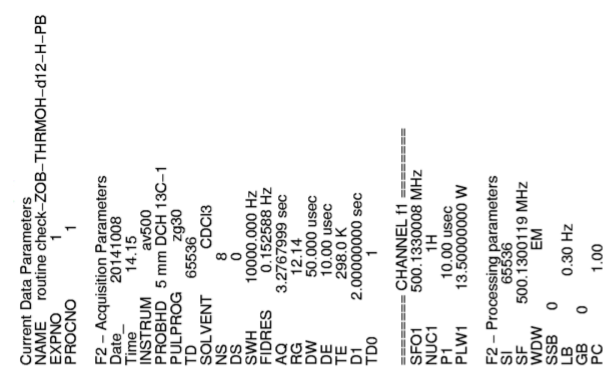

$08 L^{\prime} Z-$

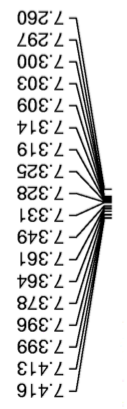

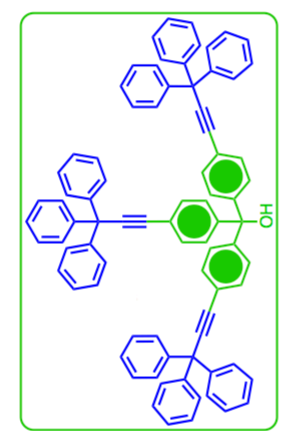

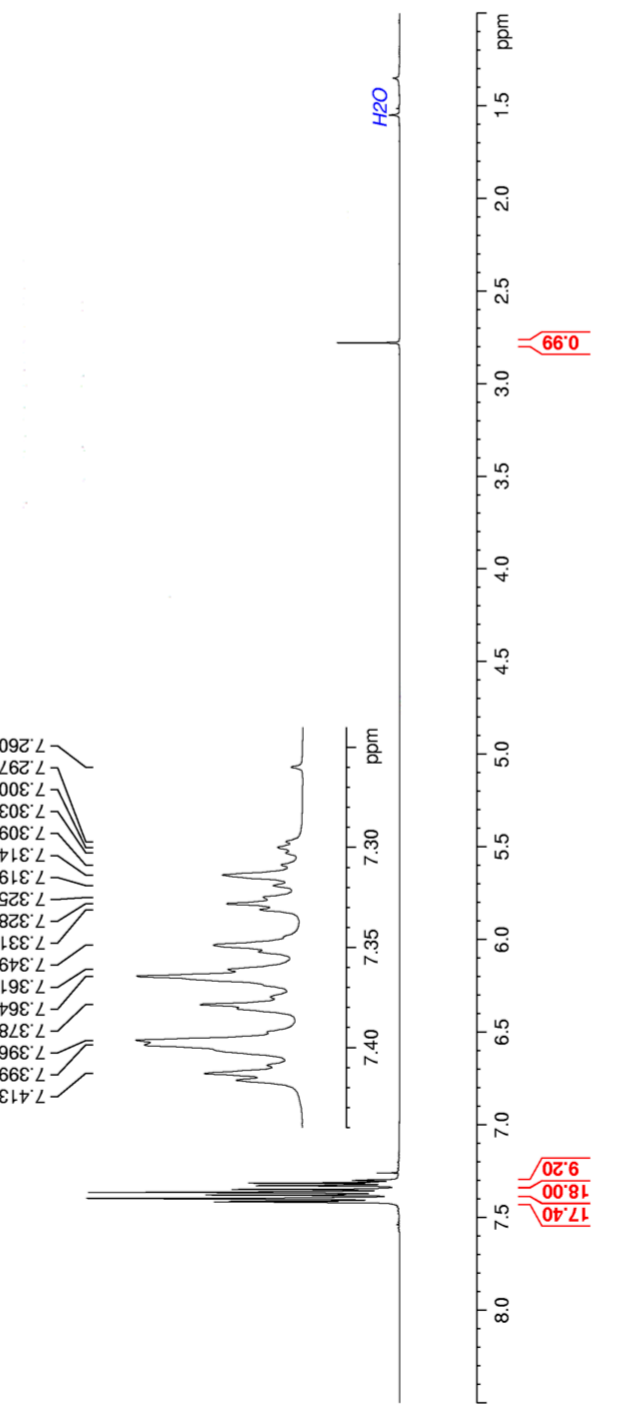

Figure S21. ${ }^{1} \mathrm{H}$ NMR of compound 5- $d_{12}$ at $500 \mathrm{MHz}$ in $\mathrm{CDCl}_{3}$. 


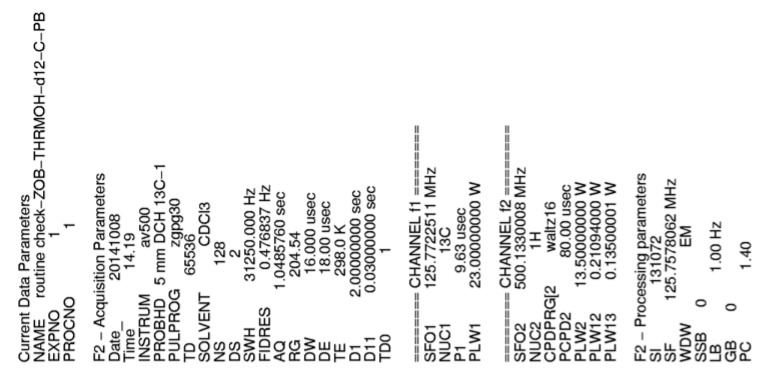

$1 \cdot 99$

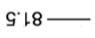

$9 \triangleright 8$

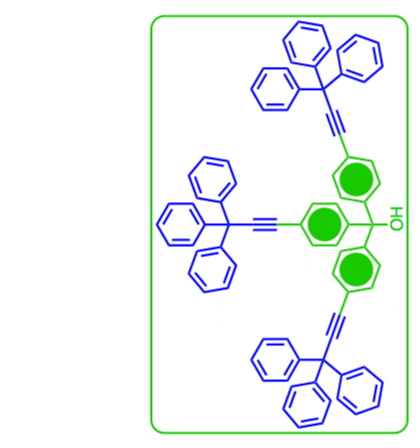

$\tau 96$
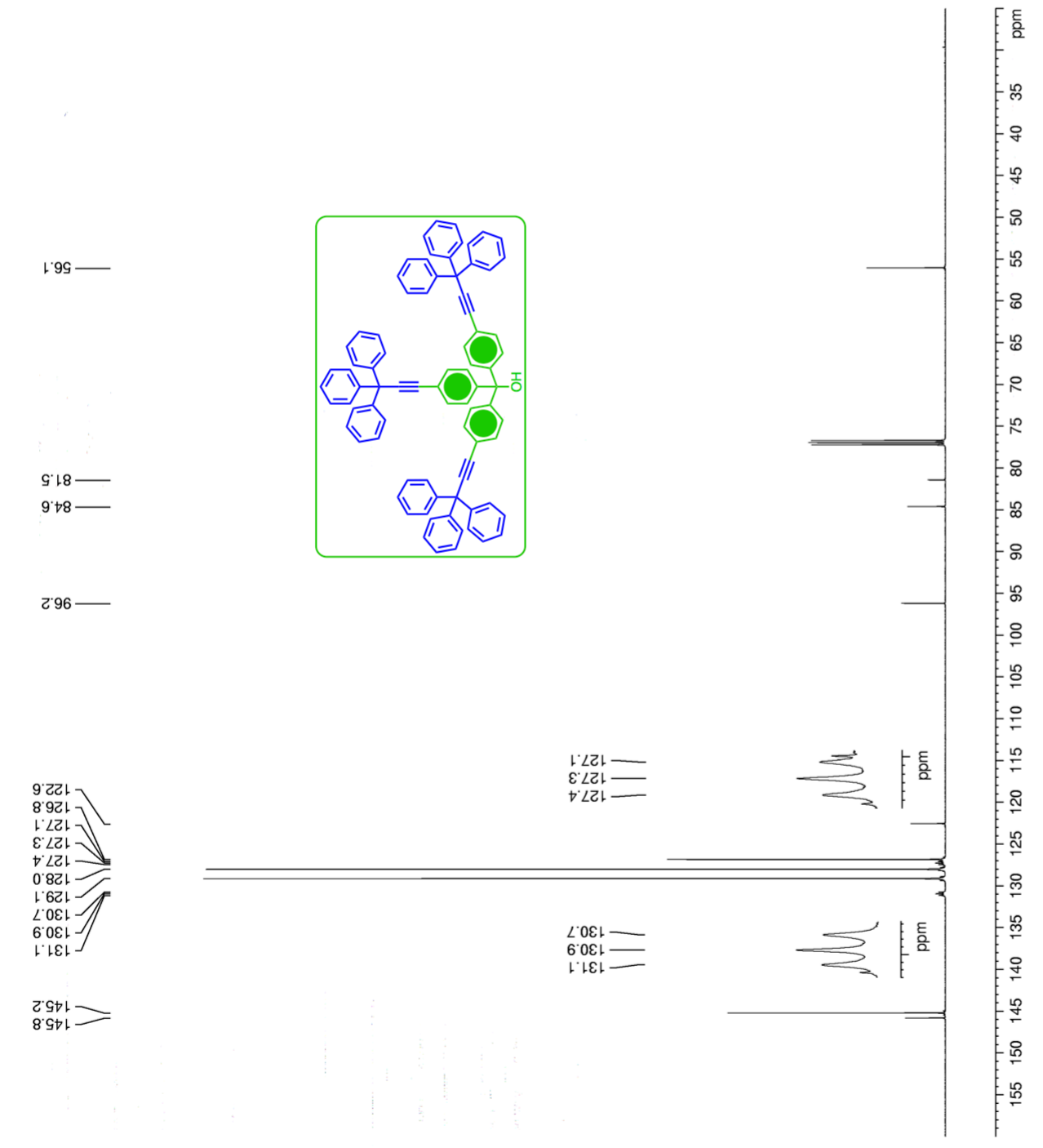

Figure S22. ${ }^{13} \mathrm{C}$ NMR of compound 5- $d_{12}$ at $125 \mathrm{MHz}$ in $\mathrm{CDCl}_{3}$. 


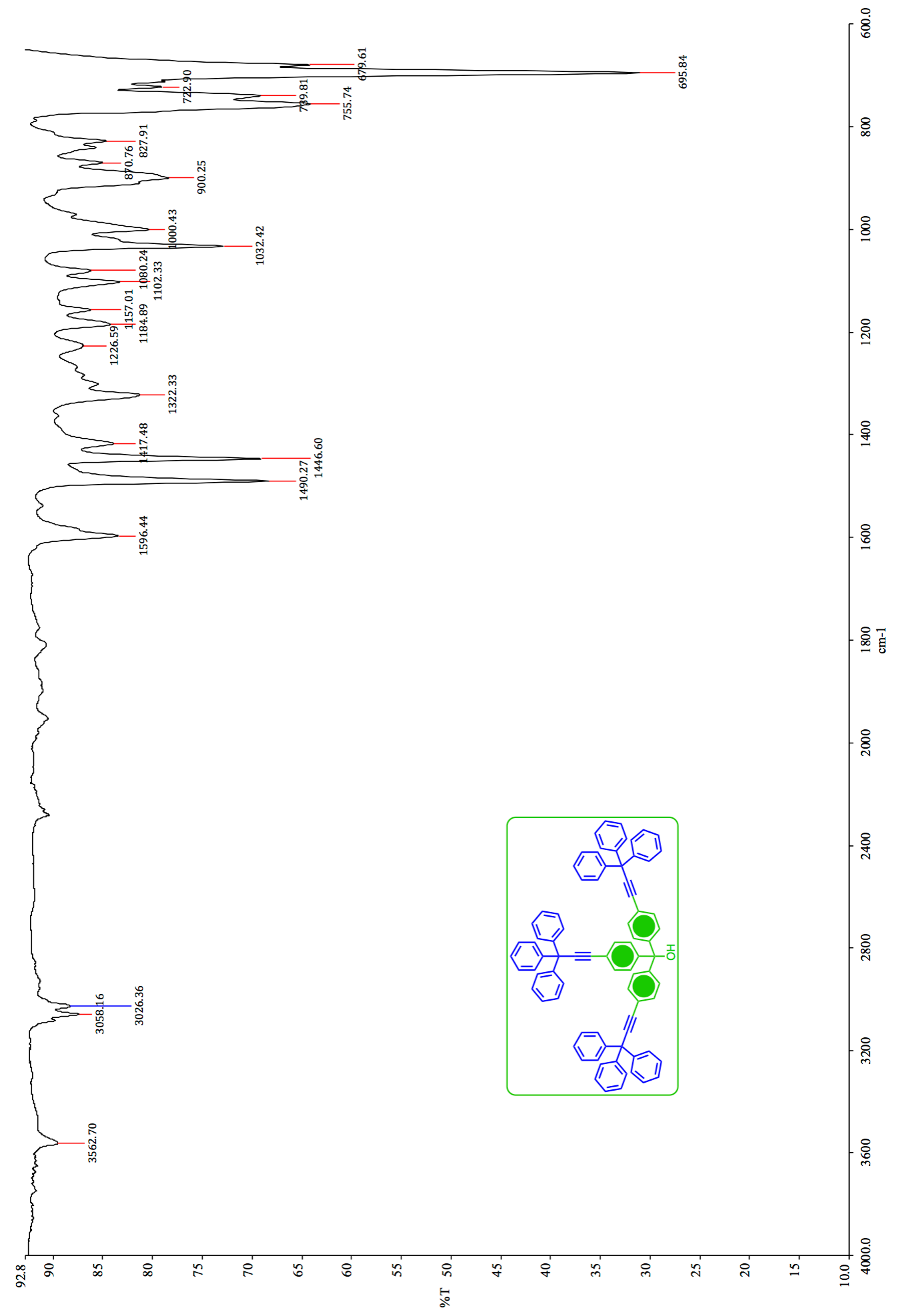

Figure S23. IR of compound 5- $d_{12}$. 


\subsection{Synthesis of tris[4-(3,3,3-triphenylpropynyl)phenyl]propyne 6- $d_{12}$}
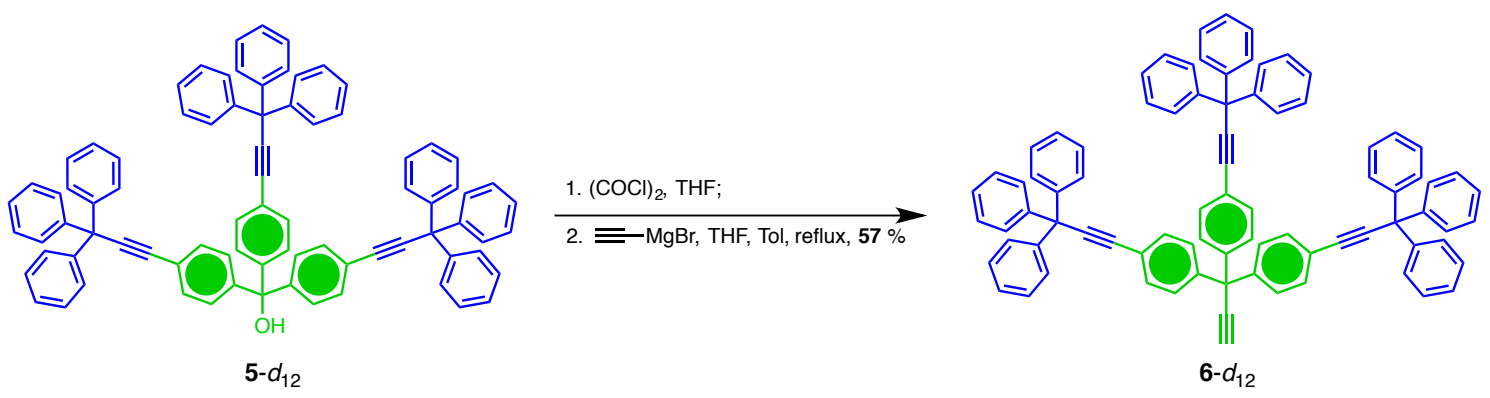

Triarylmethanol 5- $d_{12}(976 \mathrm{mg}, 0.91 \mathrm{mmol})$, anhydrous THF $(5 \mathrm{~mL})$, and oxalyl chloride $(2.0 \mathrm{~mL})$ were added to a round bottom flask and the resulting mixture was stirred at room temperature overnight. The solvents were then removed by evaporation in vacuo. The residue was taken up in anhydrous toluene $(10 \mathrm{~mL})$ and the solvent was removed again. The residue was dissolved in anhydrous toluene $(50 \mathrm{~mL})$ and the resulting solution was heated up to reflux under argon. Ethynylmagnesium bromide ( $0.5 \mathrm{M}$ solution in THF, $10.0 \mathrm{~mL}, 5.0 \mathrm{mmol})$ was added to the flask, and the reaction mixture was refluxed for $4 \mathrm{~h}$ before it was allowed to cool down to room temperature. Saturated $\mathrm{NH}_{4} \mathrm{Cl}$ solution $(30 \mathrm{~mL})$ was added in to quench the reaction, and the mixture was extracted with DCM $(50 \mathrm{~mL})$ twice. The combined organic layers were washed with brine, dried over $\mathrm{Na}_{2} \mathrm{SO}_{4}$, and concentrated to give a brown crude. Flash column chromatography (dry loading) of the crude product using a mixture of hexanes and DCM (4:1, v/v) as the eluent yielded the desired compound $6-d_{12}(565 \mathrm{mg}, 57 \%)$.

6- $d_{12}$ : White solid, m.p. $285-286{ }^{\circ} \mathrm{C} ;{ }^{1} \mathrm{H}$ NMR (500 MHz, $\left.\mathrm{CDCl}_{3}, \mathrm{ppm}\right): \delta 2.72$ (s, 1H), 7.23-7.33 $(\mathrm{m}, 45 \mathrm{H}) ;{ }^{13} \mathrm{C} \mathrm{NMR}\left(125 \mathrm{MHz}, \mathrm{CDCl}_{3}, \mathrm{ppm}\right): \delta 55.0,56.1,74.2,84.6,88.4,96.2,122.3,126.8$, 128.0, 128.4 (t, $J=24.2 \mathrm{~Hz}$ ), 129.1, 131.0 (t, $J=24.2 \mathrm{~Hz}$ ), 143.8, 145.2; IR (powder, $\mathrm{cm}^{-1}$ ): $v$ 680(m), 696(s), 722(w), 756(s), 871(w), 902(w), 1002(w), 1033(m), 1080(w), 1158(w), 1183(w), 1322(w), 1411(m), 1447(s), 1490(s), 1596(m), 1952(w), 3022(w), 3059(w), 3284(w); HRMS (ESI/APCI, TOF): $\mathrm{m} / \mathrm{z}$ calculated for $\mathrm{C}_{84} \mathrm{H}_{47} \mathrm{D}_{12}\left(\mathrm{MH}^{+}\right): 1079.5365$, found: 1079.5374 . 


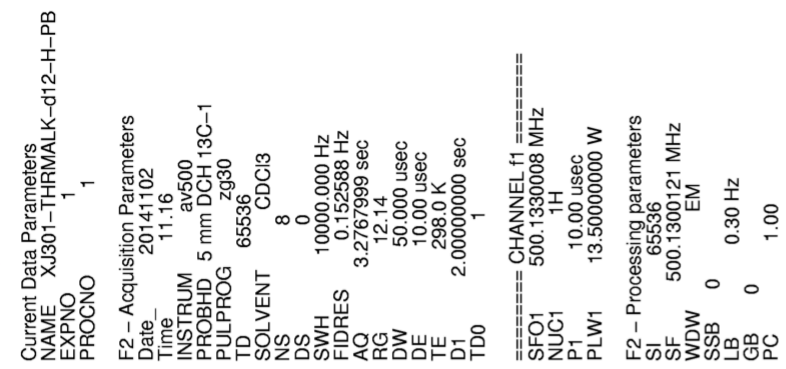

$91<2$

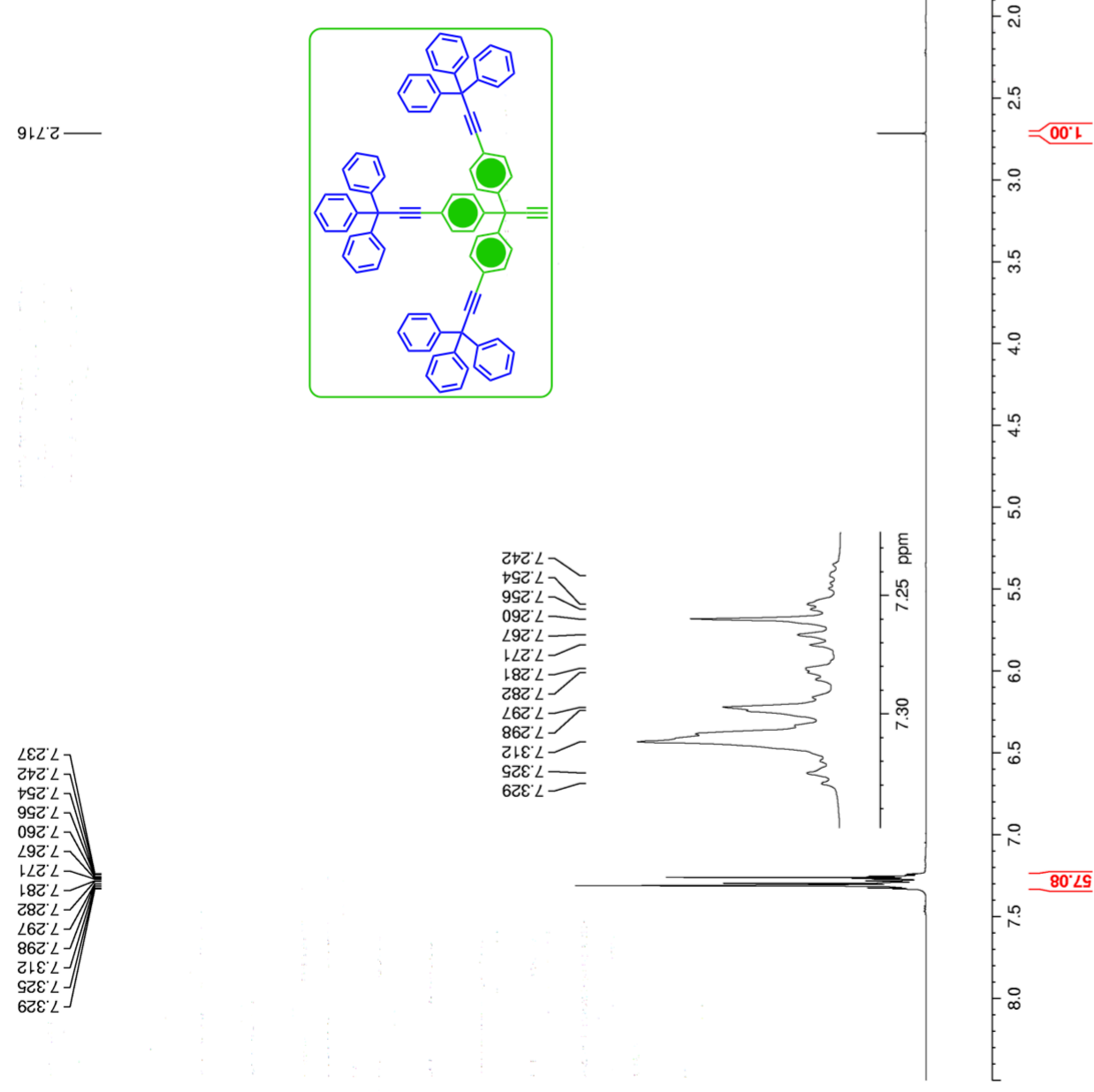

Figure S24. ${ }^{1} \mathrm{H}$ NMR of compound 6- $d_{12}$ at $500 \mathrm{MHz}$ in $\mathrm{CDCl}_{3}$. 

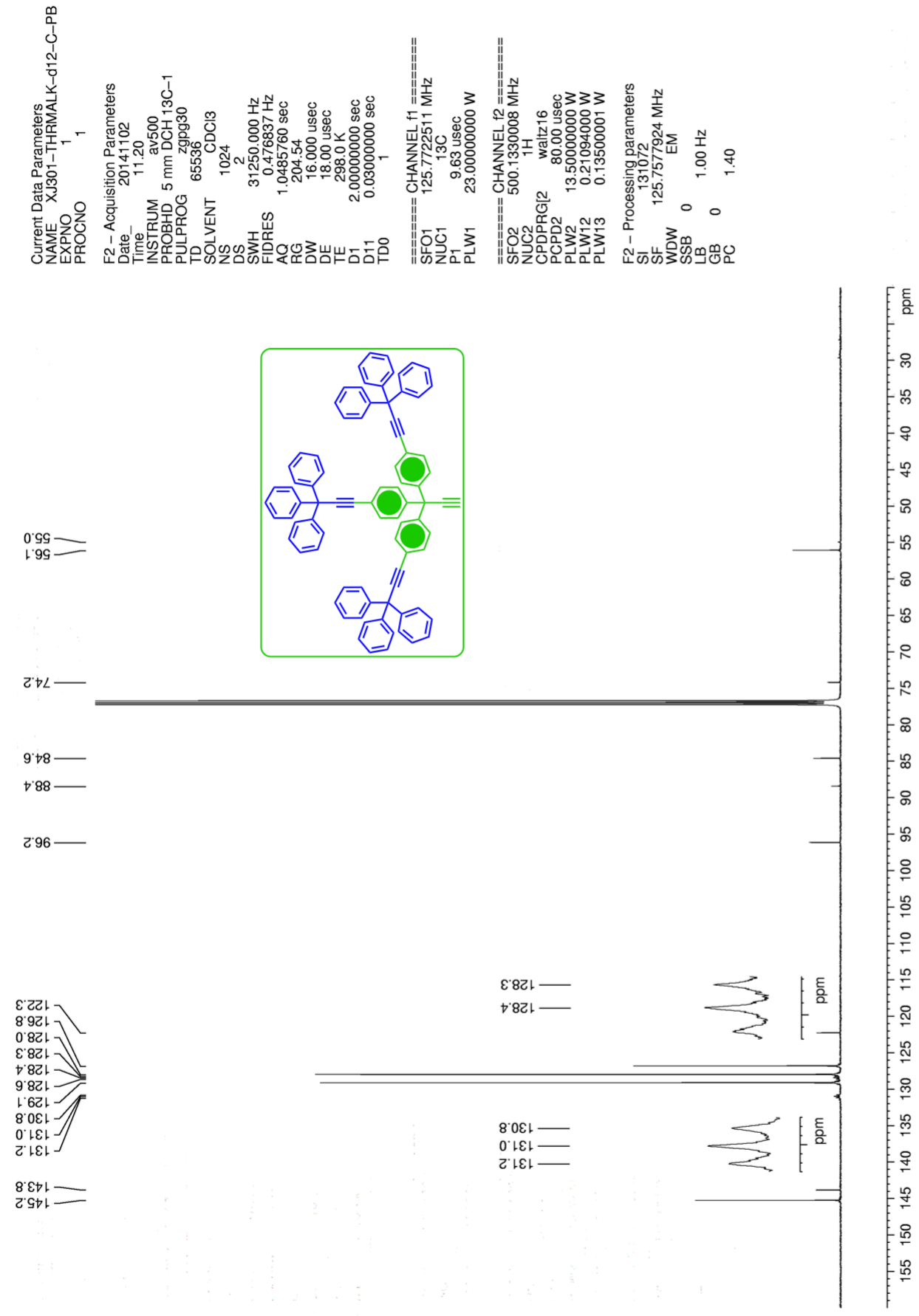

Figure S25. ${ }^{13} \mathrm{C}$ NMR of compound 6- $d_{12}$ at $125 \mathrm{MHz}$ in $\mathrm{CDCl}_{3}$. 


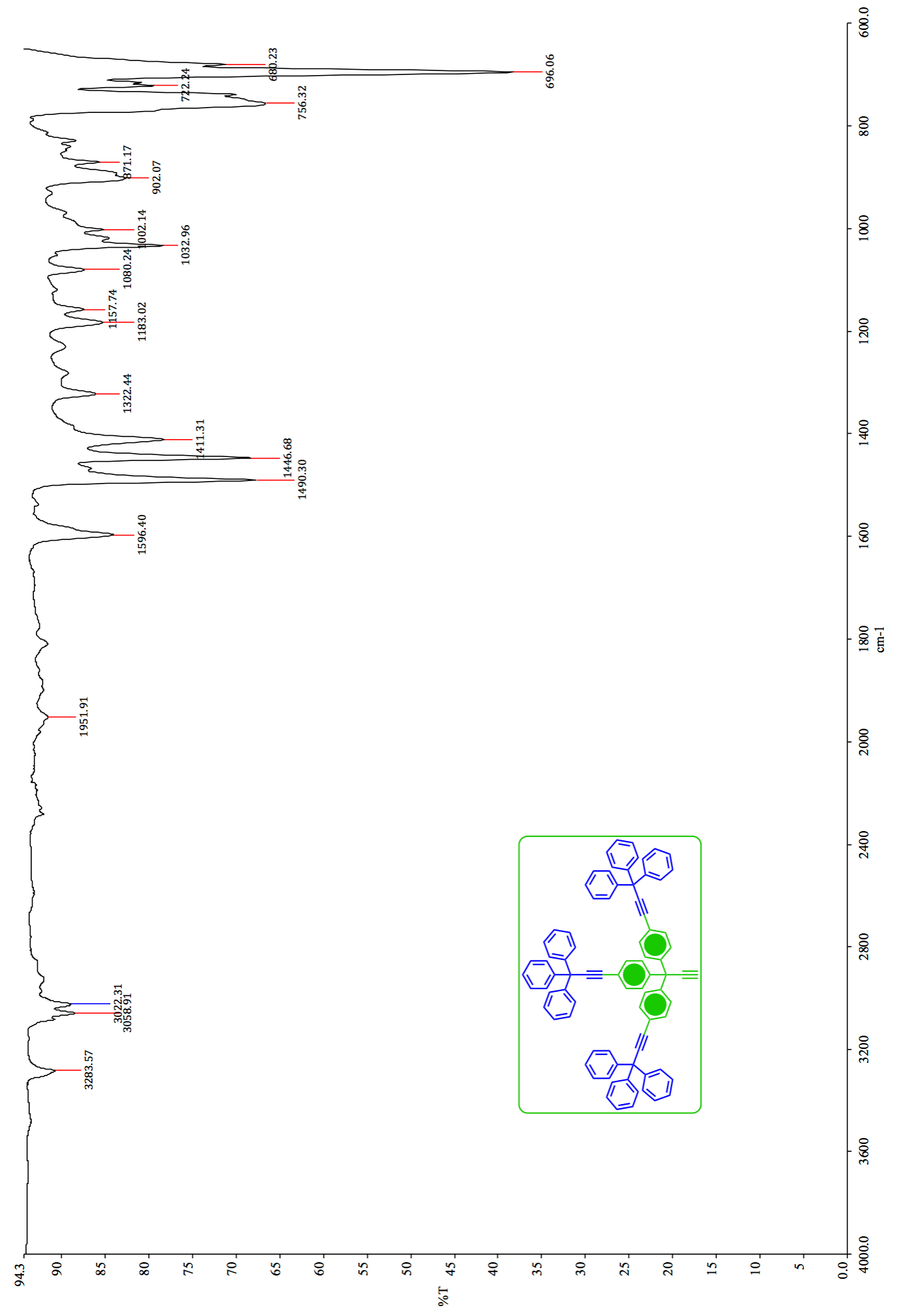

Figure S26. IR of compound 6- $d_{12}$. 


\subsection{Synthesis of 1,4-bis $\{3,3,3-$ tris [4-(3,3,3-triphenylpropynyl)phenyl]- propynyl\}benzene- $d_{24} 2-d_{24}$}

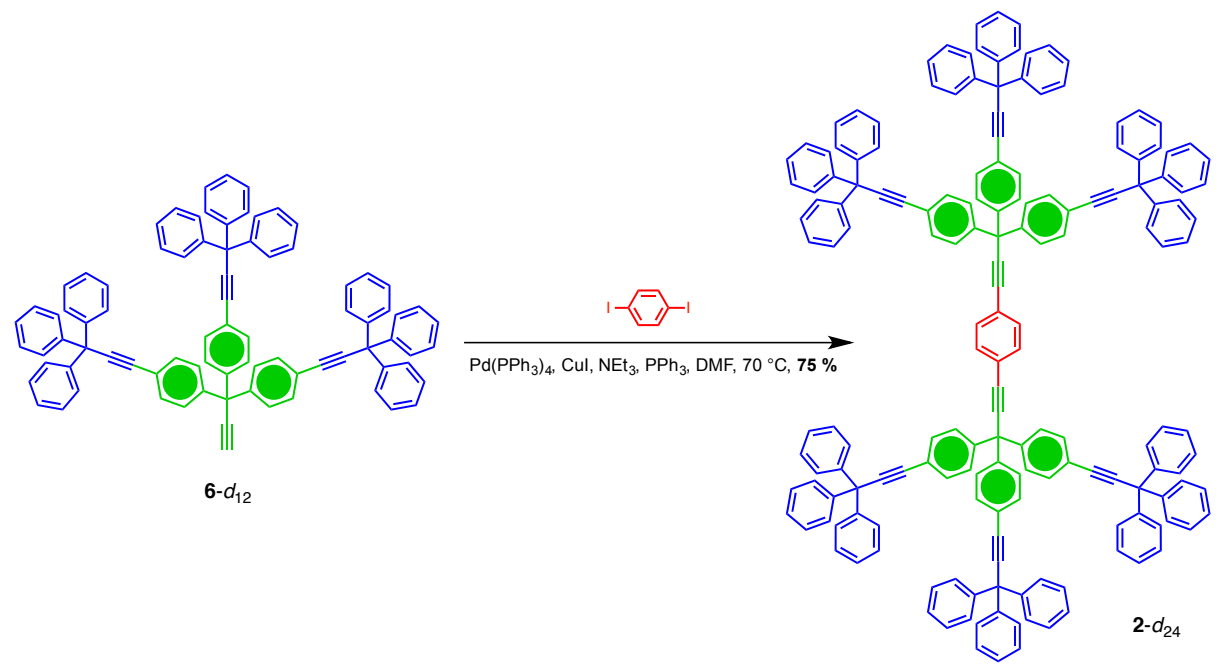

To a round bottom flask was added $6-d_{12}(565 \mathrm{mg}, 0.523 \mathrm{mmol}), 1$,4-diiodobenzene $(86.3 \mathrm{mg}$, $0.261 \mathrm{mmol})$, triphenylphosphine $(27 \mathrm{mg}, 0.10 \mathrm{mmol})$, and triethylamine $(1 \mathrm{~mL})$ in anhydrous DMF (5 mL) under argon. The flask was placed in an acetone-dry ice bath and connected to vacuum for $30 \mathrm{~min}$ to remove residual oxygen. Then palladium tetrakis(triphenylphosphine) (60 $\mathrm{mg}, 0.052 \mathrm{mmol})$ and copper iodide $(10 \mathrm{mg}, 0.053 \mathrm{mmol})$ were then added into the flask. The reaction mixture was stirred at $70{ }^{\circ} \mathrm{C}$ overnight before it was cooled back to room temperature and poured into saturated $\mathrm{NH}_{4} \mathrm{Cl}$ solution $(50 \mathrm{~mL})$. The compound was extracted with $\mathrm{DCM}$ $(30 \mathrm{~mL})$ twice and the combined organic layers were washed with $\mathrm{H}_{2} \mathrm{O}$ and brine, and dried over anhydrous $\mathrm{Na}_{2} \mathrm{SO}_{4}$. The solvent was removed in vacuo and a light brown crude was obtained. Flash column chromatography (dry loading) using a mixture of hexanes and DCM $(3: 1, \mathrm{v} / \mathrm{v})$ removed most of the impurities in the crude. Further purification by crystallizations from a hexanes-benzene mixture $(1: 1, v / v)$ yielded the pure product $2-d_{24}(440 \mathrm{mg}, 75 \%)$.

2- $d_{24}$ : white solid, m.p. $401-402{ }^{\circ} \mathrm{C} ;{ }^{1} \mathrm{H}$ NMR (500 MHz, $\left.\mathrm{CDCl}_{3}, \mathrm{ppm}\right): \delta 7.26-7.36(\mathrm{~m}, 90 \mathrm{H})$, 7.43 (s, 4H); ${ }^{13} \mathrm{C}$ NMR (125 MHz, $\left.\mathrm{CDCl}_{3}, \mathrm{ppm}\right): \delta 55.7,56.1,84.7,85.5,96.0,96.2,122.3$, 122.9, 126.8, 128.0, 128.5 (t, $J=22.8 \mathrm{~Hz}), 129.1,131.1$ (t, $J=22.8 \mathrm{~Hz}), 131.5,144.2$, 145.2; IR (powder, $\left.\mathrm{cm}^{-1}\right): v 677(\mathrm{~s}), 696(\mathrm{~s}), 723(\mathrm{w}), 739(\mathrm{w}), 758(\mathrm{~m}), 840(\mathrm{w}), 870(\mathrm{w}), 902(\mathrm{w}), 1033(\mathrm{w})$, 1079(w), 1182(w), 1323(w), 1410(w), 1446(m), 1490(m), 1596(w), 3027(w), 3059(w); MS (MALDI, TOF): $\mathrm{m} / \mathrm{z}$ calculated for $\mathrm{C}_{174} \mathrm{H}_{94} \mathrm{D}_{24} \mathrm{Na}\left(\mathrm{MNa}^{+}\right): 2255$ (100\%), 2256 (95\%), 2257 (59\%), 2254 (53.1\%), 2258 (27\%), found: 2255 (100\%), 2256 (80\%), 2257 (40\%), 2254 $(60 \%), 2258(28 \%)$. 

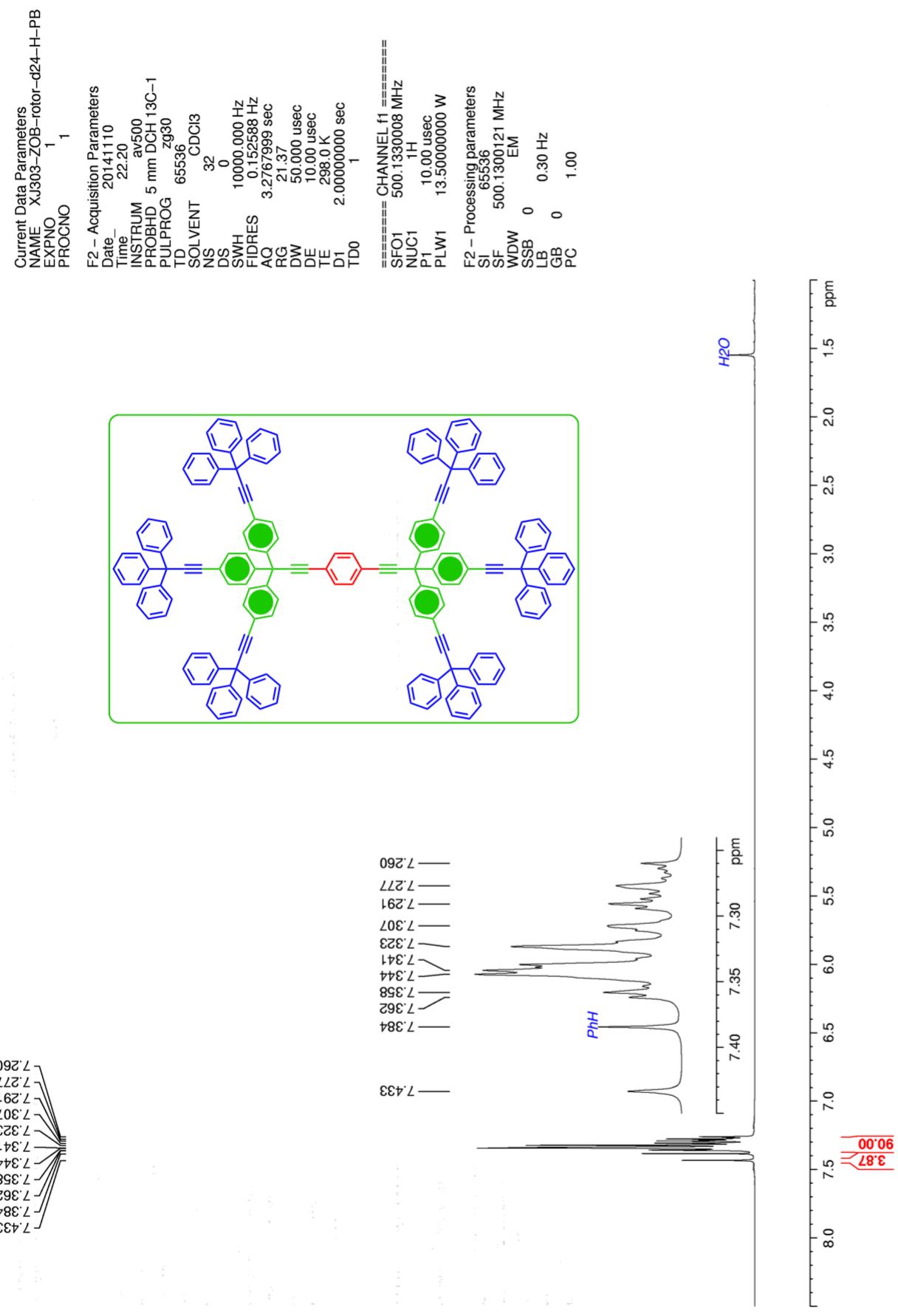

Figure S27. ${ }^{1} \mathrm{H}$ NMR of compound 2- $d_{24}$ at $500 \mathrm{MHz}$ in $\mathrm{CDCl}_{3}$. 

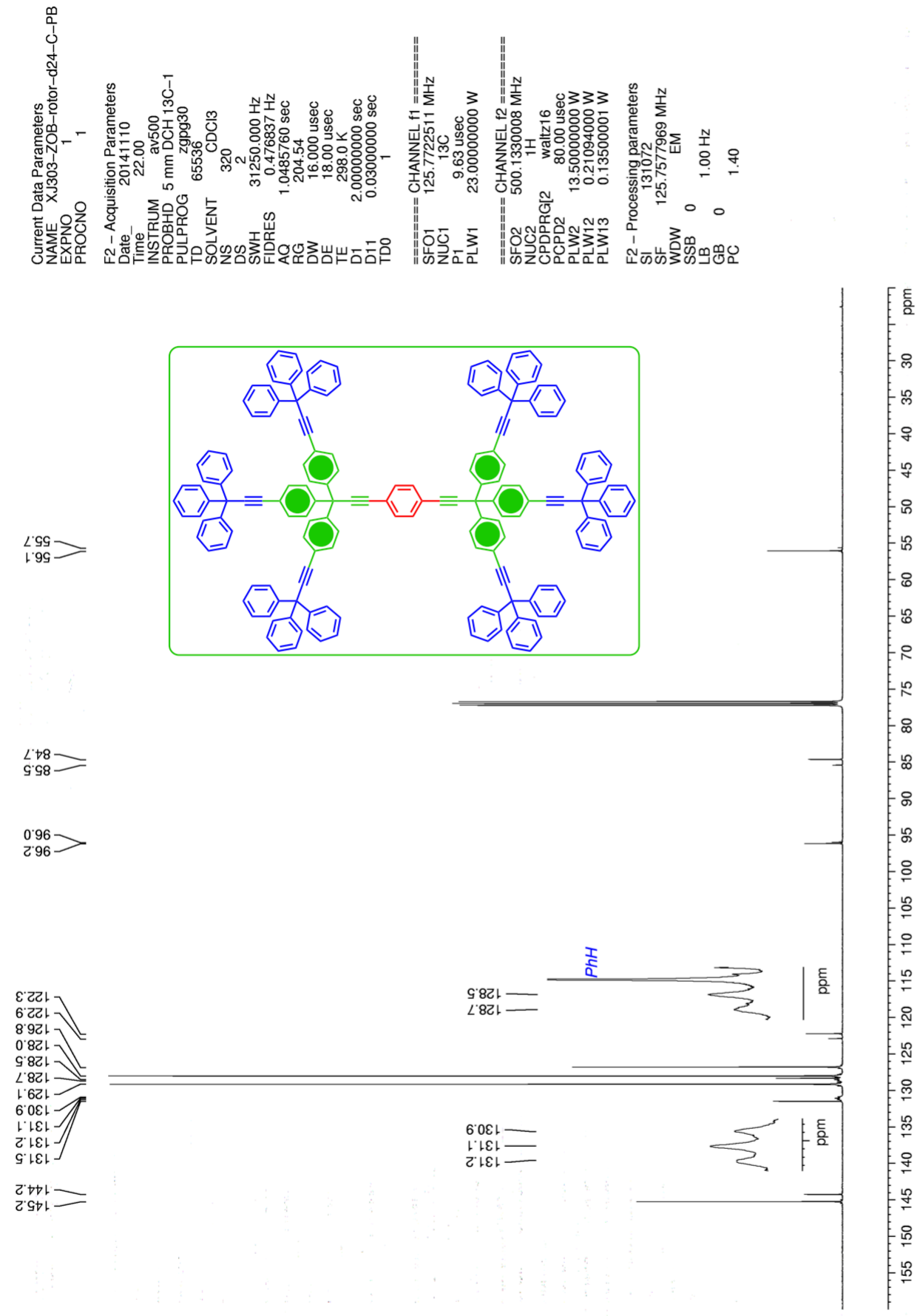

Figure 28. ${ }^{13} \mathrm{C}$ NMR of compound 2- $d_{24}$ at $125 \mathrm{MHz}$ in $\mathrm{CDCl}_{3}$. 


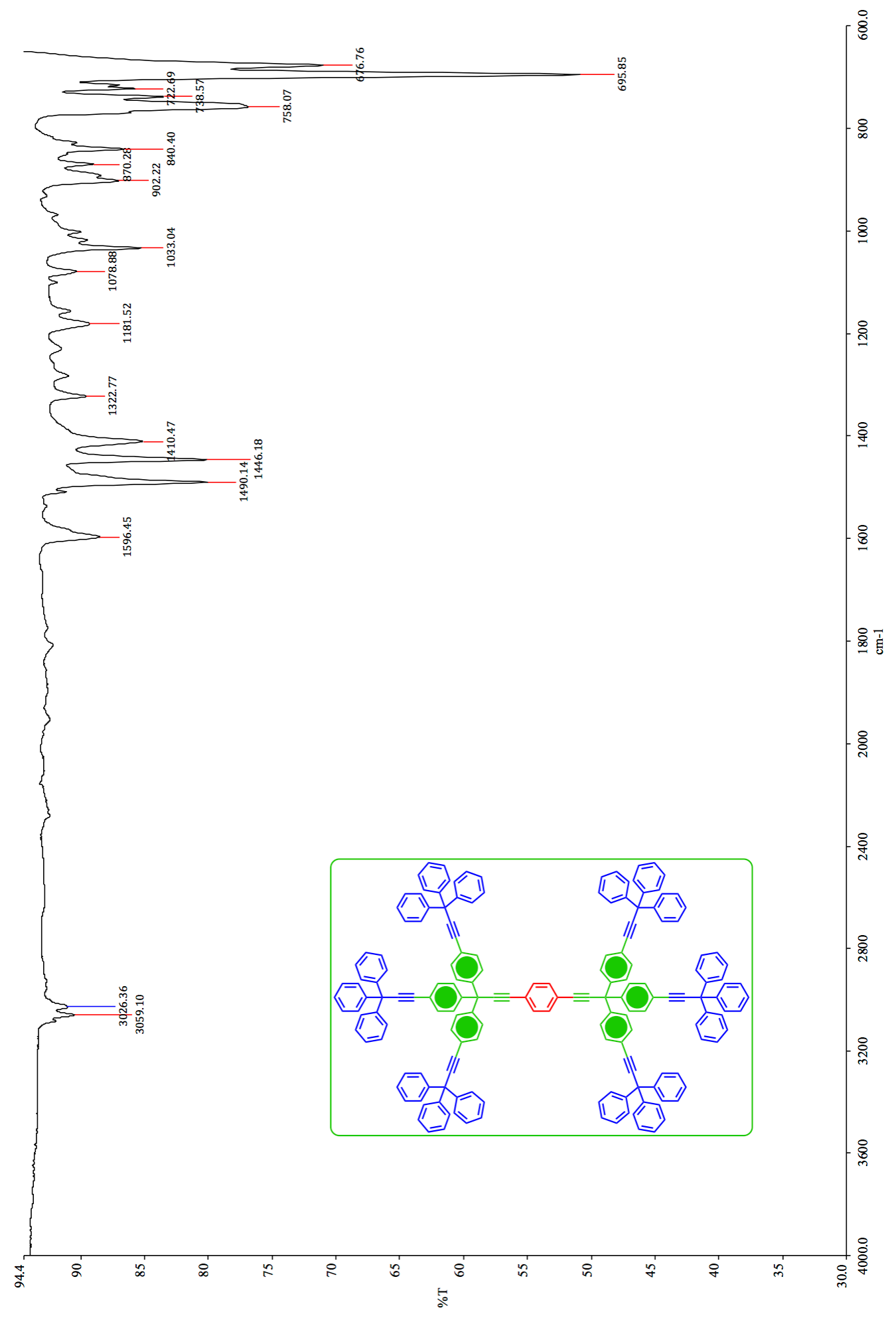

Figure S29. IR of compound 2- $d_{24}$. 


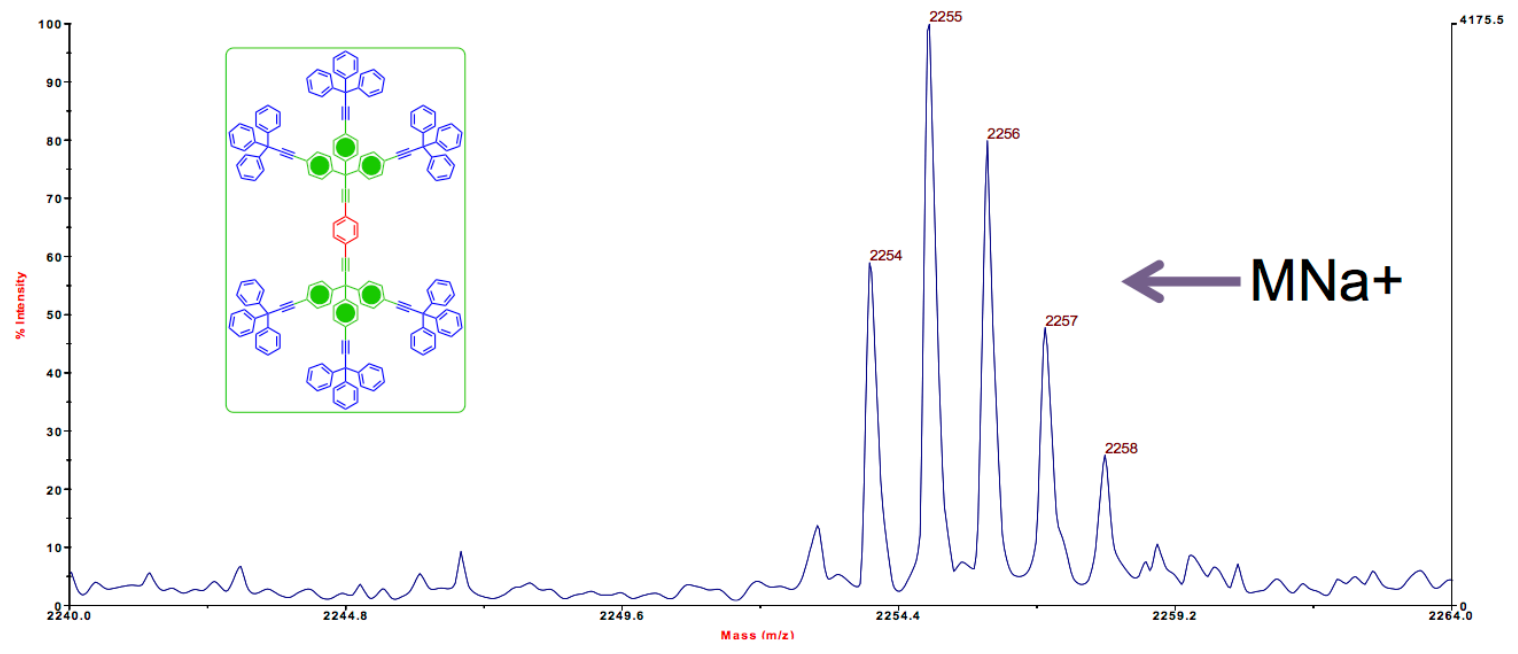

Figure S30. MS (MALDI, TOF) of compound 2- $d_{24}$ showing the cluster corresponding to $\mathrm{MNa}^{+}$. 


\subsection{Synthesis of 4-(3,3,3-triphenylpropynyl)phenyl bromide 4- $d_{15}$}

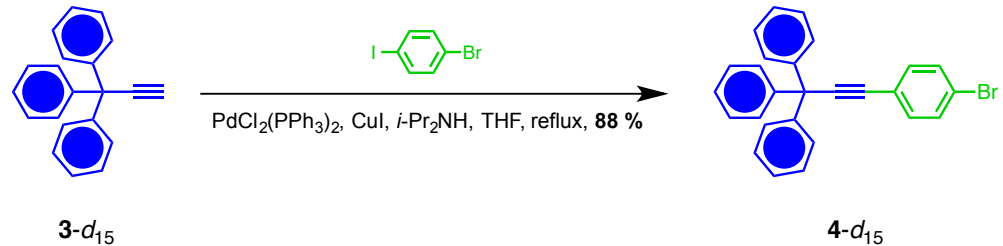

To a $100 \mathrm{~mL}$ round bottom flask with stir bar and condenser were added 3,3,3-triphenylpropyne 3- $d_{15}(283 \mathrm{mg}, 1.00 \mathrm{mmol})$, 4-bromo-1-iodobenzene (425 mg, $\left.1.50 \mathrm{mmol}\right)$, THF (10 mL), and diiso-propylamine $(10 \mathrm{~mL})$ under Ar. The resulting mixture was purged with argon for $20 \mathrm{~min}$ before palladium bis(triphenylphosphine) dichloride $(14 \mathrm{mg}, 0.02 \mathrm{mmol})$ and copper iodide $(4 \mathrm{mg}, 0.02 \mathrm{mmol})$ were added into the flask. The reaction mixture was heated to reflux for $1 \mathrm{~h}$ before it was cooled down to room temperature. Saturated $\mathrm{NH}_{4} \mathrm{Cl}$ solution $(50 \mathrm{~mL})$ was added in to quench the reaction, and the compound was extracted with ether $(50 \mathrm{~mL})$ twice. The combined organic layers were washed with brine, dried over $\mathrm{Na}_{2} \mathrm{SO}_{4}$, and concentrated under vacuum to give a dark brown crude. Flash column chromatography of the crude product using a mixture of hexanes and DCM $(10: 1, \mathrm{v} / \mathrm{v})$ as the eluent provided the desired compound $4-d_{15}(385 \mathrm{mg}, 88 \%)$.

4- $d_{15}$ : White solid, m.p. $131-132{ }^{\circ} \mathrm{C} ;{ }^{1} \mathrm{H}$ NMR (500 MHz, $\mathrm{CDCl}_{3}$, ppm): $\delta 7.36$ (app. d, $J=$ $8.5 \mathrm{~Hz}, 2 \mathrm{H}$ ), 7.45 (app. d, $J=8.5 \mathrm{~Hz}, 2 \mathrm{H}$ ); ${ }^{13} \mathrm{C} \mathrm{NMR} \mathrm{(125} \mathrm{MHz,} \mathrm{CDCl}_{3}, \mathrm{ppm}$ ): $\delta 55.9$ (weak signal due to lack of efficient relaxation), 83.9, 96.9, 122.2, 122.5, $126.4(\mathrm{t}, J=24.0 \mathrm{~Hz}), 127.5$ (t, $J=24.1 \mathrm{~Hz}$ ), 128.7 (t, $J=24.5 \mathrm{~Hz}), 131.5,133.1,144.9$; IR (powder, $\left.\mathrm{cm}^{-1}\right): v 661(\mathrm{w}), 750(\mathrm{w})$, 789(m), 821(s), 836(m), 865(m), 905(m), 961(w), 1012(m), 1071(m), 1095(w), 1261(w), 1330(m), 1362(m), 1393(w), 1486(s), 1560(w), 2274(w); HRMS (ESI/APCI, TOF): m/z calculated for $\mathrm{C}_{27} \mathrm{H}_{5} \mathrm{D}_{15} \mathrm{Br}\left(\mathrm{MH}^{+}\right)$: 438.1684 , found: 438.1687 . 

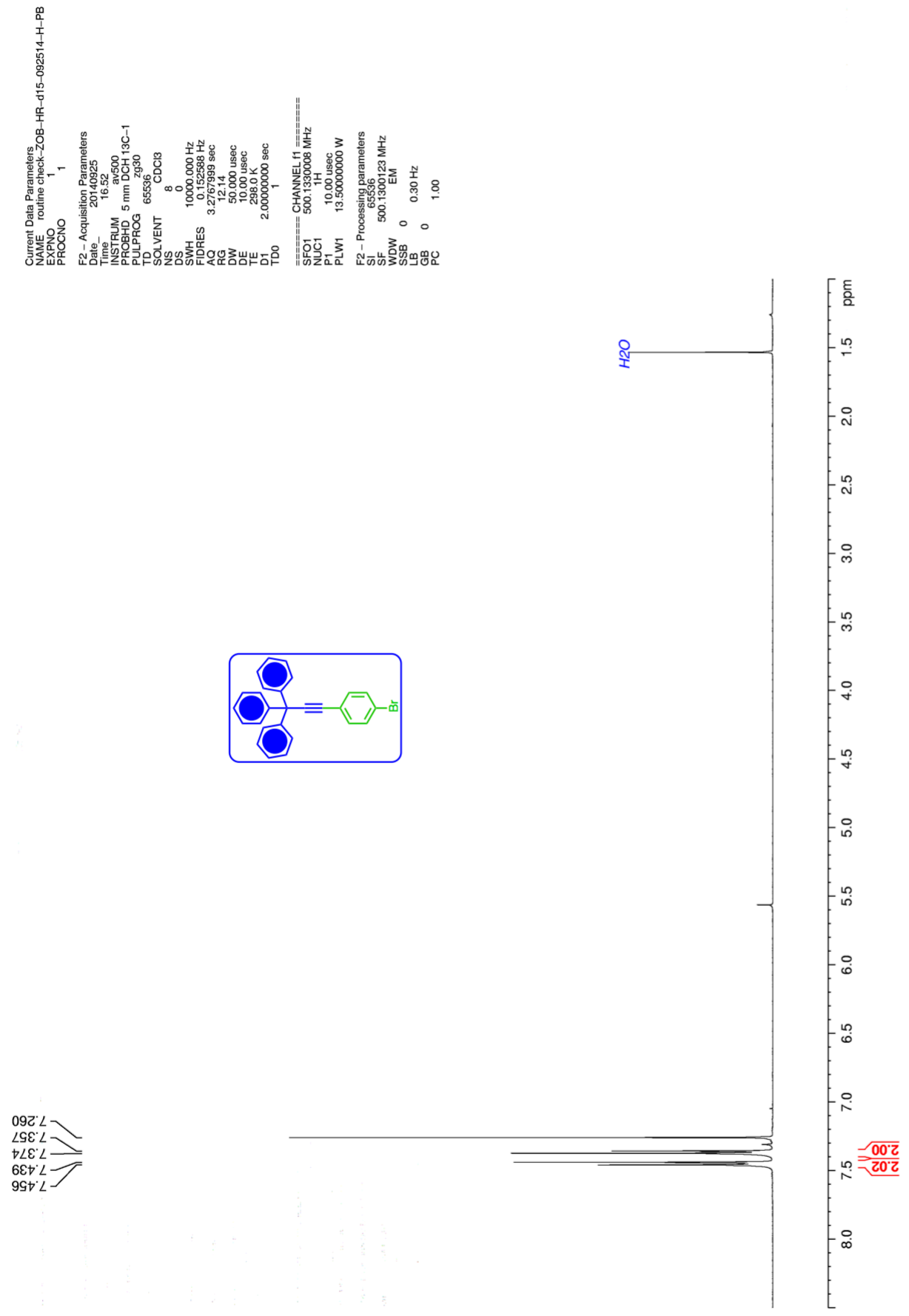

Figure S31. ${ }^{1} \mathrm{H}$ NMR of compound $4-d_{15}$ at $500 \mathrm{MHz}$ in $\mathrm{CDCl}_{3}$. 

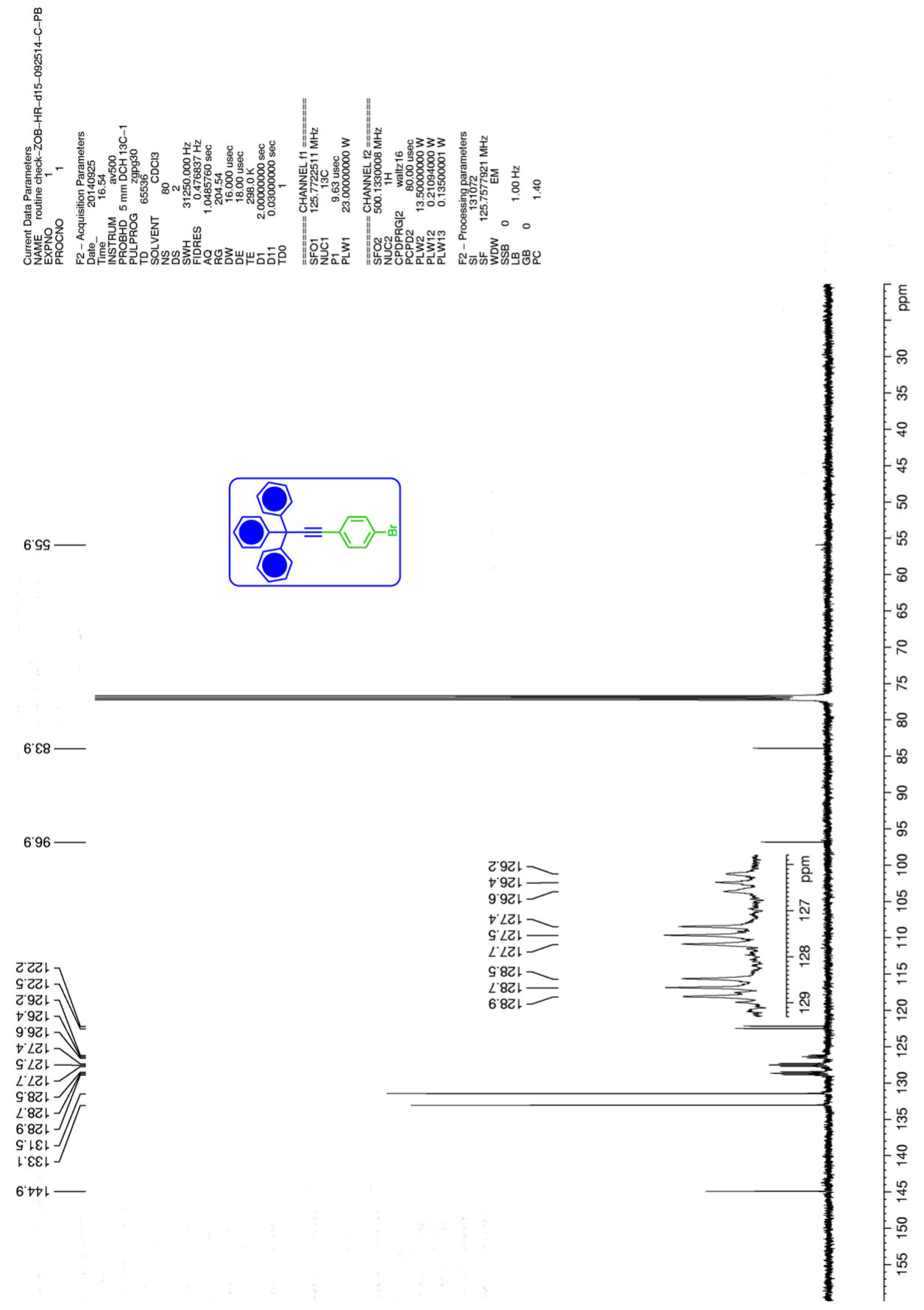

Figure S32. ${ }^{13} \mathrm{C}$ NMR of compound $4-d_{15}$ at $125 \mathrm{MHz}$ in $\mathrm{CDCl}_{3}$. 


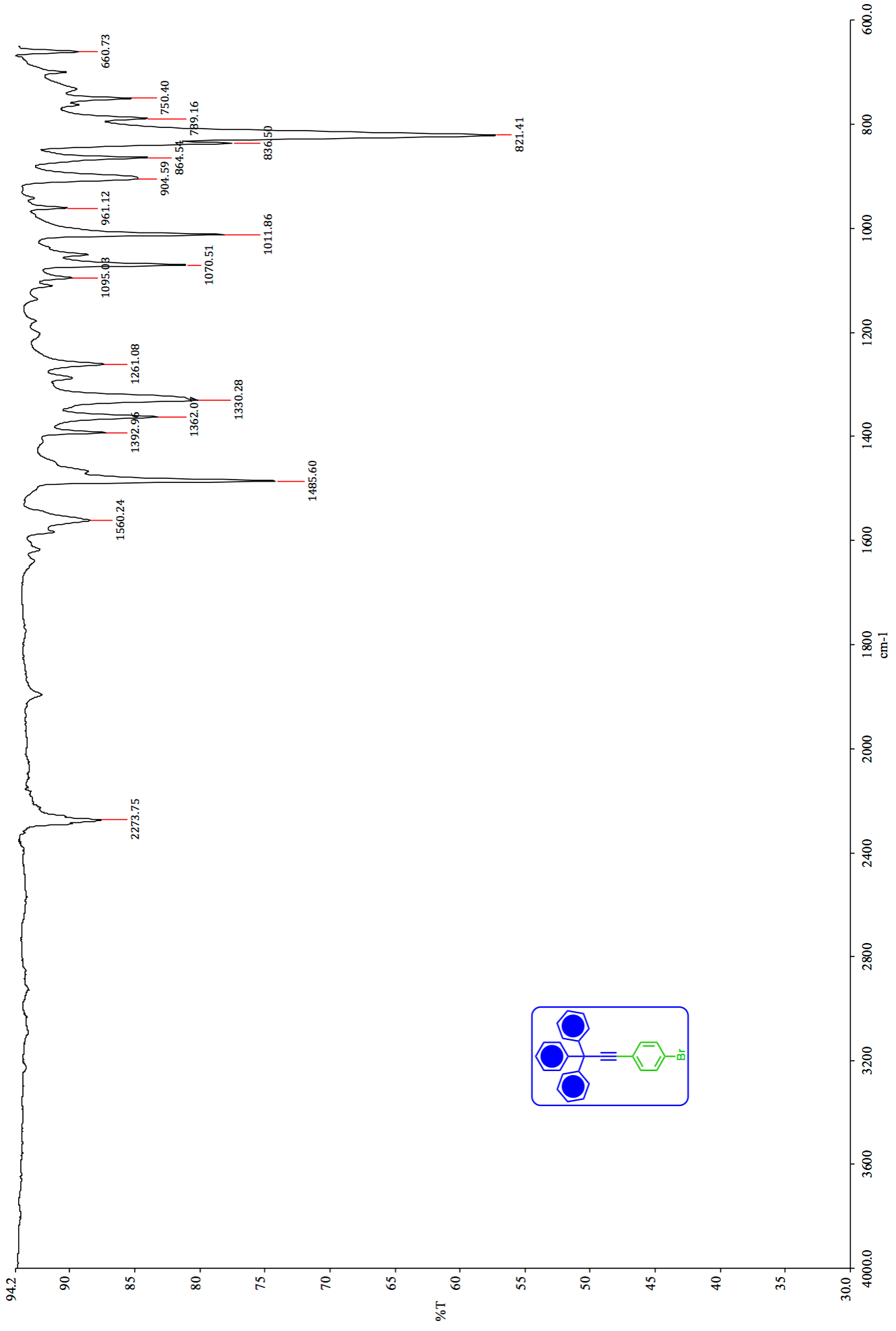

Figure S33. IR of compound 4- $d_{15}$. 


\subsection{Synthesis of tris[4-(3,3,3-triphenylpropynyl)phenyl]methanol 5- $d_{45}$}

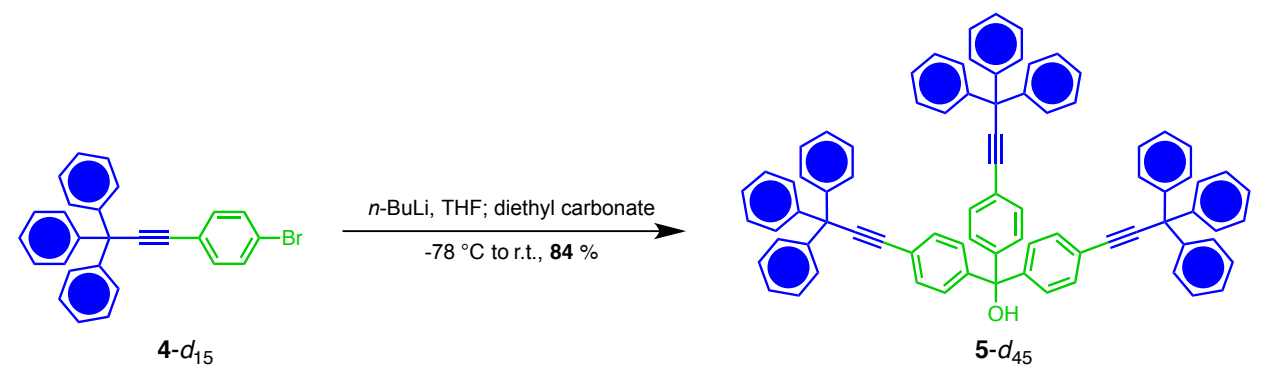

To a solution of arylbromide 4- $d_{15}(801 \mathrm{mg}, 1.83 \mathrm{mmol})$ in THF $(20 \mathrm{~mL})$ in a round bottom flask was add $n$-BuLi (1.6 M solution in hexane, $1.4 \mathrm{~mL}, 2.24 \mathrm{mmol}$ ) under argon at $-78{ }^{\circ} \mathrm{C}$. The reaction mixture was stirred for 1 hour before an excess of diethyl carbonate $(0.08 \mathrm{~mL}, 0.66 \mathrm{mmol})$ was added into the flask. The reaction mixture was stirred for another hour before it was allowed to warm up to room temperature. Saturated $\mathrm{NH}_{4} \mathrm{Cl}$ solution $(50 \mathrm{~mL})$ was added in to quench the reaction, and the product was extracted with DCM $(50 \mathrm{~mL})$ twice. The combined organic layers were washed with water and brine, dried over $\mathrm{Na}_{2} \mathrm{SO}_{4}$, and then concentrated to give a crude. Flash column chromatography of the crude product (dry loading) using a hexanes-ether mixture (4:1, $\mathrm{v} / \mathrm{v}$ ) as the eluent provided the desired compound 5- $d_{45}(563 \mathrm{mg}, 84 \%)$.

5- $d_{45}$ : White solid, m.p. $286-287{ }^{\circ} \mathrm{C} ;{ }^{1} \mathrm{H}$ NMR $\left(500 \mathrm{MHz}, \mathrm{CDCl}_{3}, \mathrm{ppm}\right): \delta 2.73(\mathrm{~s}, 1 \mathrm{H})$, 7.25 (app. d, $J=8.5 \mathrm{~Hz}, 6 \mathrm{H}$ ), 7.49 (app. d, $J=8.5 \mathrm{~Hz}, 6 \mathrm{H}$ ); ${ }^{13} \mathrm{C} \mathrm{NMR}\left(125 \mathrm{MHz}, \mathrm{CDCl}_{3}\right.$, ppm): $\delta 55.9,81.6,84.6,96.2,122.8,126.3$ (t, $J=22.2 \mathrm{~Hz}), 127.5(\mathrm{t}, J=24.0 \mathrm{~Hz}), 127.7$, $128.7(\mathrm{t}, J=24.0 \mathrm{~Hz}), 131.3,145.1,145.9$; IR (powder, $\left.\mathrm{cm}^{-1}\right): v 749(\mathrm{w}), 786(\mathrm{~m}), 827(\mathrm{~s})$, 866(m), 904(m), 961(w), 1014(m), 1154(w), 1327(m), 1362(m), 1403(w), 1502(m), 1560(w), 2275(w), 3559(w); HRMS (LIFDI, TOF): $\mathrm{m} / \mathrm{z}$ calculated for $\mathrm{C}_{82} \mathrm{H}_{13} \mathrm{D}_{45} \mathrm{O}\left(\mathrm{M}^{+}\right)$: 1103.7307, found: 1103.7301 . 


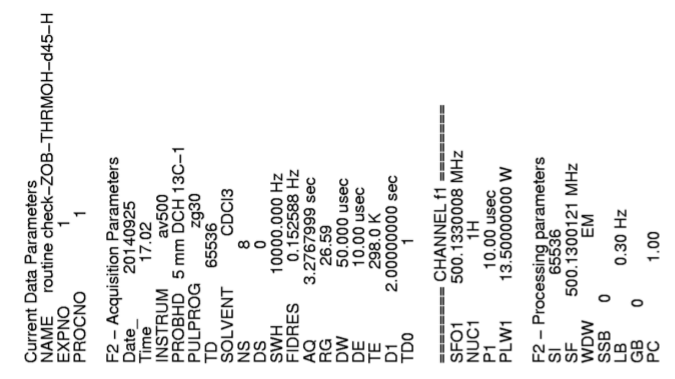

$เ \varepsilon L ' Z$

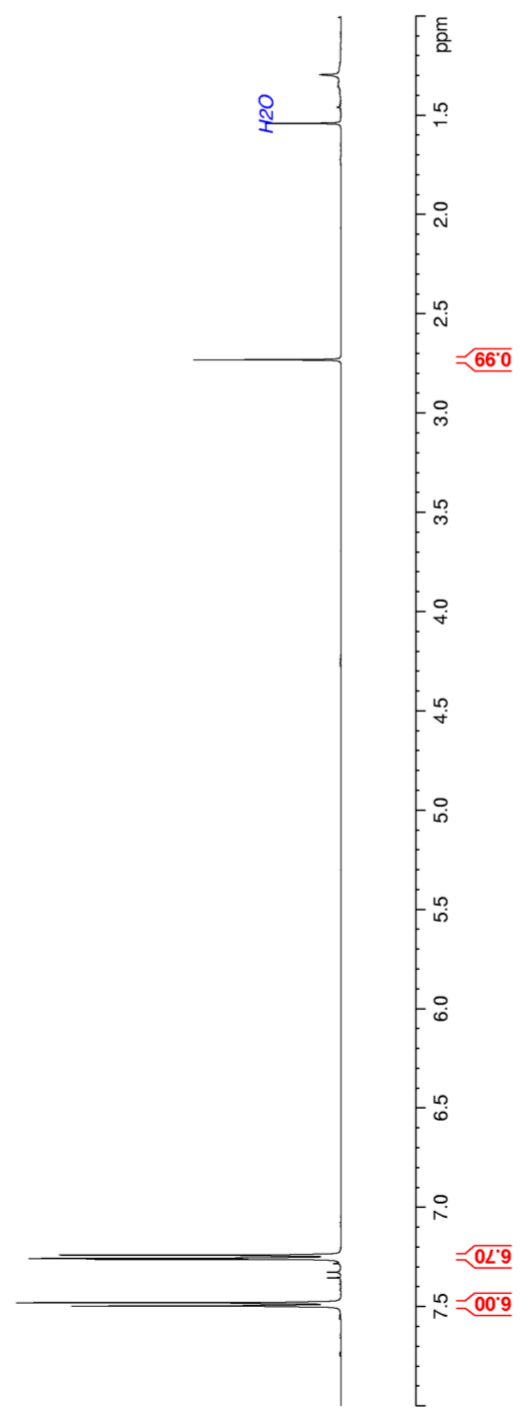

Figure S34. ${ }^{1} \mathrm{H}$ NMR of compound 5- $d_{45}$ at $500 \mathrm{MHz}$ in $\mathrm{CDCl}_{3}$. 

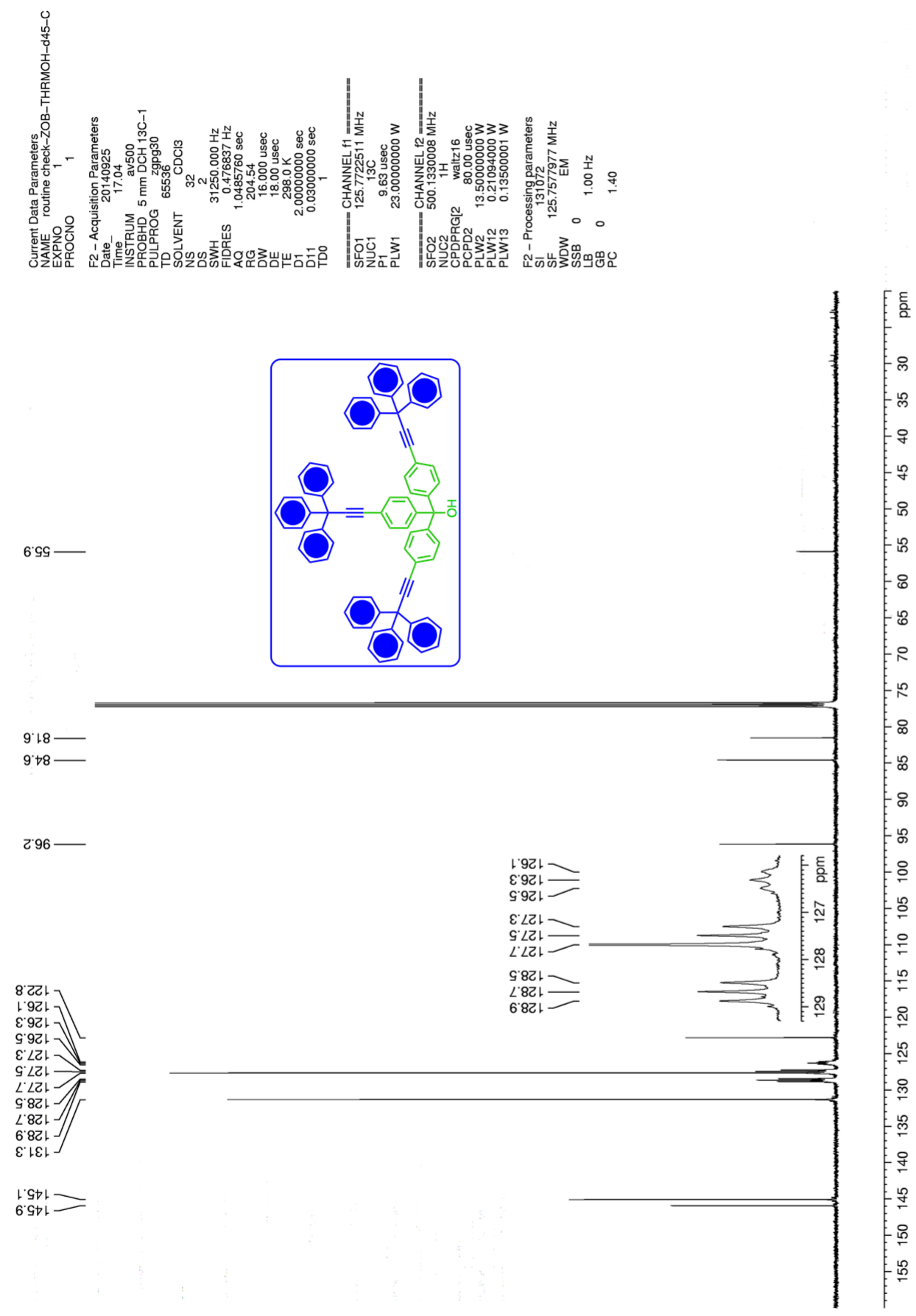

Figure S35. ${ }^{13} \mathrm{C}$ NMR of compound 5- $d_{45}$ at $125 \mathrm{MHz}$ in $\mathrm{CDCl}_{3}$. 


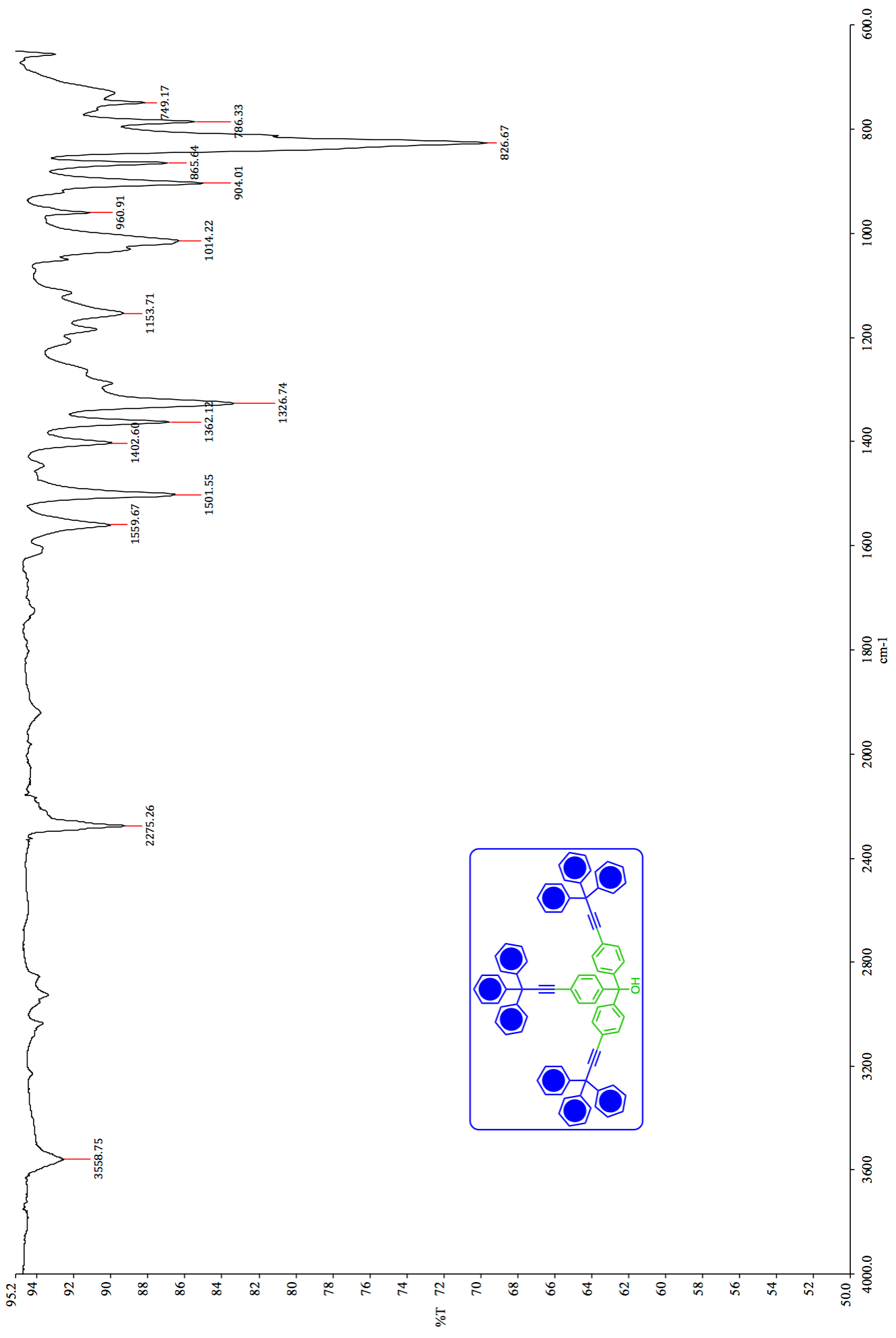

Figure 36. IR of compound 5- $d_{45}$. 


\subsection{Synthesis of tris[4-(3,3,3-triphenylpropynyl)phenyl]propyne 6- $d_{45}$}

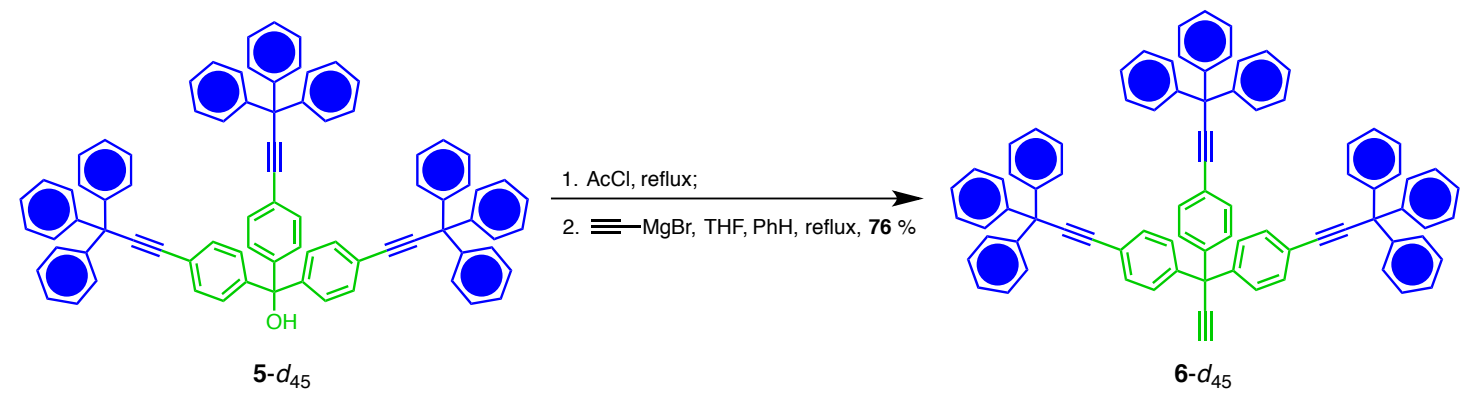

Triarylmethanol 5- $d_{45}(563 \mathrm{mg}, 0.510 \mathrm{mmol})$ and acetyl chloride $(20 \mathrm{~mL})$ were added to a round bottom flask equipped with a condenser, and the resulting mixture was heated up to reflux for 2 hours before the excess of acetyl chloride were removed by evaporation under reduced pressure. The residue was dissolved in anhydrous benzene $(50 \mathrm{~mL})$ and ethynylmagnesium bromide ( $0.5 \mathrm{M}$ solution in THF, $6.0 \mathrm{~mL}, 3.0 \mathrm{mmol}$ ) was added to the flask, and the reaction mixture was heated to reflux overnight under argon. Saturated $\mathrm{NH}_{4} \mathrm{Cl}$ solution $(50 \mathrm{~mL})$ was added in to quench the reaction, and the compound was extracted with DCM $(50 \mathrm{~mL})$ twice. The combined organic layers were washed with brine, dried over $\mathrm{Na}_{2} \mathrm{SO}_{4}$, and concentrated to give a pale yellow crude. Flash column chromatography of the crude product using a mixture of hexanes and ether $(4: 1, \mathrm{v} / \mathrm{v})$ as the eluent yielded the desired compound 6- $d_{45}(430 \mathrm{mg}, 76 \%$ ).

6- $d_{45}$ : White Solid, m.p. $252-254{ }^{\circ} \mathrm{C} ;{ }^{1} \mathrm{H}$ NMR (500 MHz, $\left.\mathrm{CDCl}_{3}, \mathrm{ppm}\right): \delta 2.83(\mathrm{~s}, 1 \mathrm{H})$, 7.38 (app. d, $J=8.5 \mathrm{~Hz}, 6 \mathrm{H}$ ), 7.60 (app. d, $J=8.5 \mathrm{~Hz}, 6 \mathrm{H}$ ); ${ }^{13} \mathrm{C} \mathrm{NMR} \mathrm{(125} \mathrm{MHz,} \mathrm{CDCl}_{3}$, ppm): $\delta 55.1,55.9,74.3,84.6,88.4,96.2,122.5,126.3(\mathrm{t}, J=21.7 \mathrm{~Hz}), 127.5(\mathrm{t}, J=$ $23.8 \mathrm{~Hz}$ ), 128.7 (t, $J=23.7 \mathrm{~Hz}), 128.9,131.4,143.9,145.0$; IR (powder, $\mathrm{cm}^{-1}$ ): $v 657(\mathrm{w})$, 748(w), 787(m), 826(s), 866(m), 904(m), 961(w), 1020(w), 1185(w), 1328(m), 1362(m), 1405(w), 1499(m), 1560(w), 2276(w), 3293(w); HRMS (ESI/APCI, TOF): m/z calculated for $\mathrm{C}_{84} \mathrm{H}_{14} \mathrm{D}_{45}\left(\mathrm{MH}^{+}\right)$: 1112.7436 , found: 1112.7449 . 


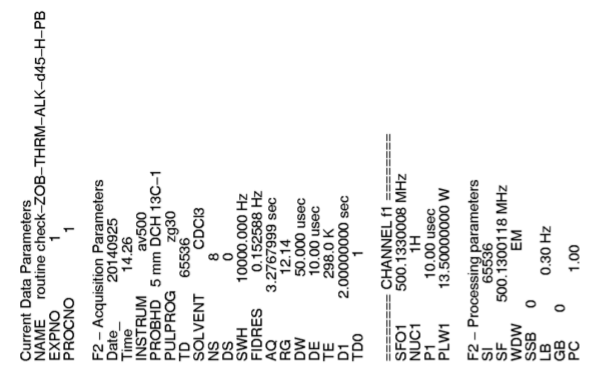

$828 \mathrm{C}$
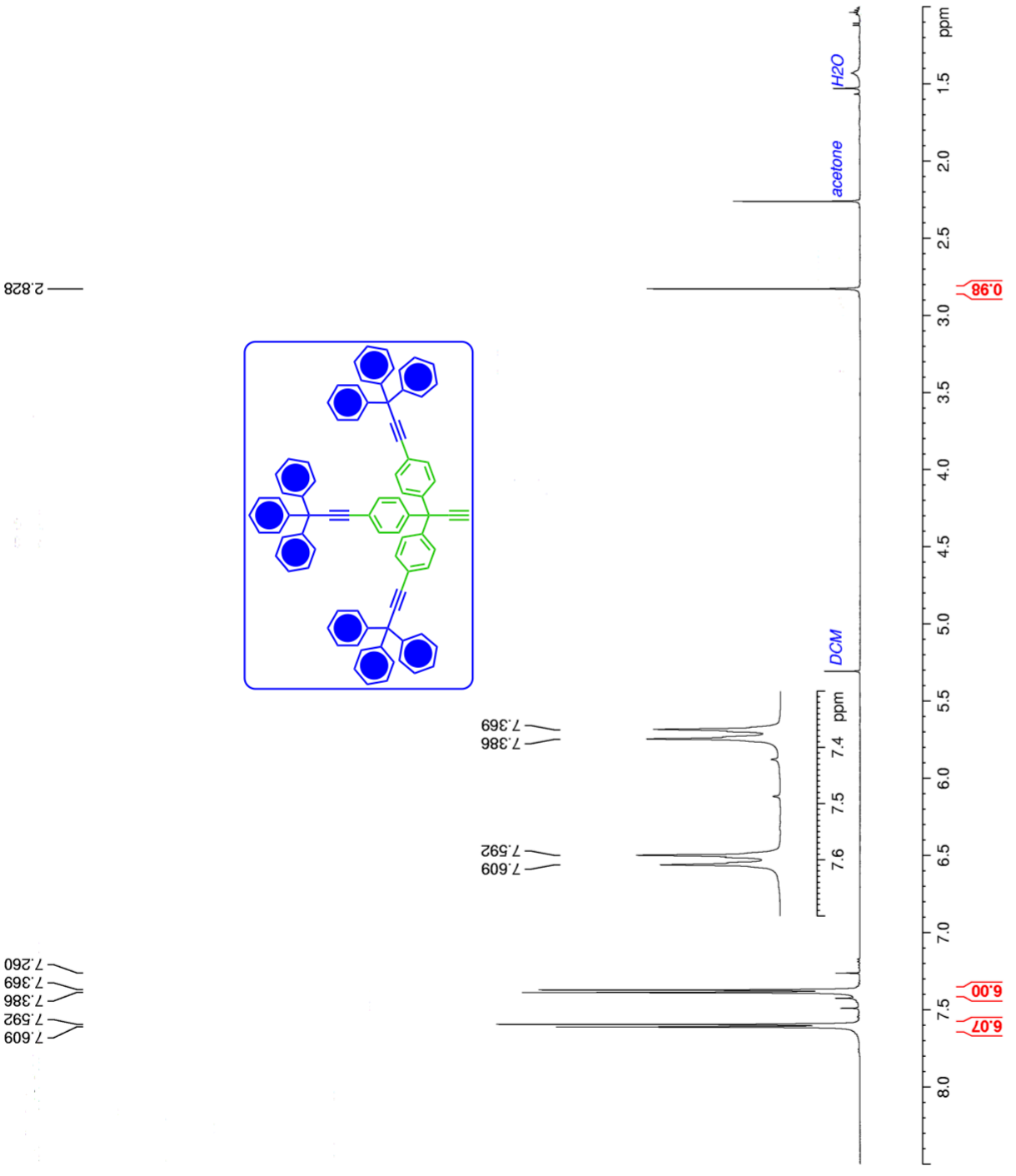

Figure S37. ${ }^{1} \mathrm{H}$ NMR of compound 6- $d_{45}$ at $500 \mathrm{MHz}$ in $\mathrm{CDCl}_{3}$. 

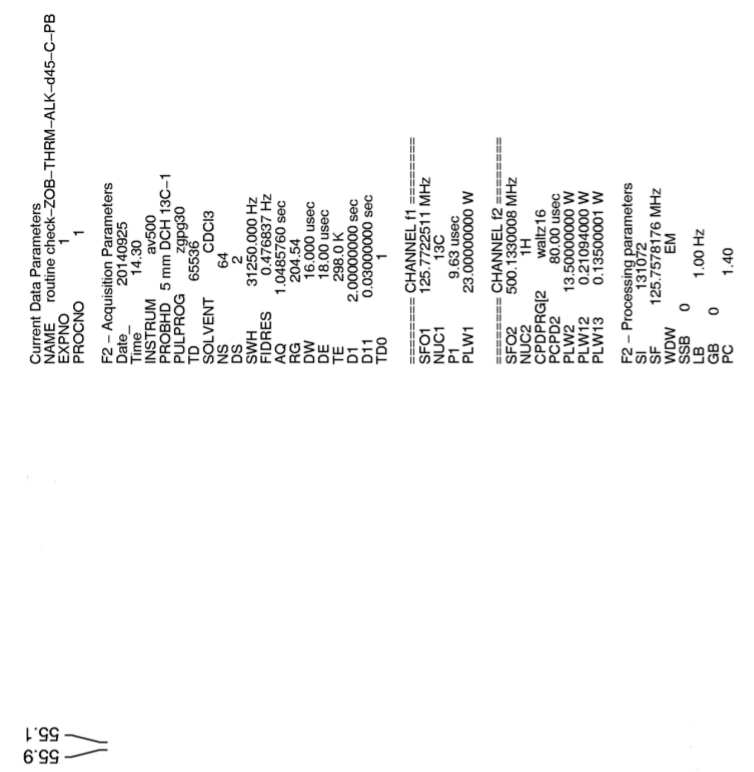

$\varepsilon \bullet\llcorner-$

$9 \bullet 8-$

乙 96
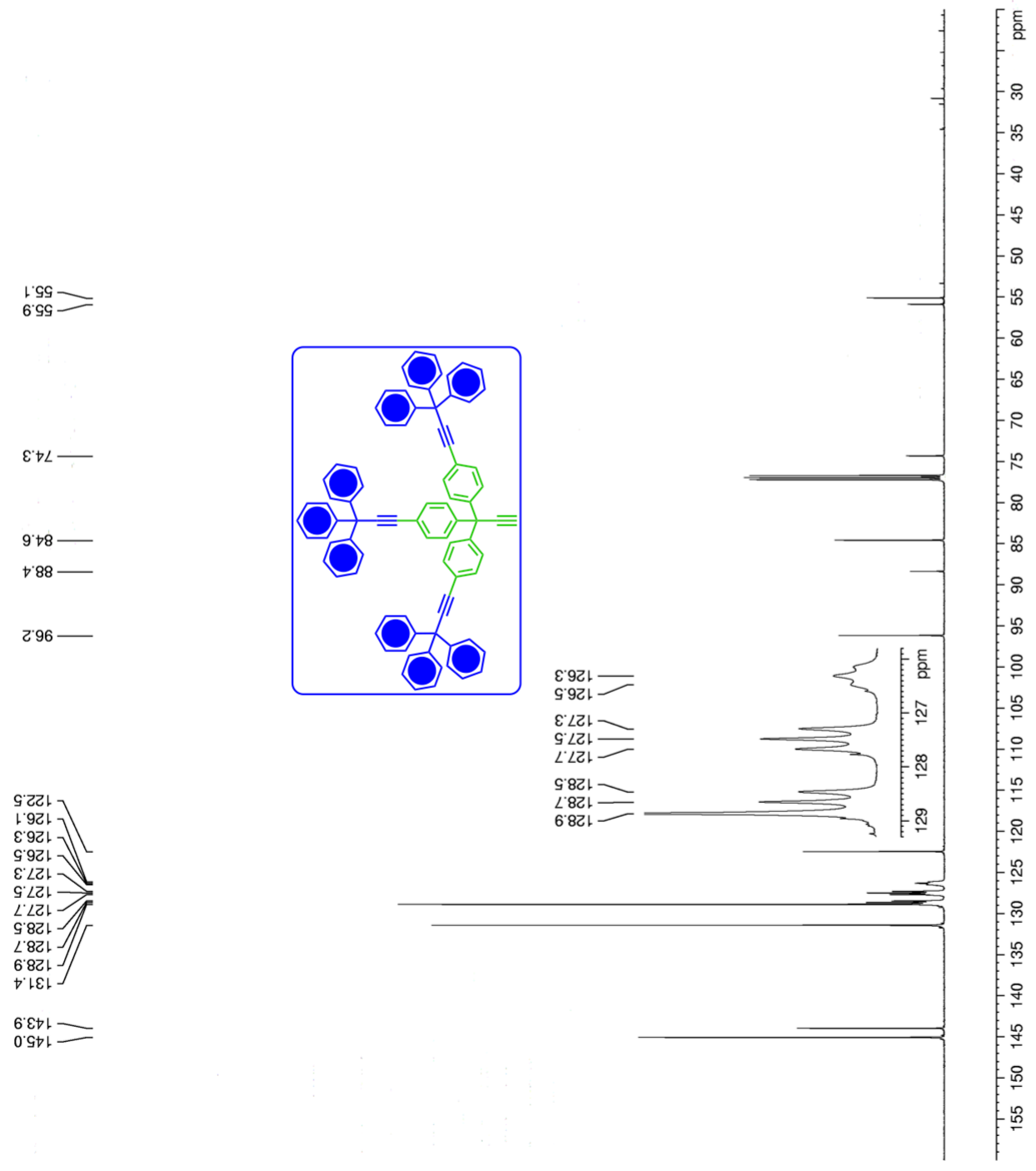

.

Figure S38. ${ }^{13} \mathrm{C}$ NMR of compound 6- $d_{45}$ at $125 \mathrm{MHz}$ in $\mathrm{CDCl}_{3}$. 


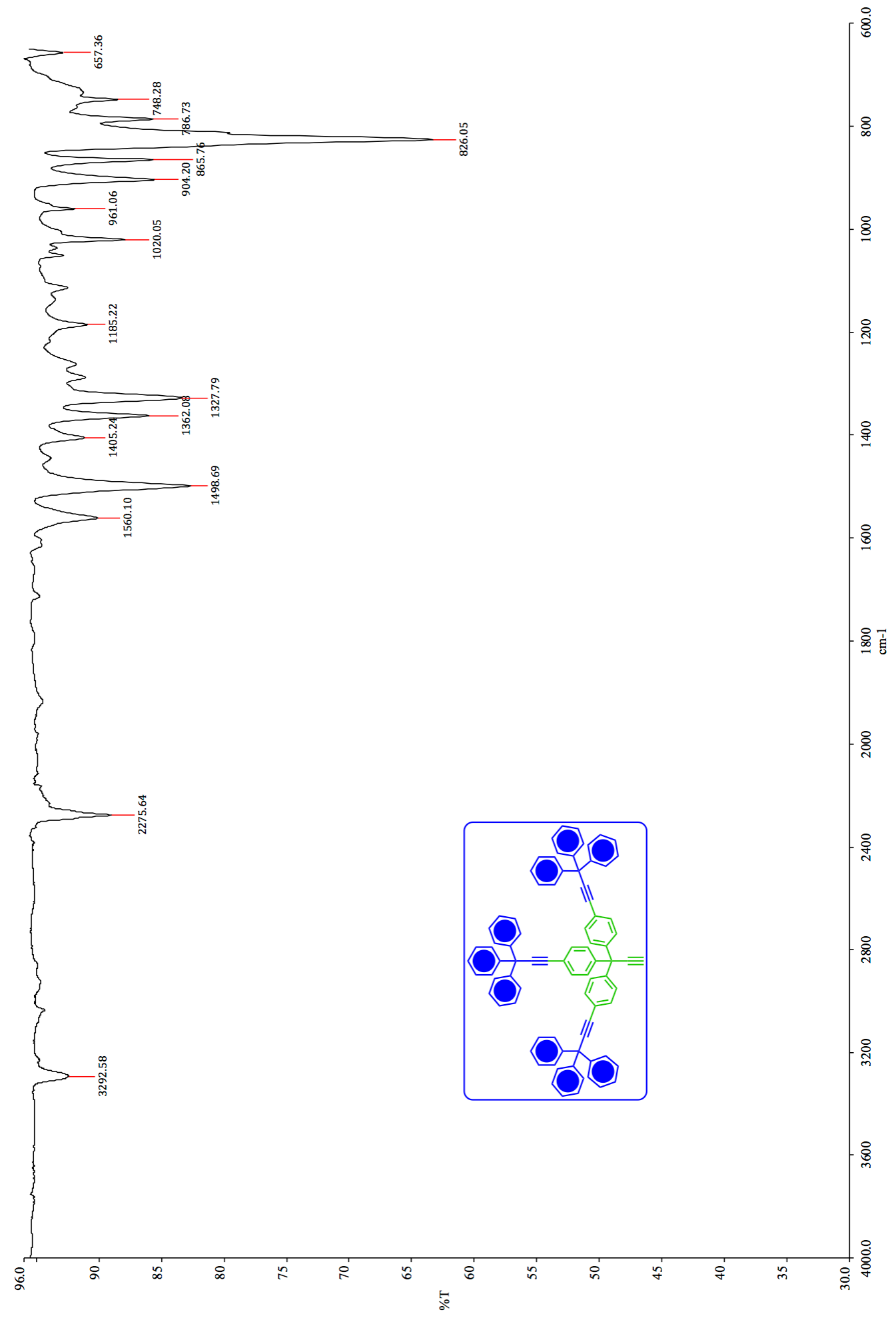

Figure S39. IR of compound 6- $d_{45}$. 


\subsection{Synthesis of 1,4-bis $\{3,3,3$-tris[4-(3,3,3-triphenylpropynyl)phenyl]- propynyl $\}$ benzene- $d_{90} 2-d_{90}$}

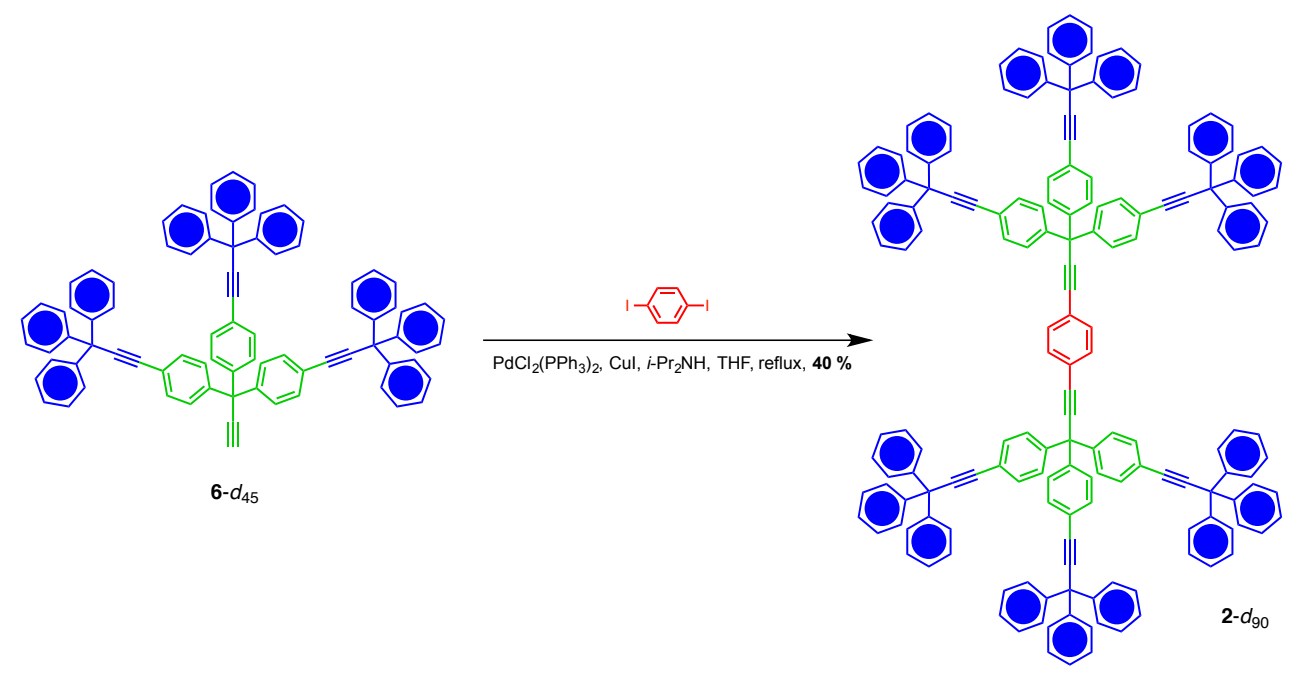

To a $50 \mathrm{~mL}$ 3-neck flask was added 6- $d_{45}(550 \mathrm{mg}, 0.494 \mathrm{mmol}), 1,4$-diiodobenzene $(74 \mathrm{mg}$, $0.22 \mathrm{mmol})$, THF $(20 \mathrm{~mL})$, and di-iso-propylamine $(5 \mathrm{~mL})$, and the resulting mixture was degased for $30 \mathrm{~min}$ before palladium bis(triphenylphosphine) dichloride (31 $\mathrm{mg}, 0.044 \mathrm{mmol}$ ) and copper iodide $(8.4 \mathrm{mg}, 0.044 \mathrm{mmol})$ were added to the flask under argon atmosphere. The reaction mixture was refluxed overnight before it was poured into saturated $\mathrm{NH}_{4} \mathrm{Cl}$ solution $(50 \mathrm{~mL})$. The mixture was extracted with DCM $(50 \mathrm{~mL})$ twice and the combined organic layers were washed with brine, and dried over anhydrous $\mathrm{Na}_{2} \mathrm{SO}_{4}$. The solvent was removed in vacuo and a light brown crude was obtained. Flash column chromatography (dry loading) using a hexanes-DCM mixture (3:1, v/v) as the eluent removed most of the impurities in the crude, but a significant amount of Further purification by fractional crystallization from a benzene and hexanes mixture $(1: 1, \mathrm{v} / \mathrm{v})$ provided the desired product $2-d_{90}(208 \mathrm{mg}, 40 \%)$.

2- $d_{90}$ : White solid, m.p. $405-406{ }^{\circ} \mathrm{C} ;{ }^{1} \mathrm{H}$ NMR (500 MHz, $\left.\mathrm{CDCl}_{3}, \mathrm{ppm}\right): \delta 7.25$ (app. d, $J=8.5$ $\mathrm{Hz}, 6 \mathrm{H}), 7.40$ (s, 4H), 7.46 (app. d, $J=8.5 \mathrm{~Hz}, 6 \mathrm{H}) ;{ }^{13} \mathrm{C} \mathrm{NMR}\left(125 \mathrm{MHz}, \mathrm{CDCl}_{3}, \mathrm{ppm}\right): \delta 55.8$, 55.9, 84.6, 85.5, 96.0, 96.2, 122.5, 122.9, 126.3 (t, $J=23.1 \mathrm{~Hz}), 127.5$ (t, $J=23.9 \mathrm{~Hz}), 128.7$ (t, $J=24.1 \mathrm{~Hz}), 128.9,131.5,144.4,145.1$; IR (powder, $\left.\mathrm{cm}^{-1}\right): v 657(\mathrm{w}), 695(\mathrm{w}), 748(\mathrm{w}), 787(\mathrm{~m})$, 827(s), 865(m), 904(m), 961(w), 1020(m), 1185(w), 1328(m), 1362(m), 1404(w), 1500(m), 1560(w), 2276(w); MS (MALDI, TOF): m/z calculated for $\mathrm{C}_{174} \mathrm{H}_{28} \mathrm{D}_{90} \mathrm{Na}\left(\mathrm{MNa}^{+}\right): 2321(100 \%)$, 2322 (93\%), 2323 (58 \%), 2320 (53\%), 2324 (27\%), found: 2321 (100\%), 2322 (60\%), 2323 $(50 \%), 2320(80 \%), 2324(23 \%)$. 

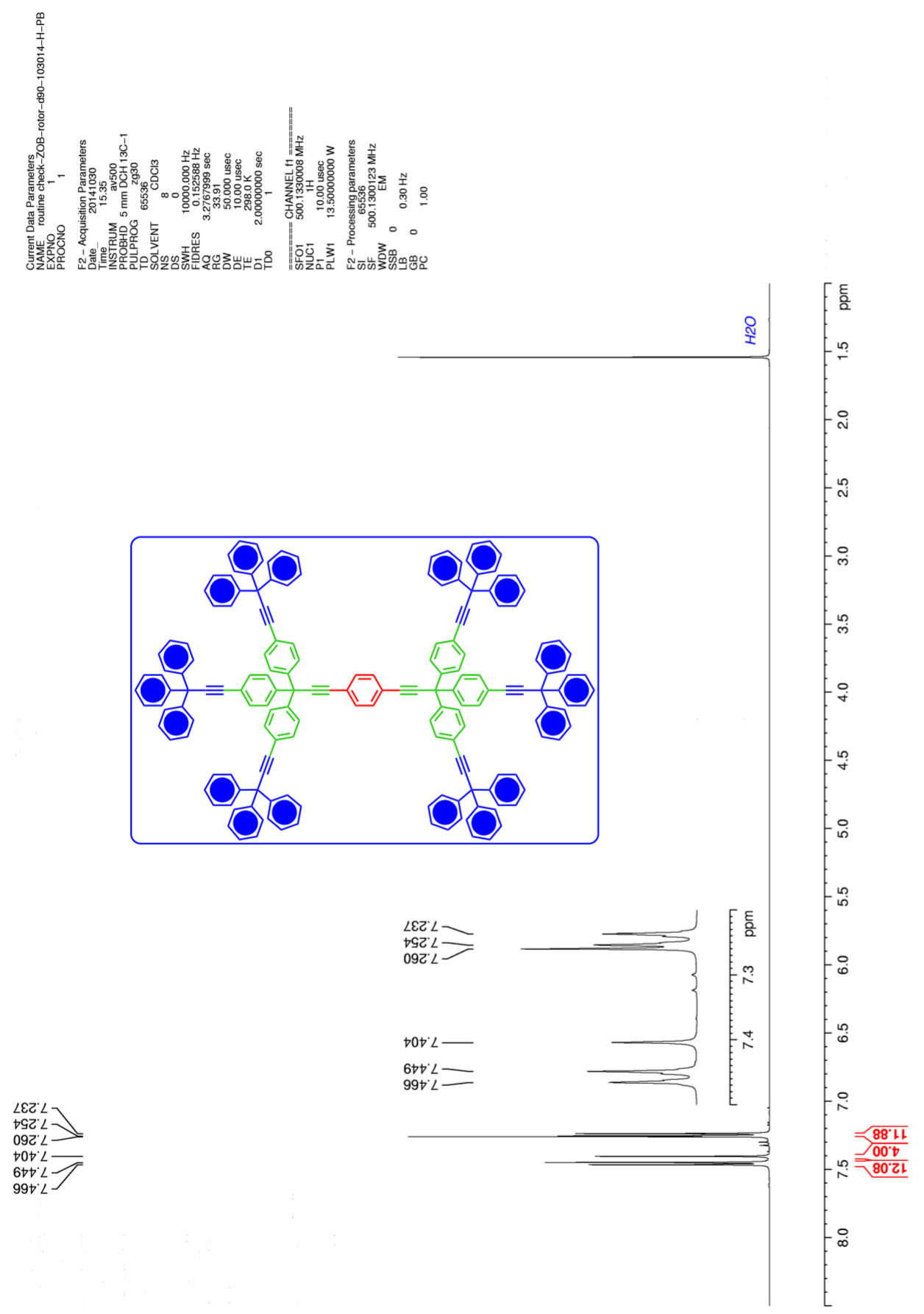

Figure S40. ${ }^{1} \mathrm{H}$ NMR of compound $2-d_{90}$ at $500 \mathrm{MHz}$ in $\mathrm{CDCl}_{3}$. 

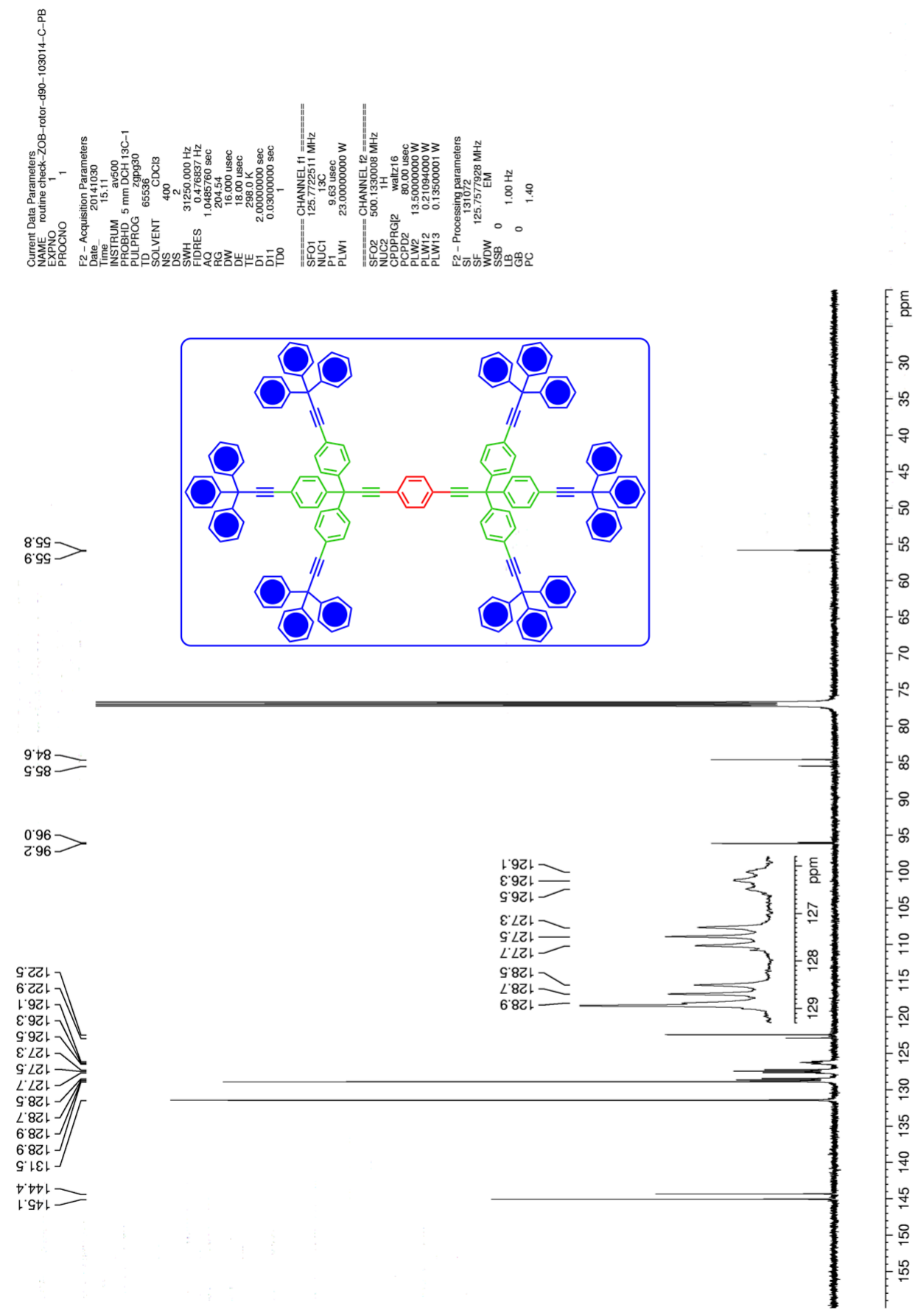

Figure S41. ${ }^{13} \mathrm{C}$ NMR of compound 2- $d_{90}$ at $125 \mathrm{MHz}$ in $\mathrm{CDCl}_{3}$. 


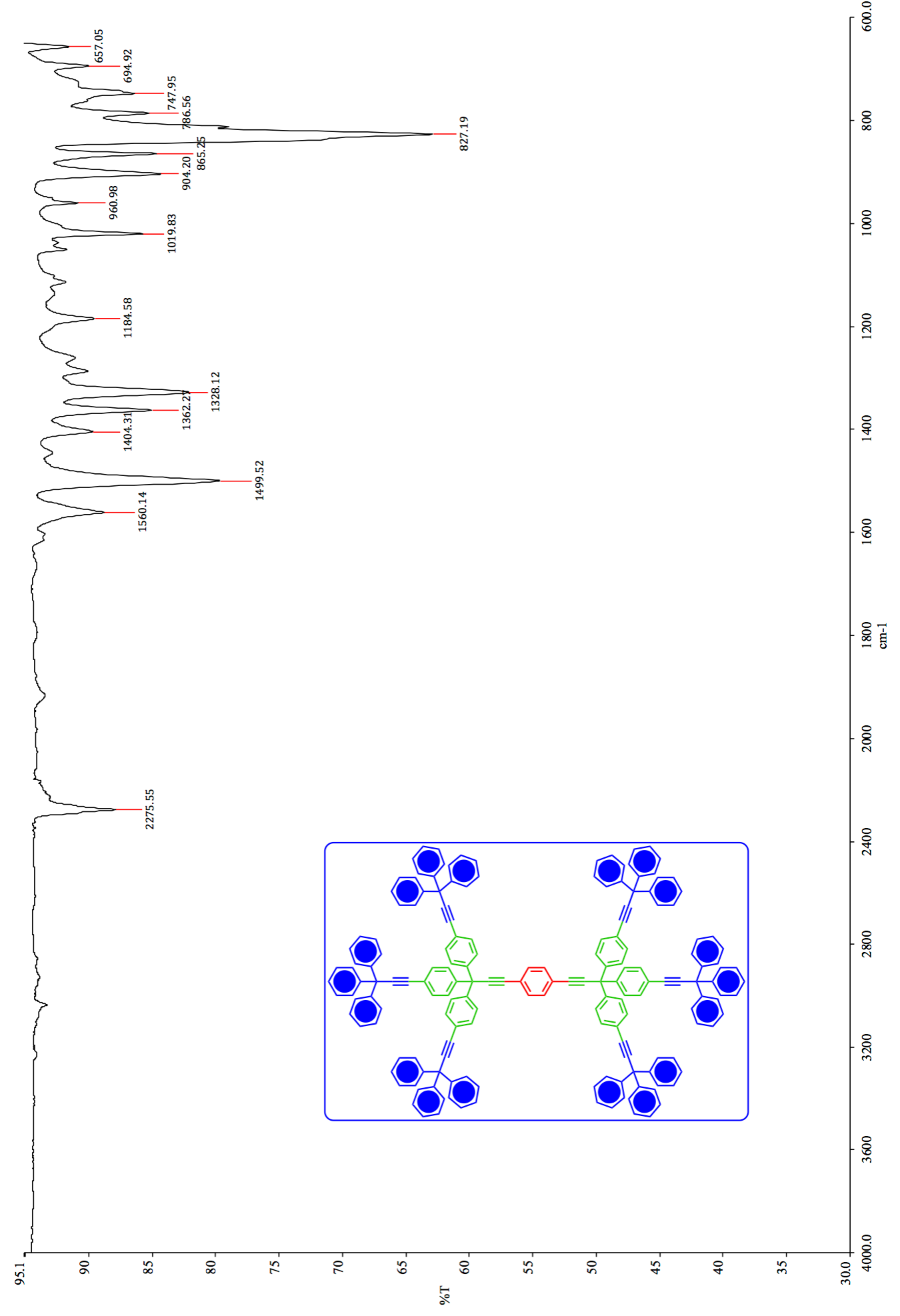

Figure S42. IR of compound 2- $d_{90}$. 


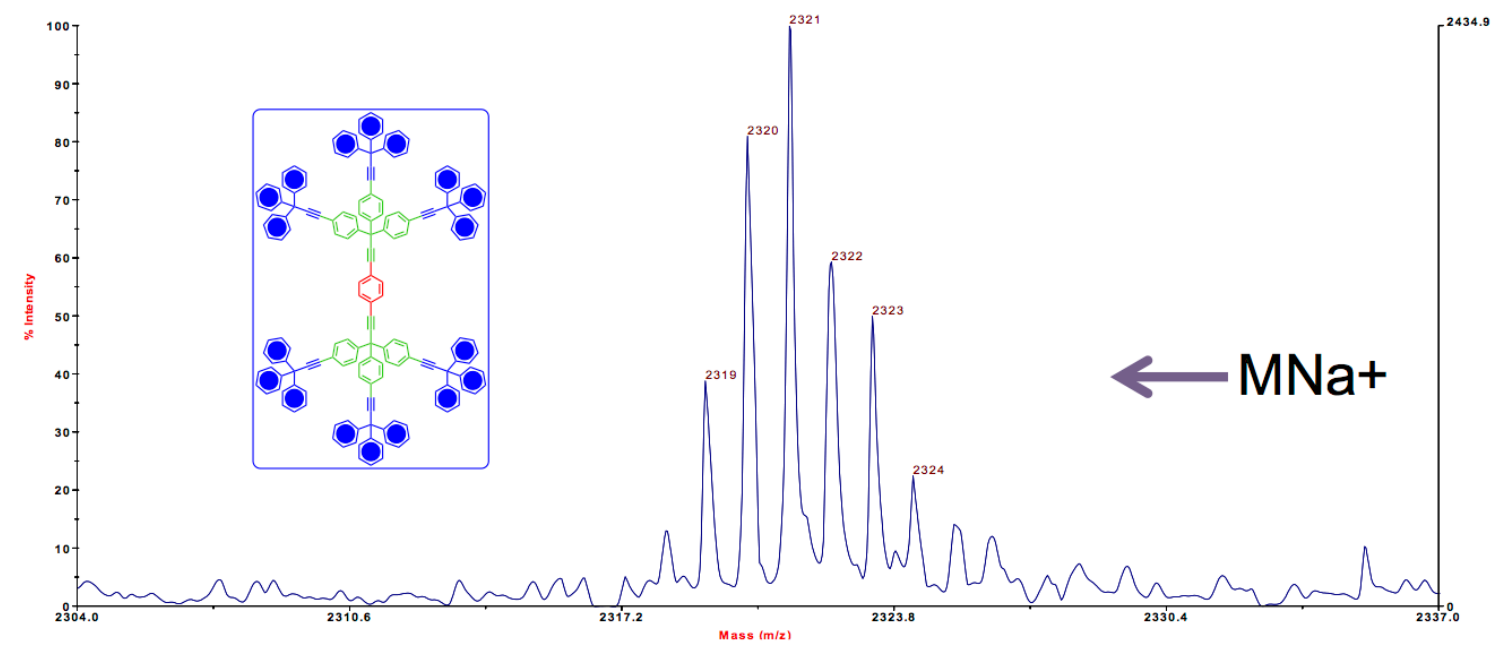

Figure S43. MS (MALDI, TOF) of compound 5 showing the cluster corresponding to $\mathrm{MNa}^{+}$.

\section{Crystallization, X-Ray Diffraction of Single Crystals, and PXRD}

\subsection{Crystallization Conditions and X-Ray Diffraction of Single Crystals.}

Colorless prisms of compound 2 could be obtained by addition of 2,2,4-trimethylpentane to a hot solution of $\mathbf{2}$ in 2,4,6-trimethylpyridine followed by slowly cooling down the mixture to room temperature. Similar crystals could be obtained from a mixture of 2,2,4-trimethylpentane and $o$ xylene in the same manner. For both cases, the volume percentage of 2,2,4-trimethylpentane in the solvent mixture was about $30 \%$. The prisms were immediately subjected to diffraction after they were removed from the mother liquor to avoid solvent loss. The diffraction data was obtained at $100 \mathrm{~K}$ on an $\mathrm{X}$-ray diffractometer system with Mo-K $\alpha$ radiation $(\lambda=0.71073 \AA)$ and an area detector. The structure was solved and refined using the SHELXTL software package. All atoms were refined anisotropically, and hydrogen atoms were placed at calculated positions. The disordered solvent molecules were removed using the SQUEEZE algorithm.

\subsection{Powder X-Ray Diffraction (PXRD).}

PXRD Analyses were carried out using $\mathrm{Cu}-\mathrm{K}_{\alpha 1}=1.5406 \AA$ radiation. Data were collected at room temperature in the range of 2 theta $=5-50^{\circ}$. The measurements were done with a thin layer of finely ground sample on a zero-background plate. Attempting to prevent the loss of solvent during the measurement we added a drop of 2,2,4-trimethylpentane/2,4,6-trimethylpyridine onto the plate. In spite of this precaution, the match between experimental and calculated PXRD was not optimal. However, when the cell constants of several small single crystals were analyzed 
they were shown to belong to the same phase. We conclude that a phase transition must occur upon grinding.

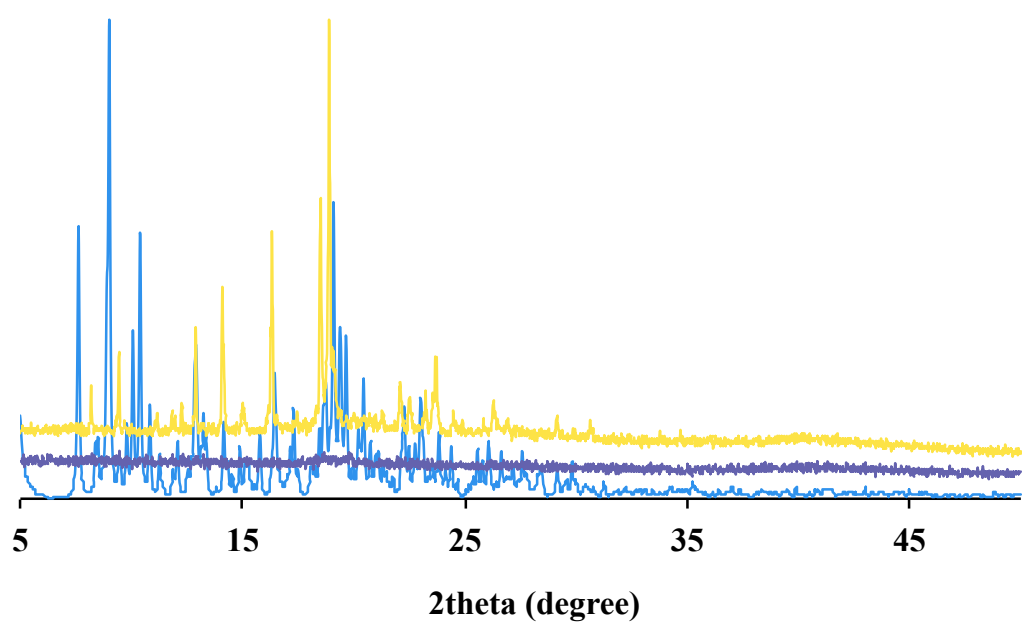

Figure S44. Experimental PXRD patterns obtained for the crystalline (yellow) and the amorphous (dark blue) sample of $\mathbf{2}$ and the calculated (light blue) pattern.

\section{Solid-state ${ }^{2}$ H NMR Quadrupolar Echo Experiment and Simulation}

\subsection{Solid-state ${ }^{2}$ H NMR Quadrupolar Echo Experiment}

Solid-state ${ }^{2} \mathrm{H}$ NMR spectra were acquired on a Bruker DRX 300 instrument at ${ }^{2} \mathrm{H}$ frequency of 46.07 MHz. In the spin-echo experiments, a quadrupolar-echo sequence with phase cycling was used to suppress undesired single- and double-quantum coherence-transfer artifacts. A pulse of $50 \mu$ s with a refocusing delay of $42 \mu$ s was used in the sequence. The spectrometer produced 2.5$\mu \mathrm{s}{ }^{2} \mathrm{H}$ 90-degree pulses $(46.07 \mathrm{MHz}$ ) with recycle delays of $20 \mathrm{~s}$ between pulses inside the coil. Variable temperature experiments were performed between $243 \mathrm{~K}$ and $453 \mathrm{~K}$. For all these experiments, $45 \mathrm{mg}$ to $100 \mathrm{mg}$ solid sample was placed inside a borosilicate glass NMR tube between two glass rods and sealed with Teflon tape. For the crystalline samples, small cotton balls saturated with a mixture of 2,2,4-trimethylpentane/2,4,6-trimethylpyridine were placed at both ends of the tubes to prevent desolvation. After performing high temperature or low temperature experiments, the samples were cooled/warmed back to the starting temperature and a ${ }^{2} \mathrm{H}$ NMR spectrum taken again to ensure that no irreversible transition had occurred during the VT experiments. The number of scans to obtain spectra with decent signal to noise ratio ranges from a few hundred to a few thousand. The data was processed with a line broadening of $5 \mathrm{kHz}$.

\subsection{Simulation of the Experimental Spectra}

All simulation was performed utilizing the online program offered by professor H. W. Spiess. ${ }^{3}$ The spectra obtained for $\mathbf{2}-d_{4}$ (crystalline sample) and $\mathbf{2}-d_{24}$ (crystalline and amorphous samples) 
were quickly identified to be the result of simple 2-fold rotations (Figure 3). For the samples of 2$d_{90}$, the line-shape of the spectra could not be reproduced with a simple 2-fold rotation model (Figure S45a). Next we considered a 4-fold flips since the intrinsic symmetry of phenyls $\left(C_{2 v}\right)$ limits their possible dynamics to $2 n$-fold $(n=1,2,3,4 \ldots)$ flips. It was not surprising that simulations using a simple 4-fold rotation model with even distribution of occupation at all 4 sites also failed to reproduce the experimental line-shapes given that not much disorder was observed crystallographically (Figure S45b). To our delight, the 4-fold rotational model together with a $2: 1: 2: 1$ ratio of occupation at the four sites. Other ratios $(3: 1: 3: 1$ and $4: 1: 4: 1)$ were also explored but they offered spectra with line-shapes different from the experimental ones (Figure S46). Including a distribution of rotational frequencies or jump angles did not improve the simulation at all, nor did the complex combination of 2-fold and 4-fold rotation modes. Spectra from those simulations were thus not presented here.

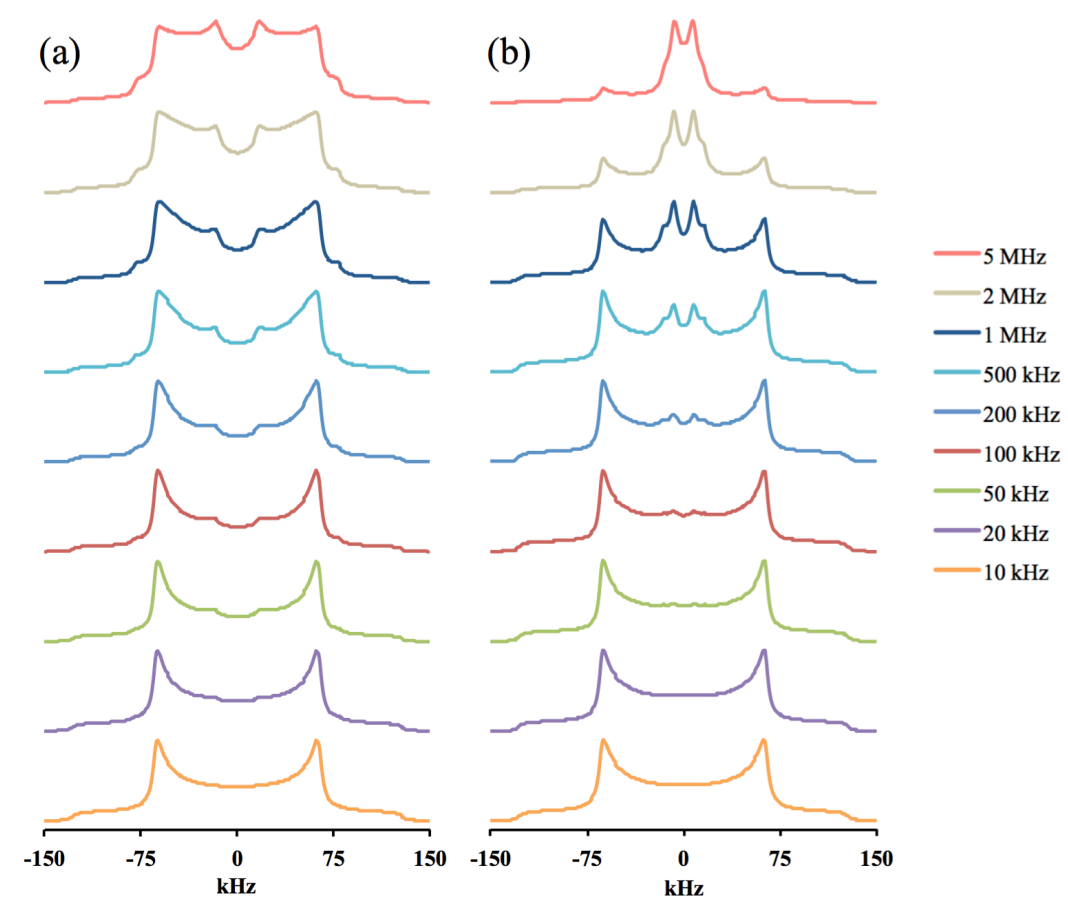

Figure S45. Simulated spectra for rotor 2- $d_{90}$ with (a) 2-fold and (b) 4-fold rotational modes at various frequencies. 


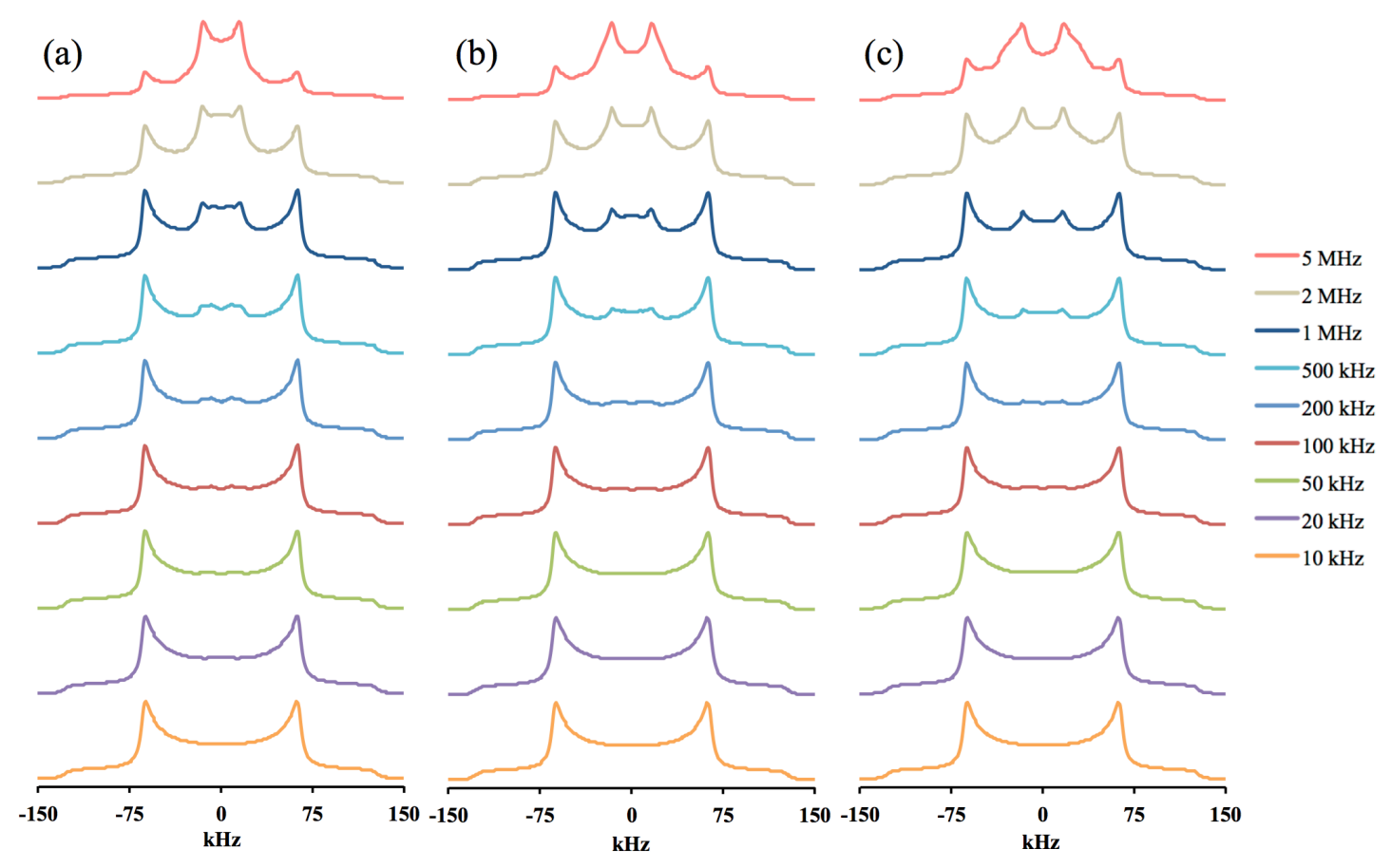

Figure S46. Simulated spectra of different frequencies for 4-fold rotations of rotor 2- $d_{90}$ with ratio of occupation at the 4 sites being: (a) 2:1:2:1, (b) 3:1:3:1, and (c) 4:1:4:1.

\section{Molecular Dynamics Simulation}

\subsection{Molecular Dynamics Simulation and Modes of Rotation in Vacuum}

Molecular dynamics simulation of rotor 2 was performed using Amber 14. ${ }^{4}$ The parameters were generated with the antechamber module using the general Amber force field (GAFF), and the atomic partial charges were assigned using the AM1-BCC method. In the simulation, the structure of $\mathbf{2}$ was first minimized in vacuum with no solvent model. The system then was heated from 0 to $300 \mathrm{~K}$ under constant pressure of $1 \mathrm{~atm}$ in $2 \mathrm{~ns}$ before it was then equilibrated for $0.5 \mathrm{~ns}$ with $1 \mathrm{fs}$ time step at a constant volume. Production trajectories were then run for additional $1 \mathrm{~ns}$ under the same simulation conditions. The dihedral angle change of each phenylene groups in one branch trityl unit was tracked and shown in Figure S47. Although much less frequent compared to the correlated motions, isolated rotation of one aromatic ring is indeed possible even in vacuum. 


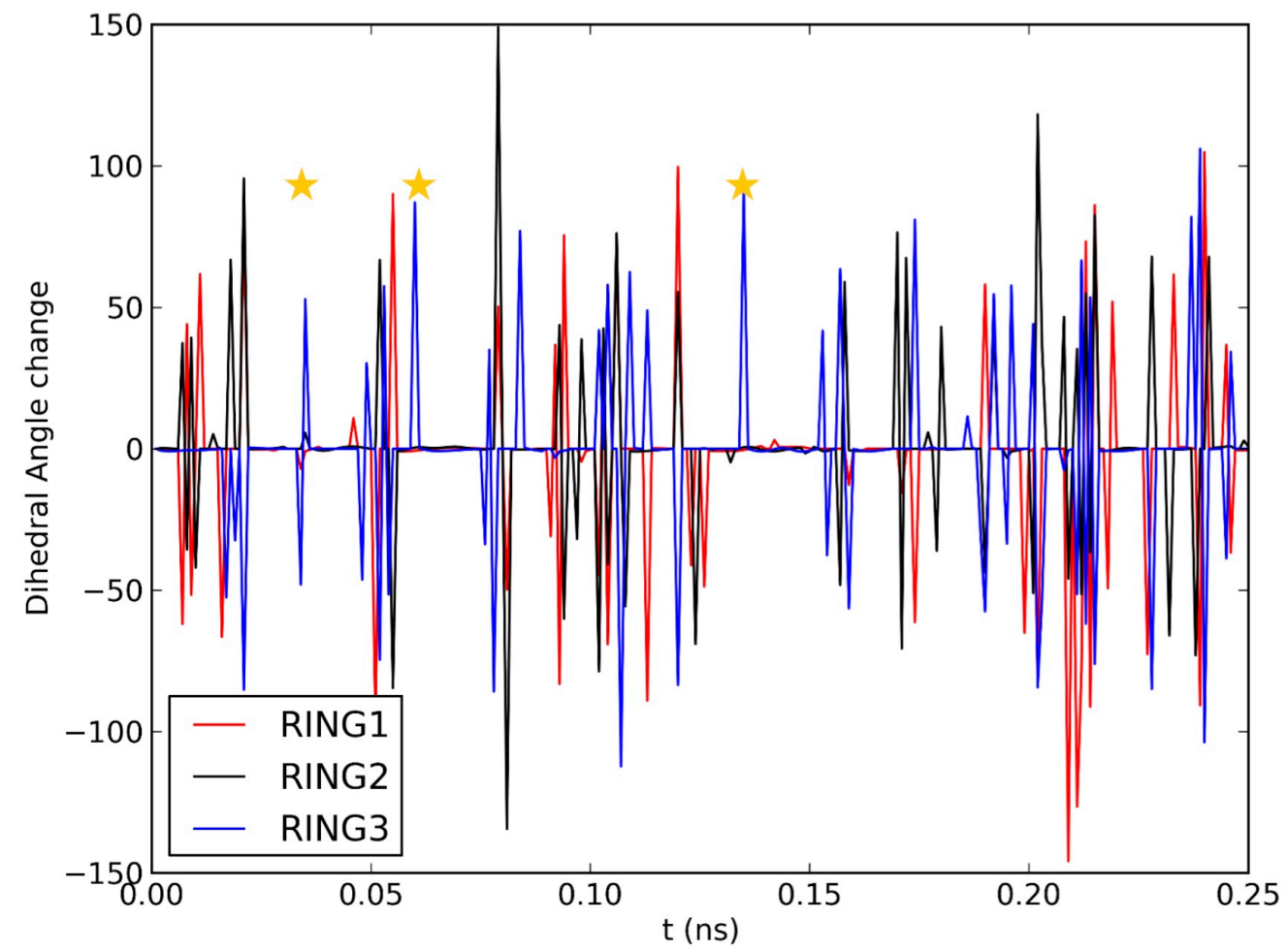

Figure S47. Dihedral angle change of three phenylene groups in the branch trityl group in $250 \mathrm{fs}$ with the independent rotation of one phenylene group labeled with yellow stars.

\subsection{Estimated Free Energy Change of Rotation}

The activation energies of branch phenylenes rotation in vacuum were studied using umbrella sampling. Potentials of mean force (PMF) were constructed using Weighted Histogram Analysis Method (WHAM) with the dihedral angles extracted every $50 \mathrm{fs} .{ }^{5}$ At each window, 1ns MD was performed with harmonic potential applied on the dihedral at $300 \mathrm{~K}$ under $1 \mathrm{~atm}$ pressure. When one phenylene explored 180-degree dihedral angle change from the lowest-energy-state with a 5-degree step width, the other two phenylene rings was allowed to relax to mimic correlated rotation (Figure S48, red circles). Umbrella constraint of $200 \mathrm{kcal} /\left(\mathrm{mol} \bullet \AA^{2}\right)$ was applied to the chosen phenylene ring. The free energy change of rotation was found to be less than $1 \mathrm{kcal} / \mathrm{mol}$ in vacuum. Since the independent rotation of one phenylene is a higher energy process in vacuum, we could only estimate the activation energy by restraining a second phenylene while the chosen phenylene group was experiencing the 180-degree dihedral angle change as described 
above. The resulting energy diagram (Figure S48, green triangles) matched well with a 2fold rotation model with activation energy of $c a$. $5 \mathrm{kcal} / \mathrm{mol}$. If we restrain both the second and the third phenylenes, the energetic change would reflect the activation barrier to rotate one phenylene with the other two being completely static (Figure S48, black squares). The activation energy of this process in vacuum (ca. $19 \mathrm{kcal} / \mathrm{mol})$ is higher than the experimental data (no more than $15 \mathrm{kcal} / \mathrm{mol}$ ).

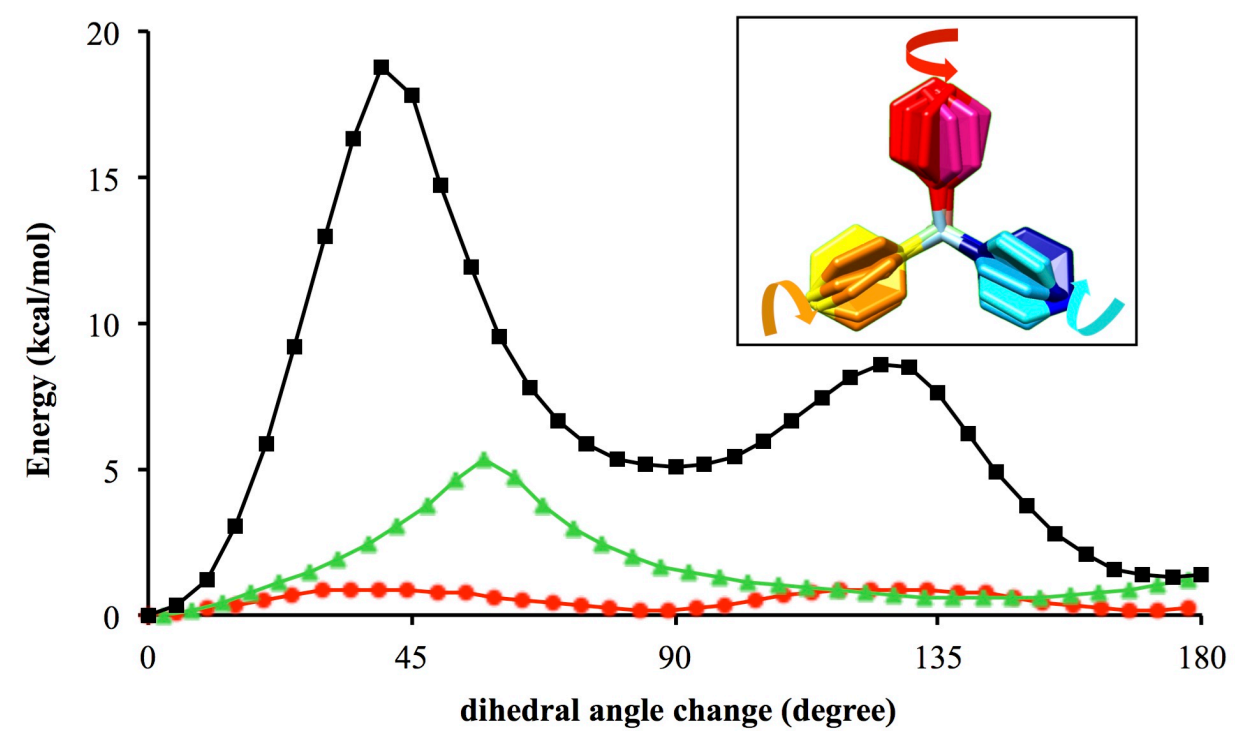

Figure S48. Free energy change of different processes in vacuum including correlated rotation (red circles), isolated rotation with one (green triangles) and two rings restrained (black squares). Insert: overlay of three snapshots, for $0^{\circ}, 45^{\circ}$, and $90^{\circ}$ in the correlated rotation (red circles on graph); trajectories of 90 degree correlated rotation are indicated in the arrows. 


\section{Temperature Dependence of Activation Energies}

If the activation energies for rotation are assumed to be temperature dependent, one can calculate "corrected" activation energies by assuming a constant pre-exponential factor of ca. $1.0 \times 10^{12} \mathrm{~s}^{-1}$. These values are listed in Table S1.

Table S1. "Corrected" activation energies of rotation.

\begin{tabular}{cccccc}
\hline \multicolumn{2}{c}{$2-d_{4}$} & \multicolumn{2}{c}{$2-d_{24}$} & \multicolumn{2}{c}{$\mathbf{2 -} d_{90}$} \\
\hline $\mathrm{T}$ & $E_{\mathrm{a}} /(\mathrm{kcal} / \mathrm{mol})$ & $\mathrm{T}$ & $E_{\mathrm{a}} /(\mathrm{kcal} / \mathrm{mol})$ & $\mathrm{T}$ & $E_{\mathrm{a}} /(\mathrm{kcal} / \mathrm{mol})$ \\
\hline $293 \mathrm{~K}$ & 6.91 & $293 \mathrm{~K}$ & 7.38 & $313 \mathrm{~K}$ & 8.16 \\
$283 \mathrm{~K}$ & 7.11 & $283 \mathrm{~K}$ & 7.91 & $303 \mathrm{~K}$ & 8.26 \\
$273 \mathrm{~K}$ & 7.24 & $273 \mathrm{~K}$ & 8.15 & $293 \mathrm{~K}$ & 8.26 \\
$263 \mathrm{~K}$ & 7.70 & $263 \mathrm{~K}$ & 8.25 & $283 \mathrm{~K}$ & 8.55 \\
$253 \mathrm{~K}$ & 7.81 & $253 \mathrm{~K}$ & 8.58 & $273 \mathrm{~K}$ & 8.74 \\
$243 \mathrm{~K}$ & 8.45 & - & - & $263 \mathrm{~K}$ & 9.05 \\
\hline
\end{tabular}




\section{References}

1. Dominguez, Z.; Dang, H.; Strouse, M. J.; Garcia-Garibay, M. A. J. Am. Chem. Soc. 2002, 124, 2398.

2. Karlen, S. D.; Garcia-Garibay, M. A. Chem. Commun. 2005, 189.

3. Macho, V.; Brombacher, L.; Spiess, H. W. Appl. Magn. Reson. 2001, 20, 405. For the online program, visit: http://weblab.mpip-mainz.mpg.de/weblab/

4. Case, D. A.; Babin, V.; Berryman, J.; Betz, R. M.; Cai, Q.; Cerutti, D. S.; Cheatham III, T. E.; Darden, T. A.; Duke, R. E.; Gohlke, H.; Goetz, A. W.; Gusarov, S.; Homeyer, N.; Janowski, P.; Kaus, J.; Kolossvary, I.; Kovalenko, A.; Lee, T. S.; LeGrand, S.; Luchko, T.; Luo,' R.; Madej, B.; Merz, K. M.; Paesani, F.; Roe, D. R.; Roitberg, A.; Sagui, C.; Salomon-Ferrer, R.; Seabra, G.; Simmerling, C. L.; Smith, W.; Swails, J.; Walker, R. C.; Wang, J.; Wolf, R. M.; Wu, X.; Kollman, P. A. AMBER 14, 2014.

5. Grossfield, Alan, "WHAM: the weighted histogram analysis method" version 2.0.9, http://membrane.urmc.rochester.edu/content/wham 